Portland State University

PDXScholar

Summer 9-12-2018

\title{
Assessing PPGIS Usability and its Relationship to Spatial Data Production: a Case Study
}

Timothy Michael Hitchins

Portland State University

Follow this and additional works at: https://pdxscholar.library.pdx.edu/open_access_etds

Part of the Geographic Information Sciences Commons, and the Spatial Science Commons Let us know how access to this document benefits you.

\section{Recommended Citation}

Hitchins, Timothy Michael, "Assessing PPGIS Usability and its Relationship to Spatial Data Production: a Case Study" (2018). Dissertations and Theses. Paper 4521.

https://doi.org/10.15760/etd.6405

This Thesis is brought to you for free and open access. It has been accepted for inclusion in Dissertations and Theses by an authorized administrator of PDXScholar. Please contact us if we can make this document more accessible: pdxscholar@pdx.edu. 
Assessing PPGIS Usability

and its Relationship to Spatial Data Production:

A Case Study

by

Timothy Michael Hitchins

A thesis submitted in partial fulfillment of the requirements for the degree of

\author{
Master of Science
}

in

Geography

Thesis Committee:

Martin Swobodzinski, Chair

David Banis

Rebecca McLain

Portland State University

2018 


\begin{abstract}
Modern Geoweb-enabled PPGIS methodologies incorporate interactive map applications as the main driver for public engagement and data collection. However, little research explores exactly how the public interact with these applications to produce spatial data, a fact that contributes to criticisms of final data quality. Usability evaluation offers a solution for developing better PPGIS data production systems by identifying problems in the application interface for which the public engage. Drawing on a case study example of a PPGIS application developed to collect socio-spatial data from members of a random public, this paper addresses usability in a three-stage approach. First, controlled experimentation methods capture performance, preference, and data production metrics. Second, visual and statistical analysis of the captured usability data identify problems in the interface. Results indicate that users learned, became efficient, and were generally satisfied with the application, but also committed errors that may have affected data quality. Third, a solution-oriented critique of the application interface suggests new design options to mitigate future problems in similar applications. The paper ends by providing a conceptual framework for usability as it relates to PPGIS data production and incorporates it into an informed discussion on data quality and future research needs for maintaining the viability of PPGIS projects.
\end{abstract}




\section{Acknowledgments}

This master's thesis would not have been possible without the support and help of numerous people, to whom I am thankful. First among these is David Banis, whose constant mentorship, encouragement, and critique helped guide me through a demanding project. David's office door was always open when I had questions or needed to vent, and the practicums he facilitated were essential for a novice to learn to code. I am also very grateful to Rebecca McLain and Zuriel van Belle, with whom I have had the great privilege to work (along with David Banis) on our Human Ecology Mapping project for over three years. I can think of no better team with which to collaborate. Thanks are also due to Martin Swobodzinski, who took me on as his first graduate student at Portland State University while I was still trying to settle on a thesis topic. Martin's feedback on my methods were crucial to improving my final work. I am also grateful to Matthew Schniderman, who graciously opened up two of his classrooms to our team for project recruitment. Thanks to Jackson Voelkel for pushing me to become a better coder. Finally, thank you to my wonderful partner, Evangeline Nichols, whose unwavering love and support kept me strong as I worked to attain a new degree. 


\section{Table of Contents}

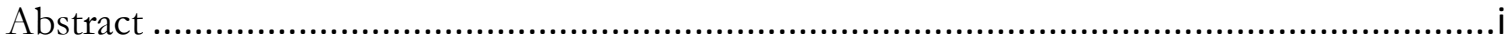

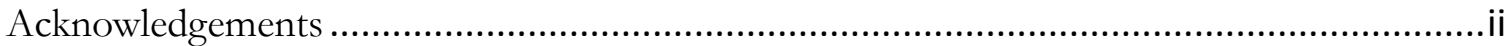

Table of Contents ................................................................................................................. ii

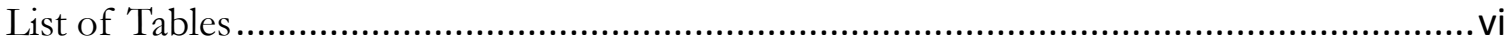

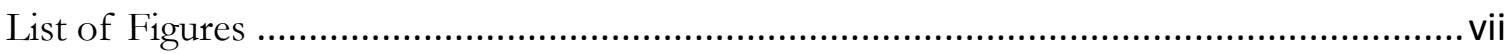

Chapter 1: From Doing to Improving PPGIS ….................................................... 1

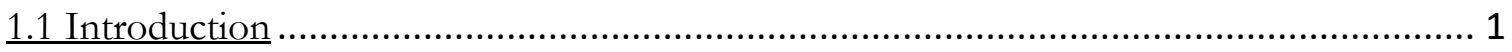

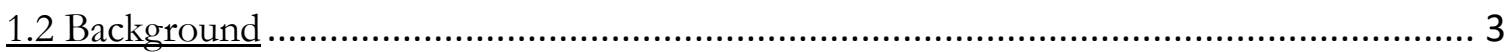

1.2.1 The Connections with Forests and Grasslands of Central Oregon Survey ................................ 3

1.2.2 Assessing the Usability of CFGCOS ........................................................................ 7

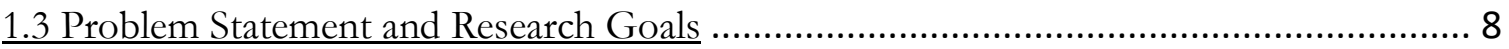

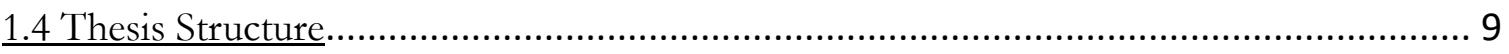

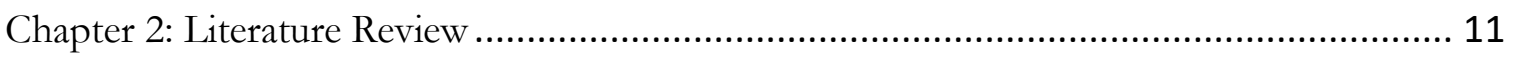

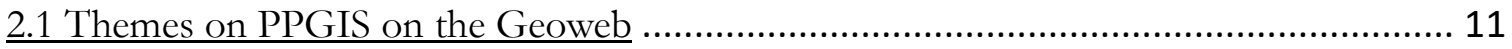

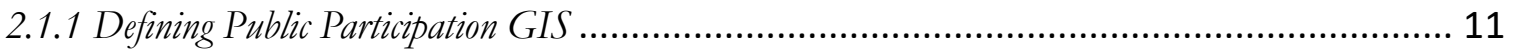

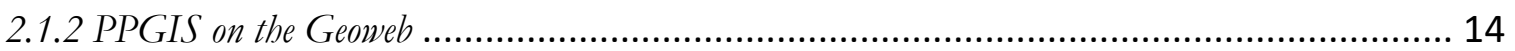

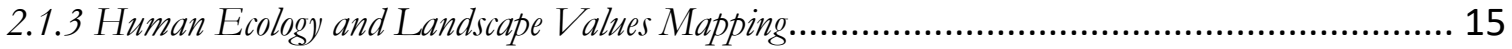

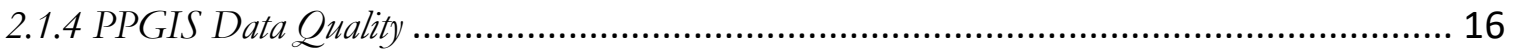

2.2 Themes on Interaction, Usability, and Data Production........................................... 18

2.2.1 Cartographic Interaction and PPGIS Data Production ....................................................... 18

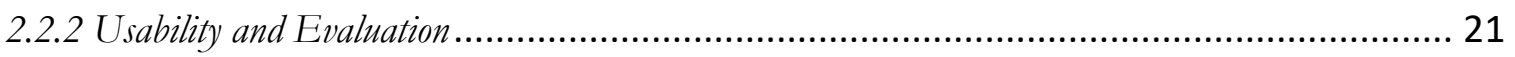

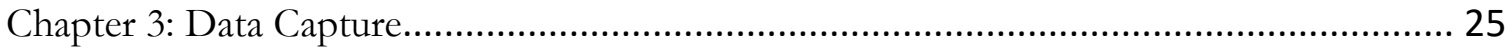

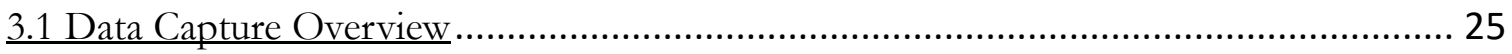


3.2 Automated Data Capture Method …………………………................................... 26

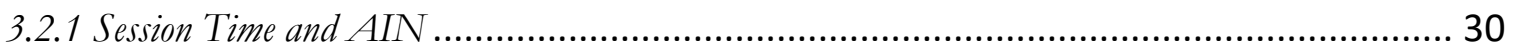

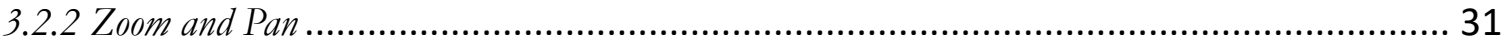

3.2.3 Point and Popир.................................................................................................... 31

3.3 Automated Data Capture Results............................................................................ 32

3.4 Non-Automated Data Capture Method ……………….................................................... 33

3.5 Non-Automated Data Capture Results ……………………................................... 36

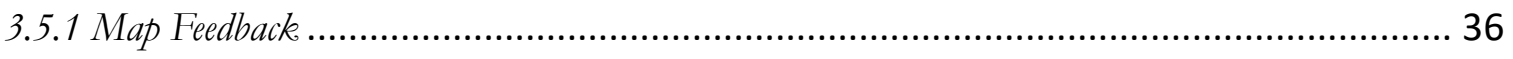

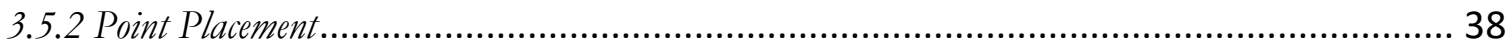

3.5.3 Sidebar / Instructions Feedback ……………………............................................... 40

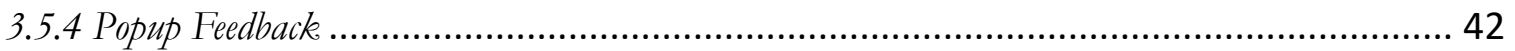

3.5.5 General Feedback ...................................................................................................... 43

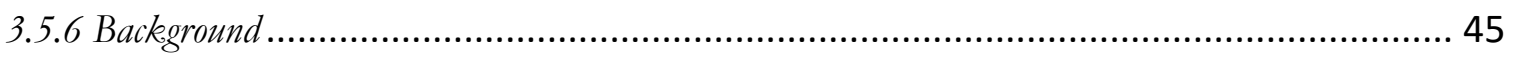

3.6 Data Capture Conclusion ……………….................................................................... 46

Chapter 4: Analysis Methods \& Results ............................................................................. 48

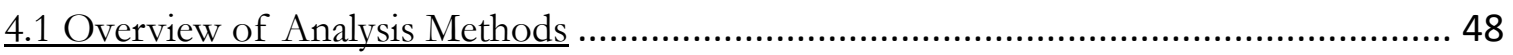

4.2 Performance Evaluation ............................................................................................. 49

4.2.1 Learnability Evaluation Method .................................................................................... 49

4.2.2 Learnability Evaluation Results............................................................................ 50

4.2.3 Efficiency Evaluation Method ........................................................................................ 57

4.2.4 Efficiency Evaluation Results................................................................................. 58

4.2.4 Error Evaluation Method .............................................................................................. 62

4.2.5 Error Evaluation Results....................................................................................... 65

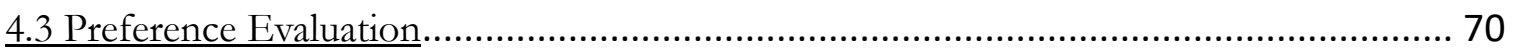

4.3.1 Satisfaction Evaluation Method...................................................................................... 71

4.3.2 Satisfaction Evaluation Results ................................................................................... 72

4.4 Data Production Evaluation .................................................................................... 77 


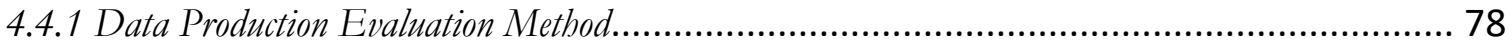

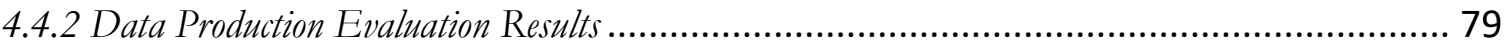

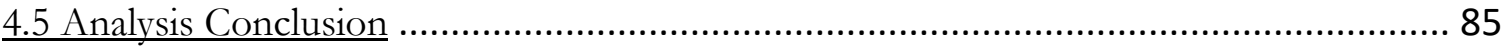

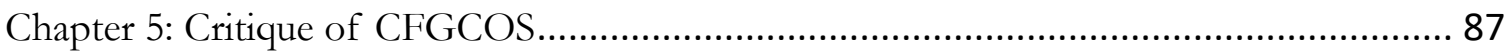

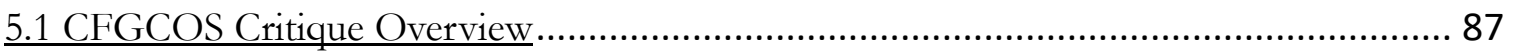

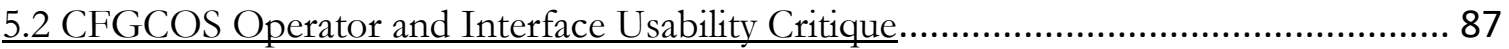

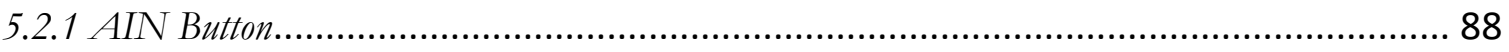

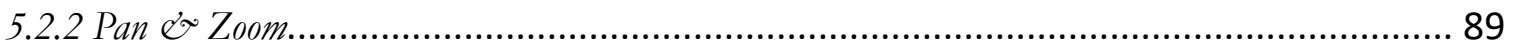

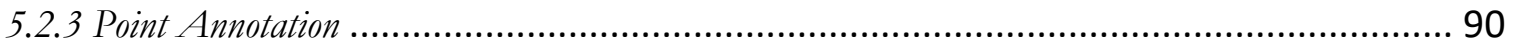

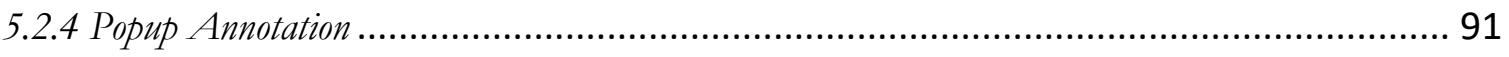

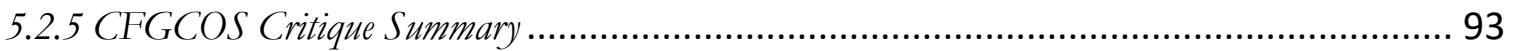

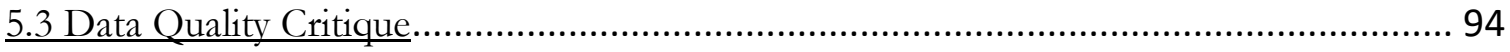

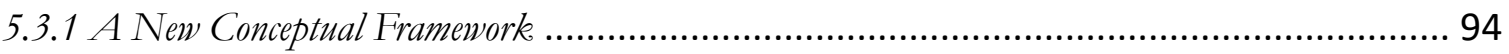

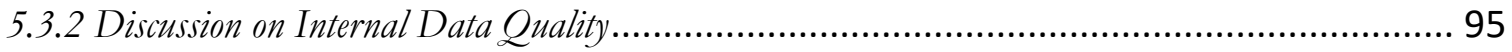

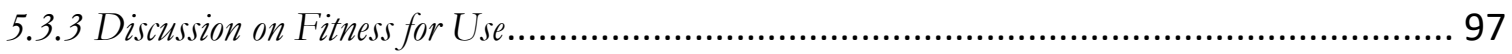

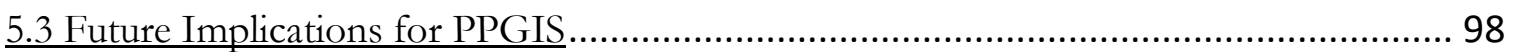

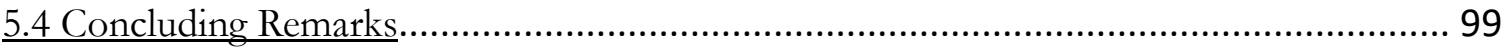

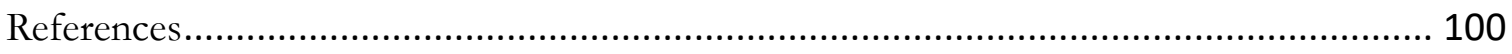

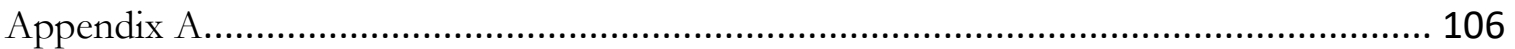




\section{List of Tables}

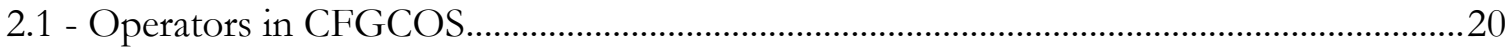

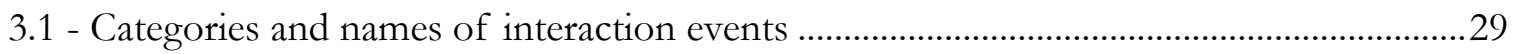

3.2 - Questions asked in the six sections of the exit survey ........................................................34

3.3 - Results from the Map Feedback portion of the exit survey ……......................................37

3.4 - Results from the Point Placement portion of the exit survey ............................................39

3.5 - Results from the Sidebar / Instructions Feedback portion of the exit survey .................40

3.6 - Results from the Popups Feedback portion of the exit survey ..........................................42

3.7 - Results from the General Feedback portion of the exit survey ………...............................44

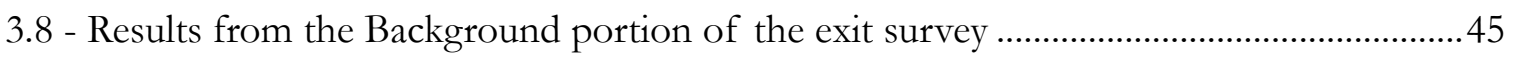

4.1 - Results of the learnability evaluation incorporating task completion times......................51

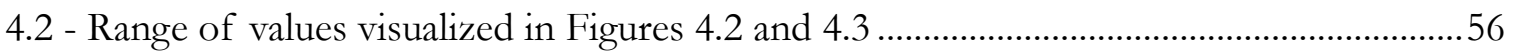

4.3 - Mean annotation task completion times ................................................................................. 61

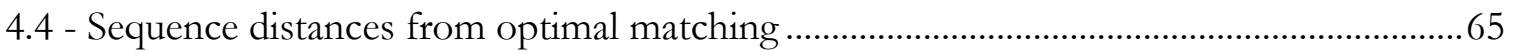

4.5 - Three most common state sequences ……….........................................................................68

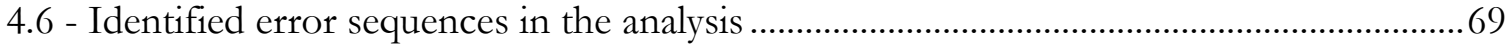

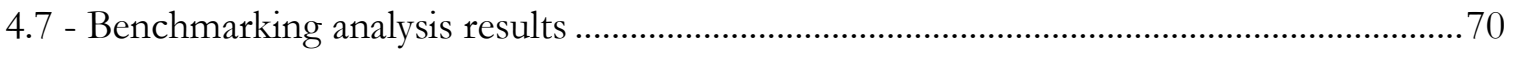

4.8 - Qualitatively assessed responses from the exit survey. ........................................................76

4.9 - Results from the pan event per location analysis.................................................................. 80

4.10 - Results from the zoom event per location analysis. ........................................................... 81

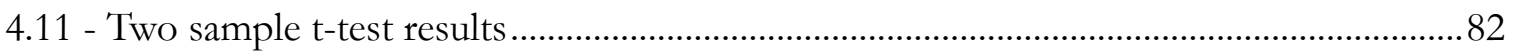

4.12 - Descriptive statistics of zoom level when point was annotated ....................................... 82 


\section{List of Figures}

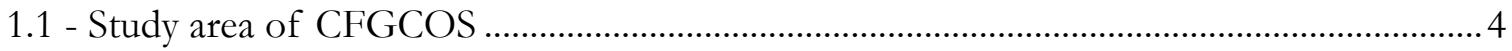

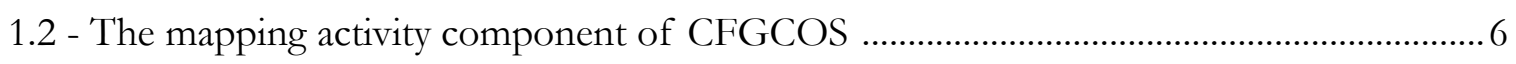

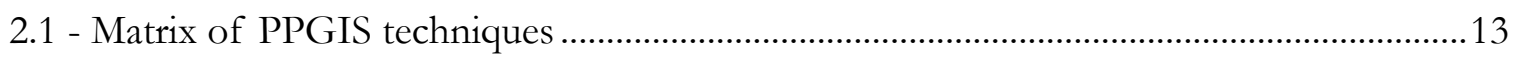

2.2 - Stages of Interaction model from Norman ..................................................................19

2.3 - Continuum of usability evaluation methods ......................................................................22

3.1 - The instructional panel in CFGCOS separated into five steps ........................................28

4.1 - Boxplots for first time task completions of CFGCOS users grouped by task ................53

4.2 - Boxplots of the range of form box annotation task completion times..............................54

4.3 - Range of individual form box annotation task completion times .....................................55

4.4 - Task completion times for point annotations related to a specific location .......................59

4.5 - Popup annotation task completion times for each associated location.............................60

4.6 - Mean popup form box annotation task times.................................................................62

4.7 - Sankey diagram for state sequences in location group one...............................................67

4.8 - Results from the task level satisfaction analysis. ............................................................... 73

4.9 - Results from the test level satisfaction analysis................................................................... 75

4.10 - Barplot showing the percentage of points annotated at each zoom level.....................83

4.11 - Barplot of form boxes annotated with and without data per location ............................ 84

4.12 - Barplot of percentage of all form boxes that were not annotated by form box............ 85

5.1 - Conceptual diagram of the usability evaluation and data production............................... 95 


\section{Chapter 1: From Doing to Improving PPGIS}

"All models are wrong, but some are useful."

- George E. P. Box

\subsection{Introduction}

Ongoing advancements in web technologies have greatly expanded the possibilities for researchers to collect data from a diverse public audience. This trend has become especially evident in the field of Public Participation GIS (PPGIS), a subfield of GIS concerned with including "the public in a participatory process that uses geospatial technologies to inform decisions that have a spatial implication” (Brown 289). Because of the ubiquitous nature, wide reach, and user-accessibility of the Geoweb - a geographic extension of Web 2.0 facilitated by a suite of mapping technologies connected through the internet - a great deal of PPGIS has shifted to incorporate specially designed interactive map applications as the main driver for public engagement and data collection (Brown and Weber 193; Sieber et al. 1031).

Many interactive web-based PPGIS applications provide instructions for a user to add a marker, or digitally annotate a multi-scale map of the study area. For example, a participant might be asked to mark an area in the public land they use, value, or believe should be prioritized for conservation. Perhaps they are directed to indicate an area in the city that needs more bike lanes or traffic lights. Whatever the case, non-expert participants from different cultural backgrounds and mapping literacy are often asked to follow instructions, navigate through a map interface, and contribute spatially explicit information 
in the form of a point, line or polygon. A common goal for such data collection is to support some planning or land management directive (Wright et al. 255; Brown and Reed 317; Brown and Donovan 37; Wolf et al.113). However, adoption of PPGIS generated data in final policy decisions are commonly hampered by mistrust of the data's quality, suspicion of data collection methods, and the lack of integration into the planning and decision support process itself (Brown and Kyttä 133-134).

As the field of PPGIS progresses, many researchers have begun to address the issues that hinder PPGIS and have shifted their analysis scope from doing PPGIS to improving PPGIS. Particular foci have centered on assessing the participatory process itself (Brown and Kyttä 134; Sieber et al.1037-1042), analyzing data quality generated through PPGIS pipeline (Brown 44, Brown et al. 229), and evaluating the usability and effectiveness of interactive PPGIS applications (Gotwald et al. 2321; Haklay and Tobón 577). This research seeks to expand on the latter two research areas by first assessing how web-based PPGIS usability and cartographic interaction relate to the production of spatial data, then by interpreting the results of the assessment to contextualize a critical discussion of the quality of the user generated data. The research draws on a case-study usability evaluation of an interactive mapping application created to collect publicly-valued landscape data of Central Oregon public lands. 


\subsection{Background}

\subsubsection{The Connections with Forests and Grasslands of Central Oregon Survey}

In May 2015, researchers from Portland State University’s (PSU) Department of Geography partnered with Region 6 of the US Forest Service (USFS) and Discover Your Forest (DYF), a Bend, Oregon based non-profit organization closely tied to the USFS, to create a web-based tool aimed at gathering local public input from communities with a stake in Central Oregon's forests and grasslands. The project was catalyzed in part by a 2012 Planning Rule released by the USFS to guide future revisions and amendments to National Forest and Grasslands land management plans. Of the eight purposes and needs outlined in the Planning Rule, one was "to provide for a transparent, collaborative process that allows for effective participation” (“36 CFR Part 219”). The tool would fill this participatory purpose and need by drawing on local socio-spatial knowledge to reveal the places that were important to people in the forests and grassland of the study area (See Figure 1.1). Data collected from the tool was intended to support the future policy and planning decisions of USFS land managers overseeing Deschutes National Forest, Ochoco National Forest, and Crooked River National Grassland. Specifically, the data could help the researchers and land managers understand why people value a particular location and what they do at these locations. 


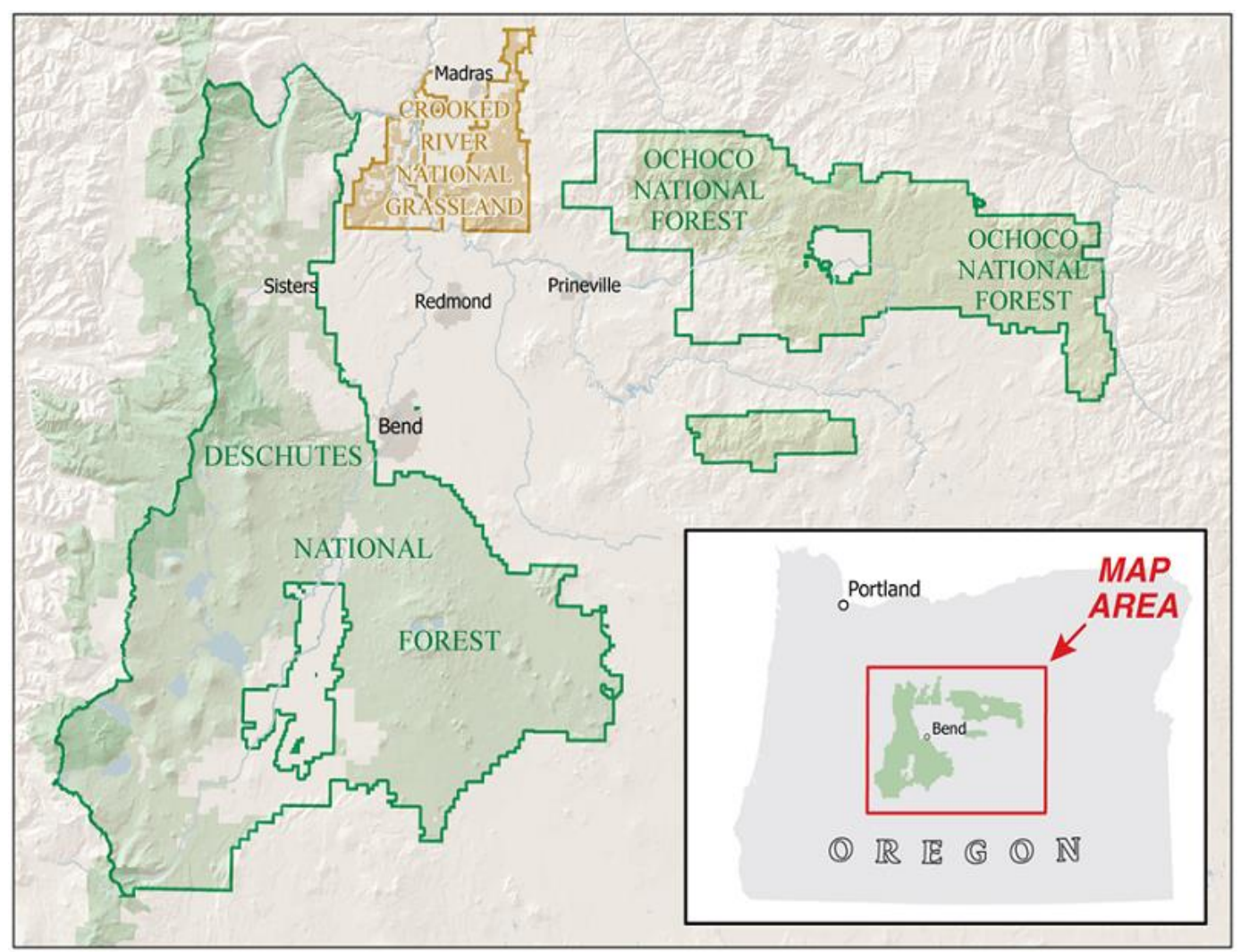

Figure 1.1 - Study area of Connections with Forests and Grasslands of Central Oregon Survey (CFGCOS).

The resulting tool consisted of two core components. This first was a mapping activity (See Figure 1.2) that instructed users to follow five steps to navigate a three-scale map, then drop a point marker and annotate a popup containing twelve form boxes for up to five locations that were important to them (See Appendix A). The application designers determined that three scales would provide the user with sufficient geographic context for finding places on the map. Feedback from USFS directed the designers to settle on eleven form boxes that asked the user to identify the place of importance by name, the benefits and features associated with that place, the activities done at that place, and perceived threats to 
that place. Design choices for the mapping activity also incorporated an AIN (Anonymous Identification Number) button that the user would click to obtain a randomly generated number that they wrote down. This feature was included so that the mapping activity could be later joined to the survey component described next. Design choices also led to the inability for the user to delete points after they were added. This was done to ensure that no points would get unintentionally removed.

The second component directed users to a survey that asked them a multitude of user attitude and ease-of-use questions regarding public land management. While all partners contributed to the design of the survey and questions used in both parts of the application, the PSU team took the lead on the actual development of the tool, which was ultimately called the Connections with Forests \& Grasslands of Central Oregon Survey. For brevity, the application will be further referred to here as CFGCOS. 


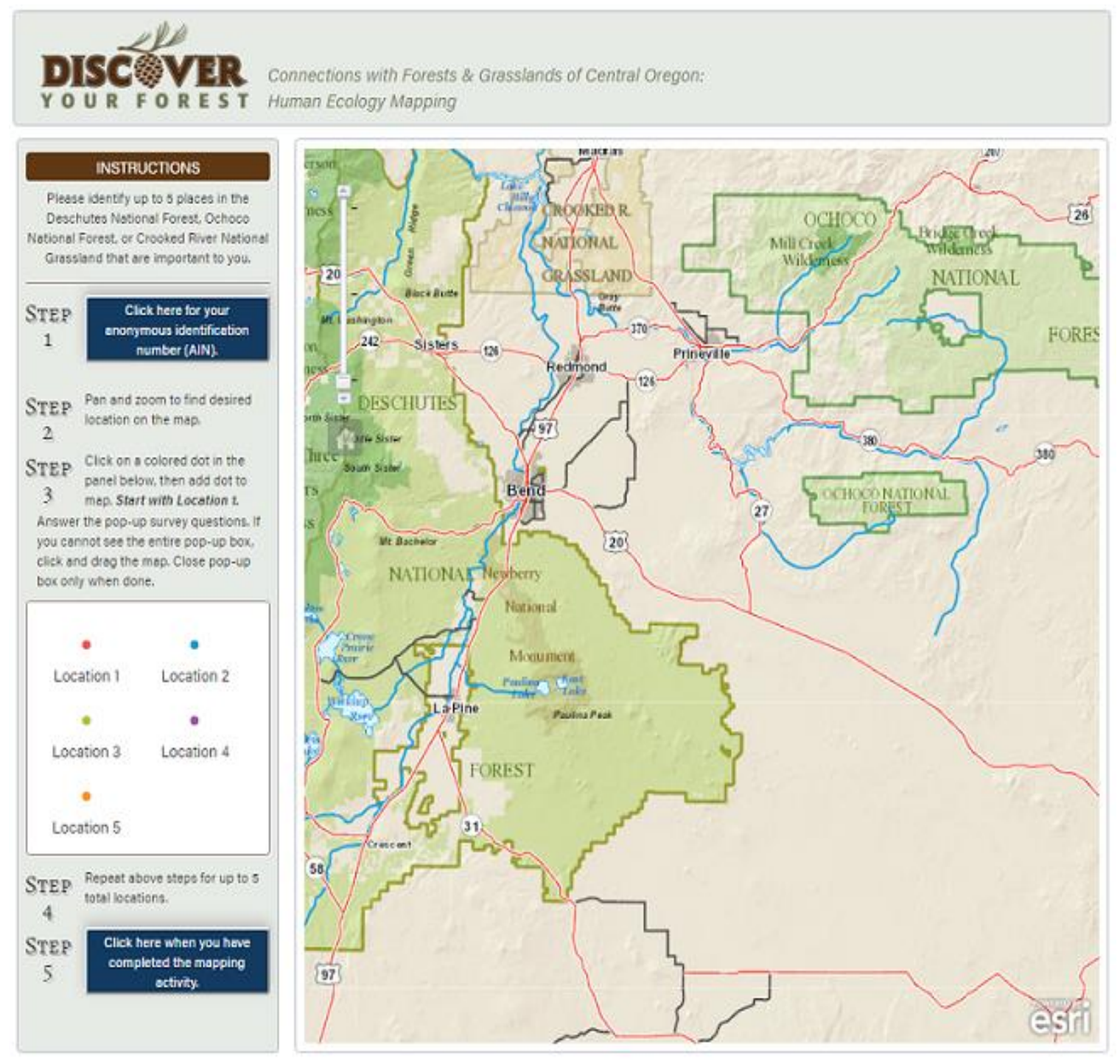

Figure 1.2 - The mapping activity component of CFGCOS. See Appendix A for all components.

CFGCOS was officially made available to the public in early October 2016.

Marketing of CFGCOS was a collaborative endeavor among the researchers and supporting organizations, but DYF took lead responsibility for promotional efforts. DYF's mission is "promoting the discovery of Deschutes and Ochoco National Forests and Crooked River 
National Grassland by enriching the experience of visitors, building community support and creating the next generation of environmental stewards" ("About"). As the main advertiser of programs and events related to Deschutes and Ochoco National Forests and Crooked River National Grassland, the organization works with a large network of community organizations with varying interests and residents of Central Oregon. After release, DYF promoted CFGCOS to all the organizations in their network.

Public engagement with CFGCOS officially ended in summer 2017 and the PSU team was tasked with analyzing the collected data and reporting the results. Since that time, meetings have been convened with the partner organizations in order to determine how to best utilize and incorporate the results in future planning and policy decisions. The PSU research team plans to publish the results and lessons-learned from the implementation of CFGCOS in the coming year.

\subsection{2 - Assessing the Usability of CFGCOS}

While data collection for the project has officially concluded and analysis is underway, the PSU research team has commenced a new research phase: conducting two studies to assess the usability of CFGCOS and its relationship to how users produce spatial data. Some members of the team had previously done research involving web-based PPGIS data collection methodologies for environmental planning in Western Washington, USA. This revealed the need to better understand "how different ways of engaging with maps might affect the quality of spatial data" (McLain et al. 73). Throughout the lifecycle of CFGCOS, the research team had pondered how the application interface, instructions, map, 
and interaction dynamics may have influenced the way users contributed data. If the application is difficult to use or hinders a user from doing what they intended, the quality of the data they are contributing could potentially be degraded. PPGIS data is commonly scrutinized for its reliability and quality (See Sections, 1.1, 2.2 and 2.1.4), but little research has been conducted to understand factors with potential to diminish data quality. This usability evaluation of CFGCOS addresses this problem by illuminating how users interact with and produce spatial data with a web-based PPGIS.

Various methods exist for assessing the usability of an interactive application. The PSU research team conducted two different studies using different methods to address the usability of CFGCOS. This study uses controlled experimentation methods (See Section 2.2.2). The second study incorporates Verbal Protocol Analysis (VPA), a method that asks study participants to think-aloud as they work through the mapping activity, providing subjective feedback on what works well and what does not. This work is ongoing.

\subsection{Problem Statement and Research Goals}

The fundamental research problem this thesis addresses is to what extent the usability of a web-based PPGIS application relates to the production of spatial data. Three goals, each augmenting the next, were developed to respond to this problem:

1) Design and implement a controlled experiment to capture CFGCOS user interactions, usability metrics, and subjective feedback;

2) Analyze usability data and sequential interaction patterns to identify problems in the 
CFGCOS interface that relate to data production;

3) Critique the usability of CFGCOS interface and data production operators with interpreted results to contextualize a discussion on data quality and inform the development of future PPGIS applications.

This study contributes to the field of PPGIS by testing claims that data collected form PPGIS on the Geoweb are unreliable. It also contributes to the field of Cartography by providing insight to future developers and researchers of explicit interface design aspects that affect the way participants use an interactive map application and generate data with it. Conclusions drawn from this analysis contribute to the ongoing academic discussion of whether data produced through a PPGIS are of the same caliber of an expert-derived counterpart. If the stigma surrounding the quality of PPGIS data is to be alleviated, then studies such as these are crucial for the future viability of PPGIS projects.

\subsection{Thesis Structure}

This thesis is divided into five chapters. Chapter 1 provides introductory context to the current status and issues facing PPGIS projects that incorporate Geoweb technologies, motivations for conducting the research, and a background on the specific PPGIS application used for this research. Chapter 2 situates the research in literature that informs PPGIS, cartographic interaction, and usability evaluation theory. Chapter 3 describes the controlled experimentation data capture methods employed to perform a usability evaluation of CFGCOS, along with descriptive results of the captured data. Chapter 4 describes the 
analysis and results of the evaluation of the usability and cartographic interaction data in order to identify the problems in the CFGCOS interface. Chapter 5 synthesizes the combined results of the evaluation in an informed and critical discussion of the potential impacts of CFGCOS usability on data quality. The chapter ends with concluding remarks about the utility of CFGCOS and how the process used to develop web-based PPGIS applications like CFGCOS might be improved in the future. 


\section{Chapter 2: Literature Review}

\subsection{Themes on PPGIS on the Geoweb}

\subsubsection{Defining Public Participation GIS}

PPGIS is often celebrated as a way to promote local and non-governmental spatial knowledge within a decision-making framework that is otherwise dominated by outsider expert and government knowledge. Schroeder originally defined PPGIS as, "a variety of approaches to make GIS and other spatial decision-making tools available and accessible to all those with a stake in official decisions" (as qtd in Sieber 492). Sieber describes PPGIS as, "pertaining to the use of geographic information systems (GIS) to broaden public involvement in policy making, as well as to the value of GIS to promote the goals of nongovernmental organizations, grassroots groups, and community-based organizations" (491). Brown claims, "PPGIS seeks to engage the 'public' in a participatory process that uses geospatial technologies to inform decisions with a spatial implication” (89). As such, PPGIS methodologies are mostly aimed at inclusivity of populations who typically have limited access or voice in the development of public policy and management directives.

Applications incorporating PPGIS have varied greatly in terms of the activities measured, methods used, and people engaged as participants. To wholly understand the depth of public participation within PPGIS requires a parsing of the terms "public" and "participation" within the spatial context of GIS. According to Schlossberg and Shuford, the domain of “"participation' can be thought of in (at least) two core ways: as specific activities that individuals engage in or in the broader purposes that participation is supposed 
to achieve" (16). "Public" can also be considered "in two distinct ways: as actual people organized in some type of grouping (e.g., decision makers) or in terms of methods for identifying and selecting such people” (18).

Schlossberg and Shuford integrate these domains with PPGIS on a visual matrix with horizontal and vertical axes of ranging interrelated complexity (See Figure. 2.1). Along the horizontal axis are the various "public." A simple public is a group that is easy to identify and engage, while a complex public is less well defined or very large and/or heterogeneous. Public actors include decision makers, implementers, affected individuals, interested observers and the random public. Along the vertical axis sits the multitude of participatory techniques. Simple participatory techniques require less effort with organization or communication and are intended for brief education or informing a certain population. Techniques with complex participation, on the other hand, require a great deal more effort with continuous engagement and emphasis on power-sharing. For example, a static webpage is simple as it offers opportunities one-way communication where participants view data on a map and hopefully educate themselves as a result; while a process of collaboration is complex because it involves consensus building and much more invested time and energy for successful outcomes (17-24). Within the context of GIS, these interrelated concepts of ranging complexity call for the use of diverse methodologies involving participatory engagements with a public audience in a process that contributes or consumes spatial data (Brown). 


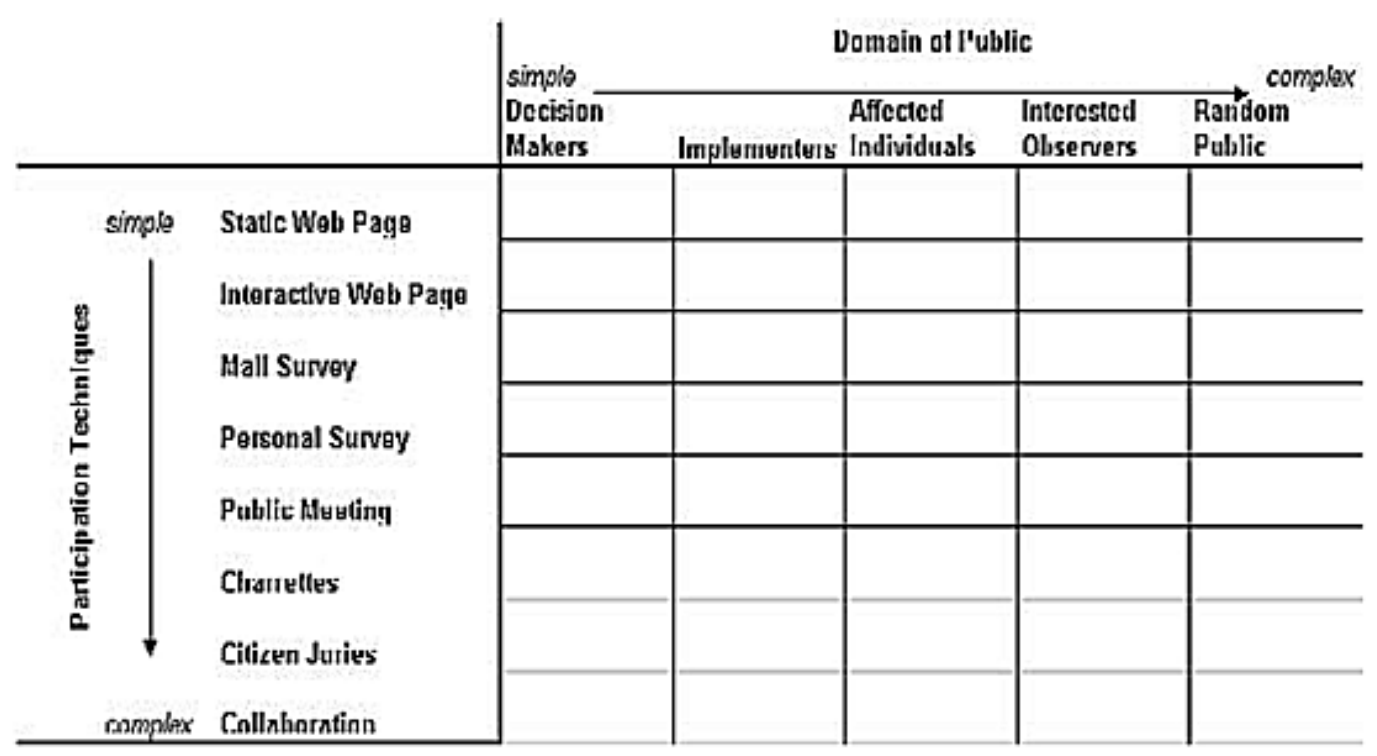

Figure 2.1 - Matrix of PPGIS techniques, from Schlossberg and Shuford (2005)

This thesis examines the class of PPGIS where members of the random public use an interactive map to contribute spatial data representing their important places in forests and grasslands in order to support a land management or policy planning process. Such employment of PPGIS for natural resource planning is common (Anderson et al. 20812089; Brown \& Reed 166-182; McLain et al. 61-74). These applications also resemble Volunteered Geographic Information (VGI), which refers to geographic information resulting from "the widespread engagement of large numbers of private citizens, often with little in the way of formal qualifications" (Goodchild 2). Many similarities exist between PPGIS and VGI; both rely on the investigation by individuals of locations that are important to them (Tulloch 161). However, distinctions between VGI and PPGIS arise when considering the reasons for an individual's participation; PPGIS are intended for decision-support in 
planning while VGI may exist for no other reason than for a participant's enjoyment (Brown 290).

\subsubsection{PPGIS on the Geoweb}

As computer technology advances, PPGIS benefits from new methodological resources. One of the more notable developments in PPGIS projects is the incorporation of the Geoweb and its facilitation of the production of vast amounts of user generated data (Sieber et al. 1031). A suite of geographically related web services and location-aware devices, the Geoweb creates the potential for nonexperts to communicate unstructured multimedia narratives, keeps contributors anonymous, disperses data asynchronously and spatially, is typically free, and is accessible. It is also the Geoweb that makes VGI and PPGIS data so readily available and easy to collect. However, while Geoweb technologies facilitate the unitization of participation, blur distinctions between experts and non-experts, expand the rungs on the ladder of participation, and heterogenize the role of the state as convener of participation, concerns remain regarding PPGIS's ineffectiveness in influencing policy, promotion of digital inequalities, and data credibility and reliability (Sieber et al.1037-1042).

It is the latter concern that is of interest for this research. Pertinent literature regarding PPGIS data produced on the Geoweb examines issues of positional accuracy (Haklay 682; Brown et al. 234), completeness (Brown et al. 234), sampling design (Brown, Kelly, \& Whitall 190), and participation (Brown 12-14), but very little research examines PPGIS design and usability impacts on user-produced data. This research attempts to address that gap by exploring the specific ways users engage with a web-based tool to 
generate data. The purpose of the research is to inform a discussion of the data's resultant quality.

\subsubsection{Human Ecology and Landscape Values Mapping}

CFGCOS was developed in order to facilitate the collection of qualitative sociospatial landscape values through an inclusionary participatory mapping process. The project falls under what is known as Human Ecology Mapping (HEM), a process that seeks to map the interrelated connections and complexities between humans and landscapes. HEM sociocultural data and analysis results are typically intended for integration into ecosystembased management and planning, however the data and analysis are not always incorporated into ecosystem-based management and planning (McLain et al. 662).

There are several approaches to HEM, one of which is Sense of Place (SOP) mapping. SOP mapping attempts to "describe the values and/or meanings that people ascribe to landscapes, particular locations on landscapes, and activities associated with those landscapes" (McLain et al. 652). CFGCOS uses a type of SOP mapping that defines benefits which are similar to "landscape values" through a specific typology. The typology is informed by a methodology introduced by Rolston and Coufal (38 - 39), clarified by Brown (240) and successfully tested by several other researchers (Beverly et al. 289-303, Brown 1920). The landscape value related benefits used in CFGCOS include many of the sociocultural, economic, and ecological values discussed in the aforementioned literature. 
Mapped landscape values can support the decision-making process of land-use planners and resource managers because they offer an "operational bridge" between places and how they are perceived in the scope of planning and management (Brown 19). However, analyses derived from landscape values mapping are seldom integrated into the planning or management process (Brown and Kyttä 134). Some suggest this phenomenon is due to resistance from land-use planners, managers, and scientists. McLain et al. cite several specific reasons: (1) insufficient training for using social-spatial data, (2) concern for costly data collection and lack of agency directives, (3) skepticism of local knowledge and its validity (662). This research addresses the third type of resistance, by examining how local knowledge is produced in an interactive map application.

\subsubsection{PPGIS Data Quality}

While this thesis does not attempt to determine the final quality of the data produced by users of CFGCOS, Chapter 5 does draw conclusions from a usability evaluation in a critical discussion of the potential implications of CFGCOS usability on data quality, a characteristic inextricably linked to the process of data production. Such a discussion is important because two of the major obstacles facing standard PPGIS integration in decision support is concern about the internal quality of PPIS produced data, and its fitness for use in a process that is not accustomed to using qualitative socio-spatial landscape values data (See Sections 1.1, 2.2, and 2.1.3). Both internal quality and fitness for use are two categories of spatial data quality defined in the literature (see Devillers and Jeansoulin for a review). 
Internal quality describes the internal characteristics of the data as they relate to the methods used in data production. Internal quality represents the difference in the produced data and the "perfect" data that is free from error (Aalders and Morrison 463). The ISO 19113 standard (2002) suggests internal data quality can be determined through five criteria: (1) completeness (presence or absence of features and attributes), (2) logical consistency (adherence to rules of data structure and attribution), (3) positional accuracy (feature position accuracy), (4) temporal accuracy (accuracy of the temporal attributes), and (5) thematic accuracy (accuracy of quantitative attributes and correctness of qualitative attributes). Fitness for use or external quality correspond to how a dataset fits the user's implicit or explicit needs (Guptill 161). Bedard and Valliere define external data quality using six characteristics: (1) definition (whether the nature of the data corresponds to the user's needs), (2) coverage (whether the data territory and the period meet user needs), (3) lineage (methods used to obtain the data and whether the data meets user needs), (4) precision (whether the data is acceptable for an expressed need), (5) legitimacy (whether the data meets official standards), (6) accessibility (ease at which the user can obtain the data). This thesis discusses internal quality in terms of potential usability impacts on attribute and feature completeness, and on positional accuracy. It considers external data quality as it pertains to lineage. 


\subsection{Themes on Interaction, Usability, and Data Production}

\subsubsection{Cartographic Interaction and PPGIS Data Production}

Evaluating how users interact with CFGCOS to produce data is central to this research. When users digitally interact with CFGOS they are facilitating a dialog between a human and a map that is mediated through a computing device. This process has been termed cartographic interaction (Roth 3). Rich cartographic interaction is possible through webbased maps and can be separated into three sets of primitives: objectives, operators and, operands (Roth 65). Objectives are open-ended goals or tasks a user sets and wishes to complete, operators are the specific system functions that facilitate objectives, and operands are map objects on which objectives are performed.

Roth incorporates these primitives within Norman's Stages of Interaction Model (See Figure 2.2) and further segments cartographic interaction into seven observable steps: (1) forming the goal (open-ended task or goal), (2) forming the intention (working toward an objective), (3) specifying an action (identifying the function of the system, or operator that facilitates the objective), (4) executing the action (using the operator), (5) perceiving the state of the system (seeing how the map display changed), (6) interpreting the state of the system (interpreting what the display change means), and (7) evaluating the outcome (using this interpretation to determine if the goal was achieved) (65). Each stage is a critical requirement for successful cartographic interaction. Failure in reaching the next stage results in an interruption, or "gulf between the user and digital map" (65). The gulf of execution represents problems that arise when there is a disconnect between a user's objective and the 
available operators, and the gulf of evaluation denotes a disconnect between the user's expected result and the result being displayed on the map.

\section{STAGES OF INTERACTION}
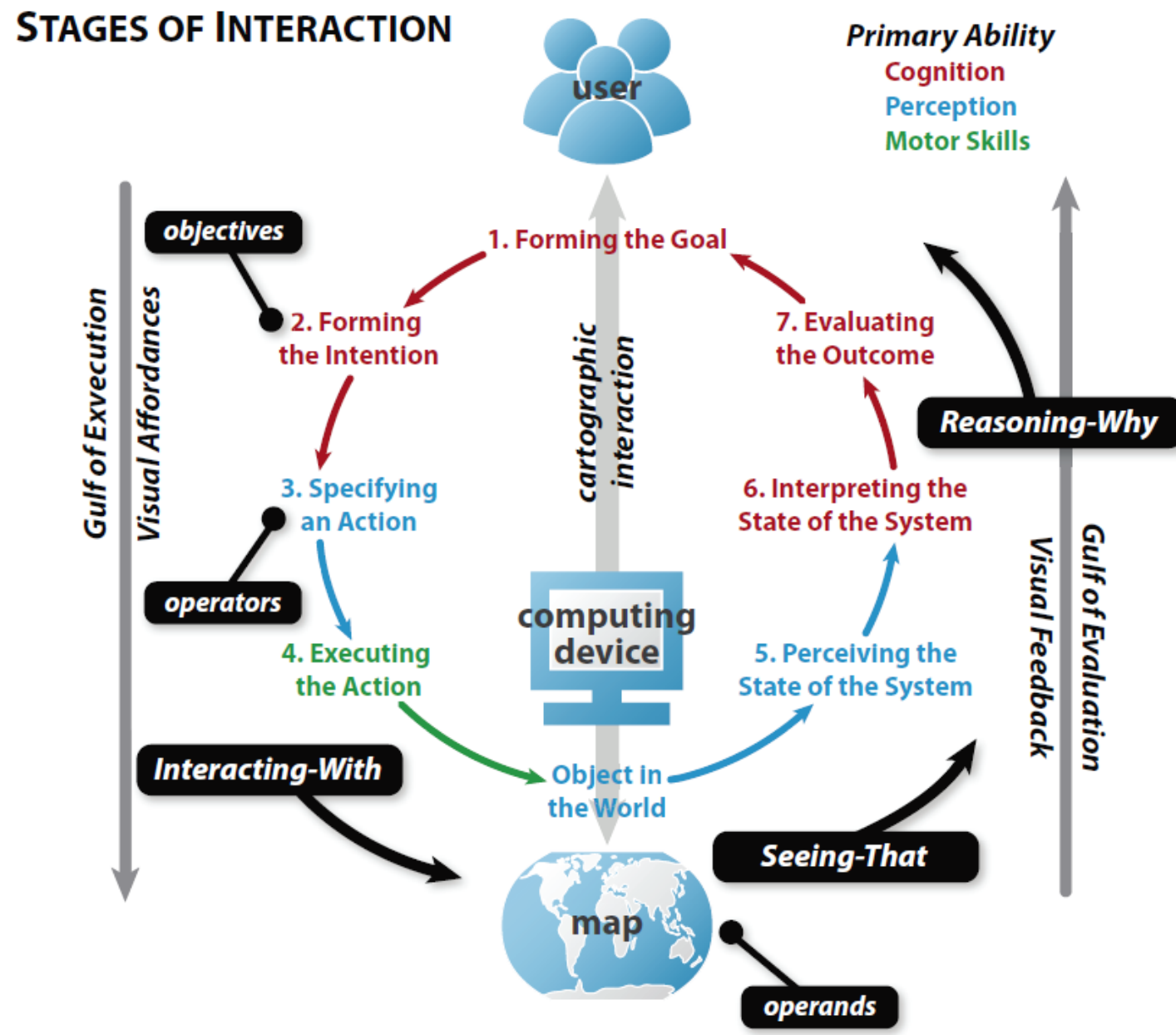

Figure 2.2 - Stages of Interaction model from Norman, modified by Roth (2011).

Considering cartographic interaction with CFGCOS, the stages of interaction the designers intended for the user are: (1) read the instructions and form the goal of digitally annotating a place of importance, (2) set an objective to mark the map with a point, (3) 
identify the operators needed to find a place, add a point, and fill in the popup box (click button, pan, zoom, location template for adding points), (4) use the operators identified to produce data, (5) see the new point added to the map, (6) interpret that the point was successfully added, (7) based on the interpretation of success, move on to adding another point. Problems in stages 1-4 (Gulf of Execution) might result in a misplaced or poorly attributed point, while problems in stages 5-7 (Gulf of Evaluation) might lead the user to think they made a mistake when adding a point.

While each stage represents a key component of cartographic interaction, stages that involve operators (stages 3 and 4) are most extensively explored in this research. Usability evaluation of the specific operators in the CFGCOS interface, both individually and in combination, provide insight into potential issues with how data are produced, and identify use patterns of spatial data production. Conclusions drawn from such insight can further inform the design of future applications. Using a taxonomy defined by Roth (94), Table 2.1 lists the CFGCOS cartographic operators (and one non-cartographic operator) used and recorded through automated capture during this research. These operators are most relevant to stage 3 and 4 of the stages of interaction model.

Table 2.1 - Cartographic and non-cartographic interaction operators in CFGCOS

\begin{tabular}{|l|l|l|}
\hline Operator & Type & Definition \\
\hline zoom & cartographic & change the extent/scale of the map display \\
\hline pan & cartographic & change the center of the map display \\
\hline annotate & cartographic & add graphical markings and textual notes to the map display \\
\hline button & $\begin{array}{l}\text { non- } \\
\text { cartographic }\end{array}$ & trigger custom action related to map use \\
\hline
\end{tabular}




\subsubsection{Usability and Evaluation}

While cartographic interaction focuses on the specific stages of a user's engagement with a digital map, usability examines the success of those interactions. Usability is an important concept for interactive map designers to understand, as it is concerned with improving upon both the usefulness of map interface operators for completing tasks, and of the ease of use of the map interface itself (Roth and Harrower 47). Usability explores the quality of user's interactive experience in terms of effectiveness, efficiency, and overall satisfaction, all of which are vital to the success of PPGIS (Haklay and Tobón 589). Nielsen (“Usability 101") categorizes usability into 5 distinct metrics that have been adopted by Roth (2015) and Usability.gov (Usability Evaluation Basics): (1) learnability (how quickly a new user can learn to finish intended tasks), (2) efficiency (how quickly a user performs tasks after the interface is learned), (3) memorability (how well the user can perform tasks during later visits to the interface), (4) error frequency and severity (how frequently the user makes an error, severity of the error, and how well the user recovers from the error), (5) satisfaction (if the user likes the interface). Because users of CFGCOS interact with the map interface once, this research explores only four of the five metrics. The user's learnability, efficiency, and error frequency and severity provide insight to the user's productivity (performance) in data creation, while satisfaction illuminates the user's general impression (preference) of the application (Roth 264-265). 
In order to determine the usability of CFGCOS, this research employs several usability evaluation (UE) methods. The various UE techniques fall into two broad methodologies, controlled experimentation and usability testing/studies (Plaisant 109). Roth and Harrower describe these methodologies as existing along a continuum representing a transition from quantitative to qualitative, individual methods (See Figure 2.3) (50). Controlled experimentation involves positivist methods that simplify and isolate user tasks in order to produce quantitative measurements of the relationship between an independent variable and a usability metric. Usability testing/studies, on the other hand, utilize postpositivist qualitative methods that collect individual accounts of personal interaction while using an application (Roth and Harrower 50). This research employs evaluation methods in the realm of controlled experimentation by capturing quantitative data through performance metrics, interaction logging, and quantitative/qualitative data in an exit survey.

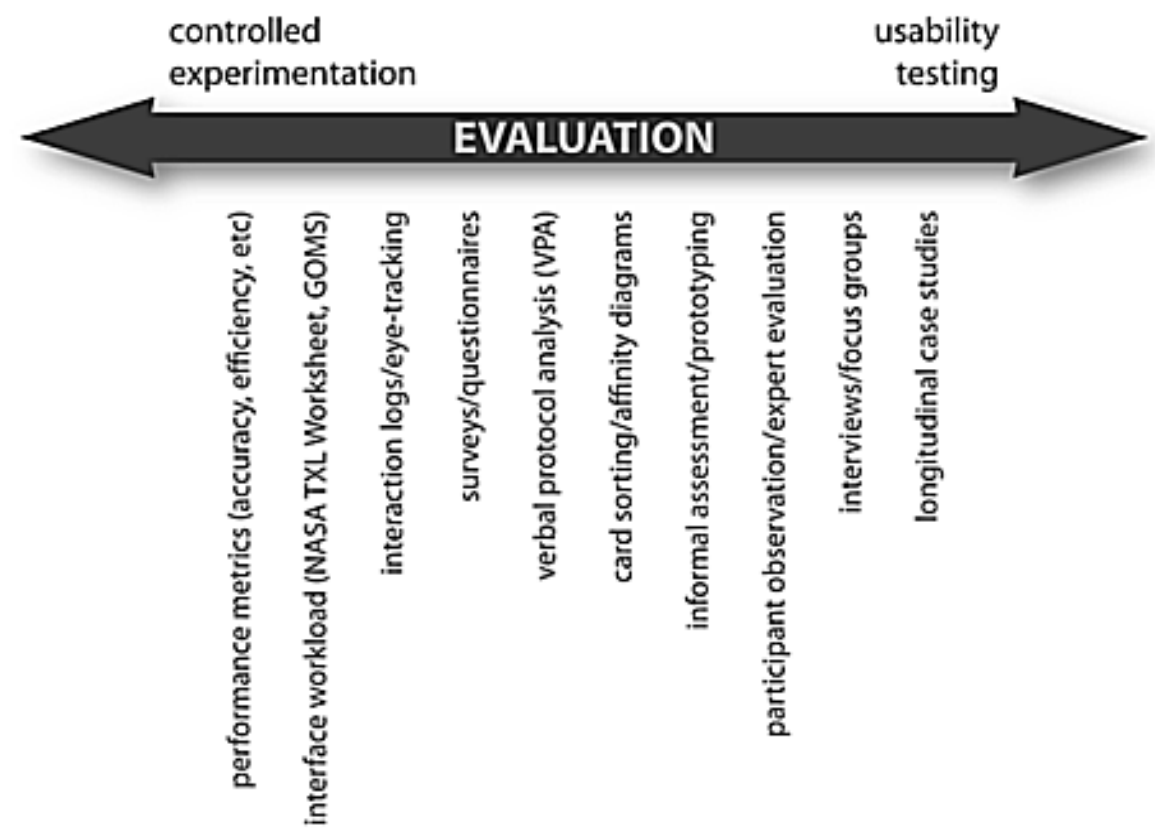

Figure 2.3 - Continuum of usability evaluation methods from Roth and Harrower (2008) 
The process of usability evaluation incorporates a multitude of activities that depend on the method employed. Ivory and Hearst describe the three main UE activities executed in stages as: (1) capture (the collection of usability data can include task completion time, and subjective ratings), (2) analysis (interpretation of usability data in order to identify interface problems), (3) critique (considering solutions and ways to mitigate issues) (470). Data capture can be partially or totally automated, however analysis and critique require an in-depth non-automated review of the usability and interaction data (Pyla et al. 620). UE of CFGCOS incorporates both automated and non-automated data capture. Automated data capture is achieved through additional software that logs the timing of completed mapping tasks and interface usage like panning and zooming. Non-automated data capture is accomplished through an exit survey the user is asked to complete after finishing the mapping activity. The captured data is then analyzed through the use of sequential pattern visualization, descriptive statistics pertaining to usability metrics and user feedback, and elementary statistical methods that test the relationships between usability, cartographic interaction, and data production. This thorough analysis identifies potential issues with the map interface that impact data production. Results of the analysis inform the critique activities. An underlying goal of this thesis is to consider how CFGCOS usability and cartographic interaction relate to data production so that a discussion on potential data quality issues are contextualized. Critique offers solutions to mitigate usability problems in CFGCOS that may ultimately affect the final data quality. 
The description of the UE process used for CFGCOS is described in the following three chapters. The data capture techniques employed in the evaluation are detailed in Chapter 3. Chapter 4 discusses the analysis methods used to identify potential problems in the CFGCOS interface and the subsequent results of that analysis. Chapter 5 details an informed and solution-oriented critique of CFGOS. 


\section{Chapter 3: Data Capture}

\subsection{Data Capture Overview}

The first stage of the usability evaluation of CFGCOS incorporated data capture activities described by Ivory and Hearst (See Section 2.6) in order to collect data concerning application ease-of-use, specific usability metrics (learnability, efficiency, error and severity, and satisfaction), cartographic/non-cartographic interaction operators (pan, zoom, annotate / button), and supplemental contextual information. Data capture activities also facilitated the first research goal of this thesis (See Section 1.4). This process was accomplished using automated (interaction logging) and non-automated (self-reported exit survey) methods in the realm of controlled experimentation as described by Roth and Harrower (50).

Controlled experimentation methods are useful because the results they produce are universal to any situation with similar control conditions and repeatable in any location, at any time, and by any researcher (Roth and Harrower 48).

Because the study area for which CFGCOS collected data encompassed Central OR forests and grasslands, the researchers travelled to Bend, Oregon on several occasions to recruit participants who were familiar with the area. Special arrangements were made with an instructor at Oregon State University (OSU) Cascades to promote and recruit for the project in several classes. The researchers gave a brief presentation and asked those in attendance of two different classes to use CFGCOS on their personal computing device, provided that the main source of interaction was not through a touch screen as the application was built for use with a trackpad or mouse. Participants were comprised of 
mostly students from OSU Cascades and some non-affiliated local residents. Their participation was voluntary. The specific methods employed to capture their use and impression of CFGCOS are discussed below.

\subsection{Automated Data Capture Method}

After the initial phase of the CFGCOS project concluded (See Section 1.2), additional software was developed to log usability performance metrics (learnability, efficiency, error) related to a user's task completion times and interaction with cartographic and noncartographic operators. The new software facilitated an automated data capture method employed in the UE central to this research. CFGCOS was developed using a combination of JavaScript and the ArcGIS JavaScript API which together provided a multitude of methods capable of logging specific events (actions or occurrences that happen in the system). The new logging functionality augmented the original design of CFGCOS in order to capture a timestamp (the exact moment of an action or occurrence) for every event the user initiated during the use session. Event timestamps are useful for quantifying learnability and efficiency of task completion as well as for determining sequential use patterns and illuminating error within those patterns (Frokjaer et al. 347). Supplementary data characteristic variables related to pan, zoom, and annotation cartographic operator interaction were also logged to provide insight to specific quantitative aspects of data production (zoom level, map coordinates, popup interaction characteristics, and point IDs).

Upon commencement of a new CFGCOS use session, the designers intended for the user to follow five instructional steps to identify and annotate points and popups for up to 
five places in the Deschutes National Forest, Ochoco National Forest, or Crooked River National Grassland that were important to them (See Figure 3.1). Step one directed the user to click on a button that generated a new Anonymous Identification Number (AIN) that uniquely identified the use session. Step two instructed the user to pan and zoom to find a desired location on the map. Step three was perhaps the most complicated for the user to interpret as it directed the user to perform several actions, the first of which was to click on the location template to select a "colored dot," starting with "Location 1." Next, the user was told to add that dot to the map. If the user noticed that the popup box that appeared wasn't in full view, they were instructed to click and drag the map until it was completely visible. The user was then directed to fill in up to eleven form boxes within the popup and close the popup box when done. For the purpose of this research step 3 was further segmented into steps $3 \mathrm{a}$ (click on colored dot), 3b (annotate point), and 3c (annotate popup). Within step $3 \mathrm{c}$ there were two more form box steps: enter the form box and exit the form box. Step four instructed the user to repeat the previous steps for up to five locations. Finally, step five directed the user to click on a button that ended the use session. 


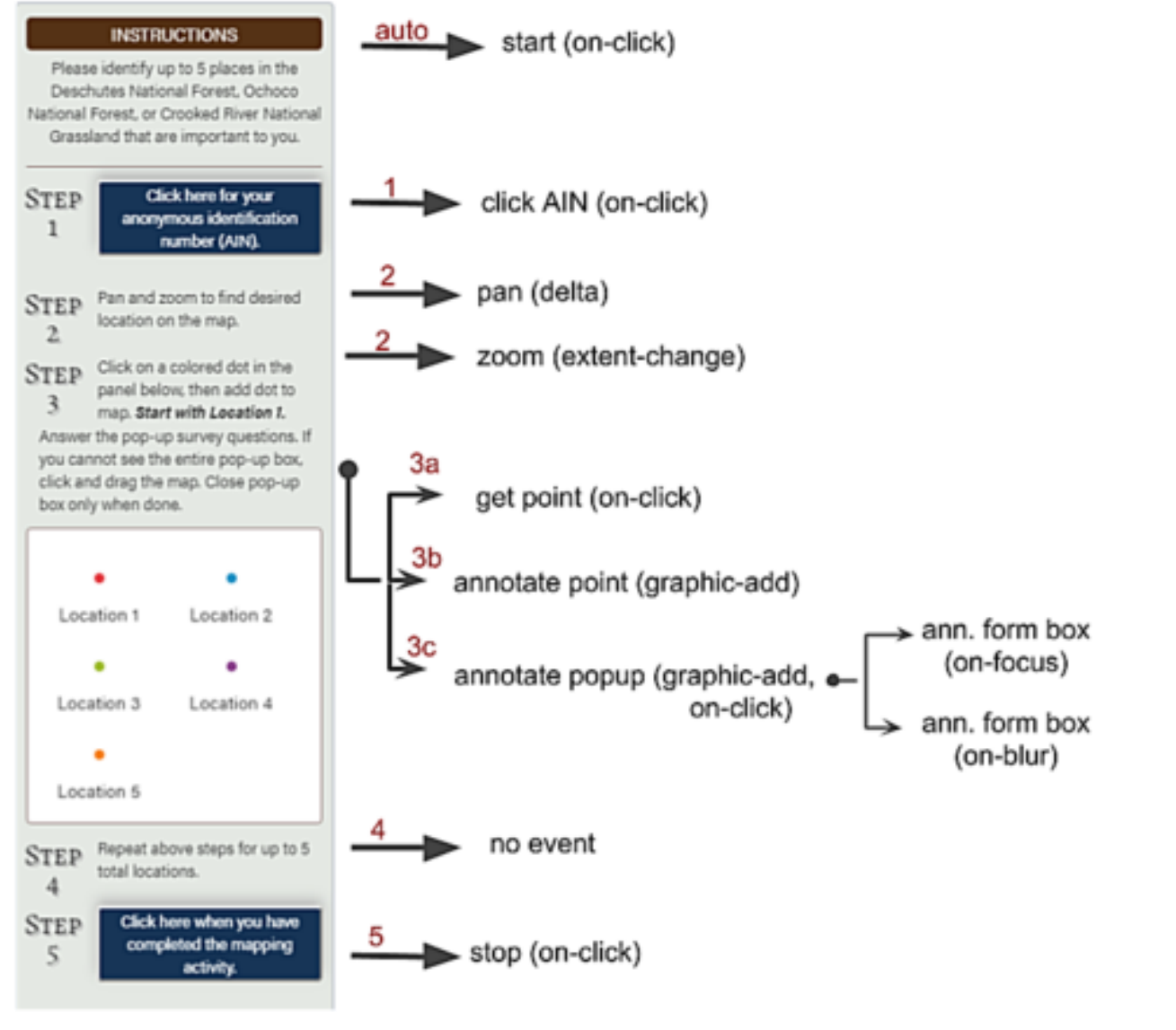

Figure 3.1 - The instructional panel in CFGCOS separated into five steps. Step 3 was further segmented into three substeps, each related to a specific interaction within the step. Within step $3 \mathrm{c}$, two more form box steps occur. All steps have an associated event as seen in Table 3.1.

In order to facilitate the process of storing data captured from interaction logging, each instructional step was divided into six categories: session time, AIN, zoom, pan, popup, point. Each category relates to different interaction and data production aspects existing within CFGCOS. When a user finished a use session by clicking the step five button, several JSON files, one for each data category, were posted to an Amazon Web Services (AWS) S3 Bucket for use in a subsequent analysis. Table 3.1 provides an overview of each instructional step and its associated data categories, events, operators, interaction types, 
variable types, and context that apply to the UE of CFGCOS. The following three subsections detail the variables collected within similar categories or steps.

Table 3.1 - Categories and names of interaction events with the associated captured variable description, operator, UE context and instructional step.

\begin{tabular}{|c|c|c|c|c|c|c|}
\hline Step & $\begin{array}{l}\text { Data } \\
\text { Category }\end{array}$ & Event & Operator & Interaction Type & Variable Type & UE Context \\
\hline NA & $\begin{array}{l}\text { session } \\
\text { time }\end{array}$ & start (on-load) & NA & non-cartographic & timestamp & $\begin{array}{l}\text { learnability, } \\
\text { efficiency, } \\
\text { error }\end{array}$ \\
\hline 5 & $\begin{array}{l}\text { session } \\
\text { time }\end{array}$ & stop (on-click) & button & non-cartographic & timestamp & $\begin{array}{l}\text { learnability, } \\
\text { efficiency, } \\
\text { error }\end{array}$ \\
\hline 1 & $\mathrm{AIN}$ & $\begin{array}{l}\text { click AIN button } \\
\text { (on-click) }\end{array}$ & button & non-cartographic & timestamp & $\begin{array}{l}\text { learnability, } \\
\text { efficiency, } \\
\text { error }\end{array}$ \\
\hline 2 & zoom & $\begin{array}{l}\text { zoom (extent- } \\
\text { change) }\end{array}$ & zoom & cartographic & timestamp & $\begin{array}{l}\text { learnability, } \\
\text { efficiency, } \\
\text { error }\end{array}$ \\
\hline 2 & zoom & $\begin{array}{l}\text { zoom (extent- } \\
\text { change) }\end{array}$ & zoom & cartographic & zoom level & $\begin{array}{l}\text { cartographic } \\
\text { interaction / data } \\
\text { production }\end{array}$ \\
\hline 2 & pan & $\begin{array}{l}\text { pan (delta / click } \\
\text { and drag map) }\end{array}$ & pan & cartographic & timestamp & $\begin{array}{l}\text { learnability, } \\
\text { efficiency, } \\
\text { error }\end{array}$ \\
\hline $3 a$ & point & $\begin{array}{l}\text { click on colored } \\
\text { dot / get point } \\
\text { (on-click) }\end{array}$ & annotate & cartographic & timestamp & $\begin{array}{l}\text { learnability, } \\
\text { efficiency, } \\
\text { error }\end{array}$ \\
\hline $3 b$ & point & $\begin{array}{l}\text { annotate point } \\
\text { (graphic-add) }\end{array}$ & annotate & cartographic & timestamp & $\begin{array}{l}\text { learnability, } \\
\text { efficiency, } \\
\text { error }\end{array}$ \\
\hline $3 b$ & point & $\begin{array}{l}\text { annotate point } \\
\text { (graphic-add) }\end{array}$ & annotate & cartographic & location ID & $\begin{array}{l}\text { cartographic } \\
\text { interaction / data } \\
\text { production }\end{array}$ \\
\hline $3 b$ & point & $\begin{array}{l}\text { annotate point } \\
\text { (graphic-add) }\end{array}$ & annotate & cartographic & zoom level & $\begin{array}{l}\text { cartographic } \\
\text { interaction / data } \\
\text { production }\end{array}$ \\
\hline
\end{tabular}




\begin{tabular}{|l|l|l|l|l|l|l|}
\hline $3 \mathrm{~b}$ & point & $\begin{array}{l}\text { annotate point } \\
\text { (graphic-add) }\end{array}$ & annotate & cartographic & $\begin{array}{l}\text { x,y map } \\
\text { coordinates }\end{array}$ & $\begin{array}{l}\text { cartographic } \\
\text { interaction } / \text { data } \\
\text { production }\end{array}$ \\
\hline $3 \mathrm{c}$ & popup & $\begin{array}{l}\text { open (graphic- } \\
\text { add) }\end{array}$ & annotate & cartographic & timestamp & $\begin{array}{l}\text { learnability, } \\
\text { efficiency, } \\
\text { error }\end{array}$ \\
\hline $3 \mathrm{c}$ & popup & close (on-click) & annotate & cartographic & timestamp & $\begin{array}{l}\text { learnability, } \\
\text { efficiency, } \\
\text { error }\end{array}$ \\
\hline $3 \mathrm{c}$ & popup & $\begin{array}{l}\text { enter form box } \\
\text { (on-focus) }\end{array}$ & annotate & cartographic & timestamp & $\begin{array}{l}\text { learnability, } \\
\text { efficiency, } \\
\text { error }\end{array}$ \\
\hline $3 \mathrm{c}$ & popup & $\begin{array}{l}\text { enter form box } \\
\text { (on-focus) }\end{array}$ & annotate & cartographic & $\begin{array}{l}\text { form box } \\
\text { name }\end{array}$ & $\begin{array}{l}\text { cartographic } \\
\text { interaction /data } \\
\text { production }\end{array}$ \\
\hline $3 \mathrm{c}$ & popup & $\begin{array}{l}\text { exit form box } \\
\text { (on-blur) }\end{array}$ & annotate & cartographic & timestamp & $\begin{array}{l}\text { learnability, } \\
\text { efficiency, } \\
\text { error }\end{array}$ \\
\hline
\end{tabular}

\subsubsection{Session Time and AIN}

All variables within session time and AIN categories were logged during noncartographic interaction occurring at the initiation of a new use session or through button operator functionality in the instructional panel. Session time contains two timestamp variables logged during two events that occurred as soon as a use session began (on-load) and when the user clicked the step five button (on-click). The AIN category contains only one timestamp variable logged when the AIN button was clicked (on-click) during step one. In the context of UE, these variables help to quantify learnability and efficiency as well as sequential use patterns. 


\subsubsection{Zoom and Pan}

Zoom and pan variables were captured during step 2 while the user identified a place of importance to annotate. Cartographic interaction with zoom and pan operators changes the scale or center of the map display respectively. CFGCOS contains three map scales. The zoom category includes two variables (timestamp and zoom level) logged for each zoom (extent-change) event. The pan category consists of one variable (timestamp) captured during each pan event (click and drag the map). These variables help to define learnability, efficiency and sequential event patterns (error) as well as provide cartographic context for the way in which users identify places of importance.

\subsubsection{Point and Popup}

Point and popup variables captured during step 3 comprise the bulk of the cartographic interaction related to the data producing annotation operators. To properly classify this step, it was segmented into three subclasses, ordered according to the sequence in which they were logged. The point category includes five variables associated with two events (click on a colored dot and annotate point) that occur during step 3a and 3b, respectively. The click on colored dot /get point event logged one timestamp variable, while the subsequent annotate point event (graphic-add) logged four related variables (timestamp, location ID, zoom level at annotation, and $\mathrm{x}, \mathrm{y}$ map coordinates) when the popup was closed. In terms of UE, the timestamps quantify efficiency, learnability and error, while the other variables provide cartographic interaction and data production context. 
The popup category contains six variables related to five events logged during step 3b. Timestamps were logged when the popup box was opened automatically (graphic-add) closed by the user (on-click), or when a particular form box was entered (on-focus) or exited (on-blur). Also, each time a form box was entered (on-focus), the name of the box was logged and when it was exited (on-blur), a boolean (true/false) variable was logged indicating whether the form box was filled in by the user. As with the point timestamps, popup timestamps help to quantify efficiency and learnability while the other variables provide cartographic interaction and data production context.

\section{$\underline{3.3 \text { Automated Data Capture Results }}$}

In summary, a total of seventeen variables related to ten unique events, four operator types, and four instructional steps were captured during interactive logging of sixty-two $(n=62)$ use sessions. After each use session, six different JSON files, one for each data category were sent to AWS and stored. Each use session, identified by a unique AIN, represented interaction by a unique participant. In preparation for the analysis stage of the UE detailed in Chapter 4, use session files for each data category were merged resulting in six larger data. Due to error in storage of seven captured data files, the analysis was subset to fifty-five use sessions $(n=55)$ and two-hundred-forty-five $(n=245)$ points. Each new merged data file contained an AIN variable so that joining among the data was possible. Analysis of all the data captured during this process are explored in detail in Chapter 4. 


\subsection{Non-Automated Data Capture Method}

The second component of data capture employed in the UE of CFGCOS incorporated a non-automated method to quantify usability preference metrics (satisfaction). When a user clicked the step 5 button to indicate they had completed a CFGCOS use session, they were directed to an exit survey created to gather subjective feedback both general and specific regarding the map, point placement, sidebar instructions, and popup. Users were also asked background questions related to their mapping and computer literacy. Collectively, these questions were designed to elicit contextual information regarding how users interacted with CFGCOS to produce data, what they found to be easy or difficult about the process, and how comfortable they were with interactive mapping in general.

The survey was ordered in six sections, each of which focused on particular aspects of CFGCOS cartographic interaction, data production, usability, or of the users themselves (See Table 3.2). For the most part, answers to single ease questions (SEQ; questions related to ease-of-use) provided a multitude of Likert scale / ordinal variables for defining satisfaction - the users' comfort with and positive attitudes towards the use of the system (Frokjaer et al. 345). Other questions provided mostly nominal, long text (open-ended), and dichotomous (yes-no) variables to offer insight into aspects of cartographic interaction that could impact data production. The following section details the variables collected within each section as well as the response results. 
Table 3.2 - Questions asked in the six sections of the exit survey including the resulting answer variable type and context for the usability evaluation.

\begin{tabular}{|c|c|c|c|}
\hline Q\# & Question & Variable Type & UE Context \\
\hline & Section 1: Map Feedback & & \\
\hline 1.1 & $\begin{array}{l}\text { How easy or difficult was it to find } \\
\text { the places you were looking for? }\end{array}$ & $\begin{array}{l}\text { Likert scale / } \\
\text { ordinal }\end{array}$ & satisfaction \\
\hline 1.2 & $\begin{array}{l}\text { Were there any elements that were } \\
\text { missing from the map that would } \\
\text { have helped you, such as: }\end{array}$ & nominal & $\begin{array}{l}\text { cartographic interaction / data } \\
\text { production }\end{array}$ \\
\hline 1.3 & $\begin{array}{l}\text { Generally speaking, how simple or } \\
\text { complicated did you find the map }\end{array}$ & $\begin{array}{l}\text { Likert scale / } \\
\text { ordinal }\end{array}$ & satisfaction \\
\hline \multirow[t]{2}{*}{1.4} & $\begin{array}{l}\text { Was there anything else about the } \\
\text { map that was particularly helpful? } \\
\text { Difficult? Any other feedback? }\end{array}$ & long text & satisfaction \\
\hline & Section 2: Point Placement & & \\
\hline 2.1 & $\begin{array}{l}\text { For each point, what kind of place } \\
\text { did you mark? }\end{array}$ & nominal & $\begin{array}{l}\text { cartographic interaction / data } \\
\text { production }\end{array}$ \\
\hline 2.2 & $\begin{array}{l}\text { Of the places that you marked, } \\
\text { how many places did you have in } \\
\text { mind when you started the survey? }\end{array}$ & integer & $\begin{array}{l}\text { cartographic interaction / data } \\
\text { production }\end{array}$ \\
\hline 2.3 & $\begin{array}{l}\text { Of the places that you marked, } \\
\text { were there any places the you were } \\
\text { reminded of when you looked at } \\
\text { the map that you didn't think } \\
\text { about in the beginning? How } \\
\text { many? }\end{array}$ & integer & $\begin{array}{l}\text { cartographic interaction / data } \\
\text { production }\end{array}$ \\
\hline \multirow[t]{2}{*}{2.4} & $\begin{array}{l}\text { Any other feedback about how you } \\
\text { decided which places to mark? }\end{array}$ & long text & $\begin{array}{l}\text { cartographic interaction / data } \\
\text { production }\end{array}$ \\
\hline & Section 3: Sidebar/Instructions & & \\
\hline 3.1 & $\begin{array}{l}\text { How easy or difficult was it to } \\
\text { understand the directions? }\end{array}$ & $\begin{array}{l}\text { Likert scale / } \\
\text { ordinal }\end{array}$ & satisfaction \\
\hline 3.2 & $\begin{array}{l}\text { How easy or difficult was it figure } \\
\text { out how to place your first point } \\
\text { on the map? }\end{array}$ & $\begin{array}{l}\text { Likert scale / } \\
\text { ordinal }\end{array}$ & satisfaction \\
\hline
\end{tabular}




\begin{tabular}{|c|c|c|c|}
\hline 3.3 & $\begin{array}{l}\text { How easy or difficult was it to } \\
\text { place subsequent points on the } \\
\text { map? }\end{array}$ & $\begin{array}{l}\text { Likert scale / } \\
\text { ordinal }\end{array}$ & satisfaction \\
\hline 3.4 & $\begin{array}{l}\text { Were there any points that you } \\
\text { wanted to delete but were not able } \\
\text { to? }\end{array}$ & dichotomous & $\begin{array}{l}\text { cartographic interaction / data } \\
\text { production, error \& severity }\end{array}$ \\
\hline 3.5 & $\begin{array}{l}\text { How easy or difficult was it to } \\
\text { figure out how to view and record } \\
\text { your AIN (anonymous } \\
\text { identification number)? }\end{array}$ & $\begin{array}{l}\text { Likert scale / } \\
\text { ordinal }\end{array}$ & satisfaction \\
\hline \multirow[t]{2}{*}{3.6} & $\begin{array}{l}\text { Was there anything else about the } \\
\text { sidebar that was particularly } \\
\text { helpful? Difficult? Any other } \\
\text { feedback? }\end{array}$ & long text & satisfaction \\
\hline & Section 4: Popup & & \\
\hline 4.1 & $\begin{array}{l}\text { Thinking about the pop-up, how } \\
\text { did you feel about the number of } \\
\text { questions you were asked? }\end{array}$ & $\begin{array}{l}\text { Likert scale / } \\
\text { ordinal }\end{array}$ & satisfaction \\
\hline 4.2 & $\begin{array}{l}\text { Were there any answers that you } \\
\text { wanted to change but were not } \\
\text { able to? }\end{array}$ & dichotomous & $\begin{array}{l}\text { cartographic interaction / data } \\
\text { production }\end{array}$ \\
\hline 4.3 & $\begin{array}{l}\text { Did you prefer a particular style of } \\
\text { question? }\end{array}$ & nominal & $\begin{array}{l}\text { cartographic interaction / data } \\
\text { production }\end{array}$ \\
\hline 4.4 & $\begin{array}{l}\text { When you selected up to three } \\
\text { benefits that you associated with } \\
\text { each place, did you select them in } \\
\text { order from most important to least } \\
\text { important? }\end{array}$ & dichotomous & $\begin{array}{l}\text { cartographic interaction / data } \\
\text { production }\end{array}$ \\
\hline 4.5 & $\begin{array}{l}\text { Was there any point where the } \\
\text { pop-up blocked information that } \\
\text { you needed to see on the map? }\end{array}$ & dichotomous & $\begin{array}{l}\text { cartographic interaction / data } \\
\text { production }\end{array}$ \\
\hline \multirow[t]{2}{*}{4.6} & $\begin{array}{l}\text { Was there anything else about the } \\
\text { pop-up that was particularly } \\
\text { helpful? Difficult? Any other } \\
\text { feedback? }\end{array}$ & long text & satisfaction \\
\hline & Section 5: General Feedback & & \\
\hline 5.1 & $\begin{array}{l}\text { Did the mapping activity take more } \\
\text { or less time than you expected? }\end{array}$ & $\begin{array}{l}\text { Likert scale / } \\
\text { ordinal }\end{array}$ & satisfaction \\
\hline 5.2 & $\begin{array}{l}\text { How important or unimportant do } \\
\text { you feel the information you }\end{array}$ & $\begin{array}{l}\text { Likert scale / } \\
\text { ordinal }\end{array}$ & satisfaction \\
\hline
\end{tabular}




\begin{tabular}{|c|c|c|c|}
\hline & $\begin{array}{l}\text { provided during the mapping } \\
\text { activity is for land management } \\
\text { and planning? }\end{array}$ & & \\
\hline 5.3 & $\begin{array}{l}\text { How motivated or unmotivated } \\
\text { were you to complete the mapping } \\
\text { activity? }\end{array}$ & $\begin{array}{l}\text { Likert scale / } \\
\text { ordinal }\end{array}$ & satisfaction \\
\hline \multirow[t]{2}{*}{5.4} & $\begin{array}{l}\text { Overall, how would you rate your } \\
\text { experience using this application? }\end{array}$ & long text & satisfaction \\
\hline & Section 6: Background & & \\
\hline 6.1 & $\begin{array}{l}\text { How often do you use maps on a } \\
\text { computer or other device? }\end{array}$ & $\begin{array}{l}\text { Likert scale / } \\
\text { ordinal }\end{array}$ & general \\
\hline 6.2 & $\begin{array}{l}\text { In general, how comfortable do } \\
\text { you feel using a map? }\end{array}$ & $\begin{array}{l}\text { Likert scale / } \\
\text { ordinal }\end{array}$ & general \\
\hline 6.3 & How often do you use a computer? & $\begin{array}{l}\text { Likert scale / } \\
\text { ordinal }\end{array}$ & general \\
\hline
\end{tabular}

\section{$\underline{\text { 3.5 Non-Automated Data Capture Results }}$}

Of the sixty-two participants that conducted a use session, fifty-seven $(\mathrm{n}=57)$

completed the exit survey. The following six subsections detail the questions asked in each section, the answer options to those questions, the number of people who selected a particular answer option, and the frequency of that answer option.

\subsubsection{Map Feedback}

The first section directed the user to "think about the map" and asked four $(n=4)$ questions. Q1.1 and Q1.3 were SEQs to which answers provided ordinal user satisfaction ratings regarding difficulty in finding places on the map and simplicity in using the map, respectively. Responses to Q1.2 provided nominal subjective opinions about missing map 
elements and desire for specific cartographic interaction/context. Q1.4 was an open-ended question meant to elicit other general feedback about the map. Results for Q1.1 - Q1.3 are outlined in Table 3.3 while Q1.4 and the “other" option to Q1.2 are discussed in the following paragraph.

Table 3.3 - Results from the Map Feedback portion (Section 1) of the exit survey.

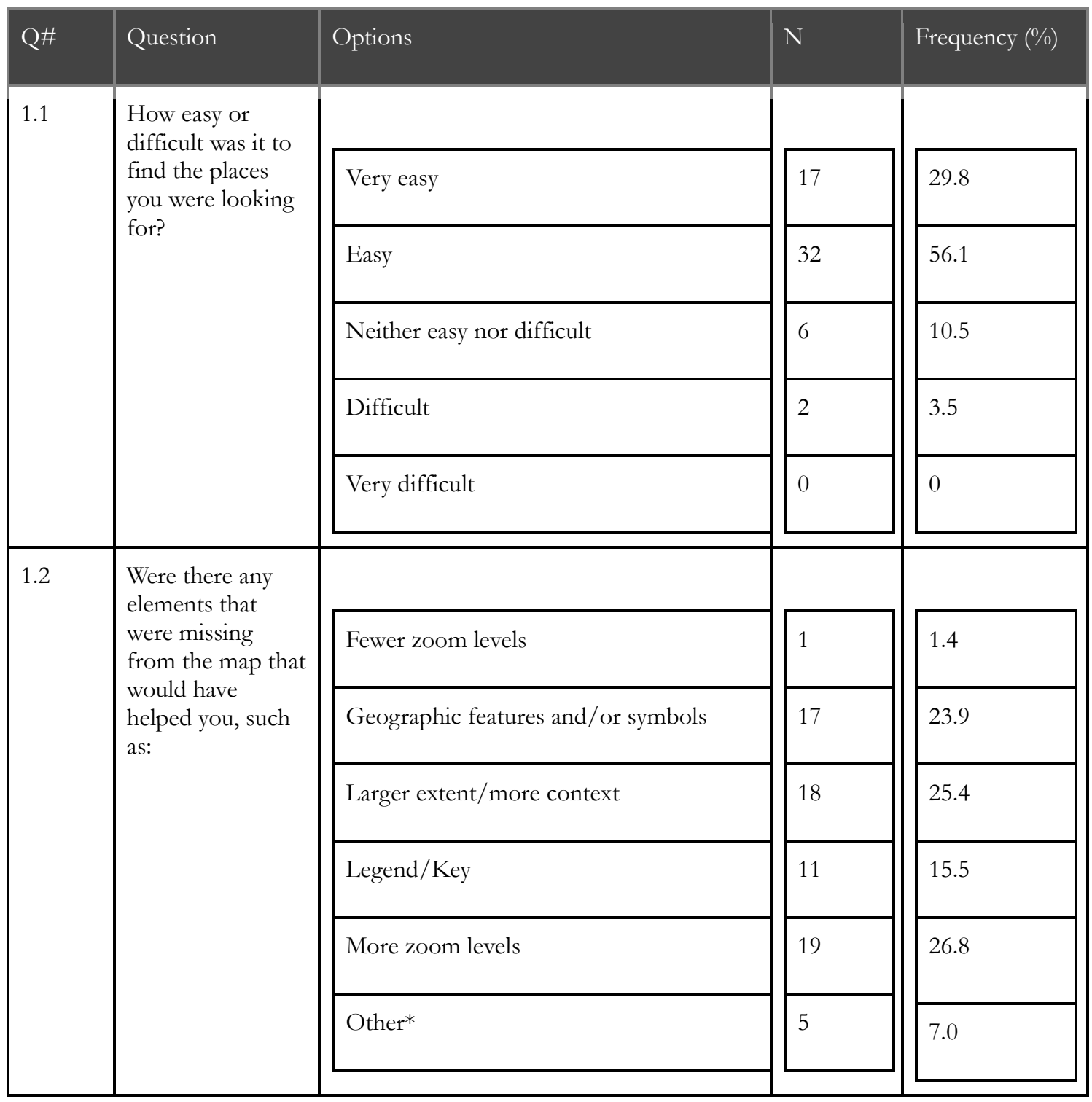




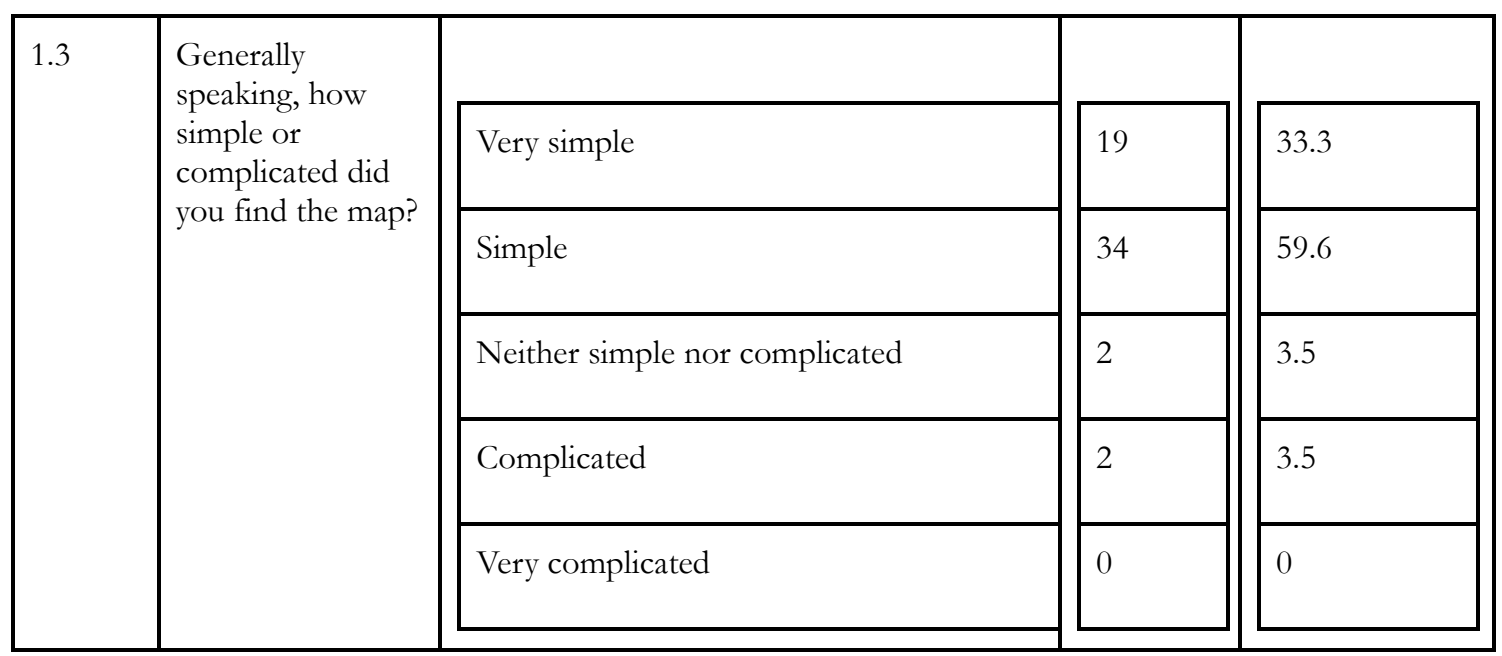

Regarding Q1.2, five ( $\mathrm{n}=5)$ participants indicated "other" as the answer to what elements were missing from the map. Three of those participants indicated that nothing was missing while the other two stated the need for "better borders" and "boundaries." The open-ended answers to Q1.4 indicated mostly positive feedback about the detail of the map while others mentioned wanting "more small streams and tributaries," and that there were "not a lot of geographic features."

\subsubsection{Point Placement}

Section two of the exit survey instructed users to "think about the places you marked on the map," and asked four questions; each of which were concerned with aspects of cartographic interaction and data production. Responses to Q2.1 provided nominal data regarding the geographic area users marked for each area. Q2.2 and Q2.3 provided integer results (1-5) from asking how many places the user had in mind before the use session or if any places came to mind during the session. Q2.4 was an open-ended question seeking 
additional information on how a user decided which places to mark. Table 3.4 outlines the results of Q2.1 - Q2.3. Open-ended answers to Q2.4 are discussed in the next paragraph.

Table 3.4 - Results from the Point Placement portion (Section 2) of the exit survey.

\begin{tabular}{|c|c|c|c|c|}
\hline Q\# & Question & Options & $\mathrm{N}$ & Frequency $(\%)$ \\
\hline \multirow[t]{6}{*}{2.1} & \multirow{6}{*}{$\begin{array}{l}\text { For each point, what kind of } \\
\text { place did you mark? }\end{array}$} & & & \\
\hline & & icon & 34 & 18.1 \\
\hline & & small lake & 50 & 26.6 \\
\hline & & started activity & 30 & 16.0 \\
\hline & & wilderness & 51 & 27.1 \\
\hline & & other & 23 & 12.2 \\
\hline \multirow[t]{7}{*}{2.2} & \multirow{7}{*}{$\begin{array}{l}\text { Of the places that you marked, } \\
\text { how many places did you have } \\
\text { in mind when you started the } \\
\text { survey? }\end{array}$} & & & \\
\hline & & 0 & 9 & 15.8 \\
\hline & & 1 & 6 & 10.5 \\
\hline & & 2 & 9 & 15.8 \\
\hline & & 3 & 15 & 26.3 \\
\hline & & 4 & 6 & 10.5 \\
\hline & & 5 & 12 & 21.1 \\
\hline \multirow[t]{7}{*}{2.3} & \multirow{7}{*}{$\begin{array}{l}\text { Of the places that you marked, } \\
\text { were there any places the you } \\
\text { were reminded of when you } \\
\text { looked at the map that you } \\
\text { didn't think about in the } \\
\text { beginning? How many? }\end{array}$} & & & \\
\hline & & 0 & 12 & 21.1 \\
\hline & & 1 & 13 & 22.8 \\
\hline & & 2 & 18 & 31.6 \\
\hline & & 3 & 6 & 10.5 \\
\hline & & 4 & 2 & 3.5 \\
\hline & & 5 & 6 & 10.5 \\
\hline
\end{tabular}


Answers to Q2.4 were open-ended and revealed one major theme (visitation) for how participants decided to mark the map. Nine people $(n=9)$ responded and all mentioned they marked places they visit often, enjoy visiting, or would like to visit again.

\subsubsection{Sidebar / Instructions Feedback}

Section three directed users to "think about the sidebar" that contained the instructions and asked six questions. Q3.1, Q3.2, Q3.3, and Q3.5 were all SEQs regarding satisfaction. The users were asked to rate how easy or difficult is was to understand the instructions, place points on the map, and generate/record their AIN. Q3.4 asked if the user wanted to delete points but couldn't. The dichotomous (yes-no) responses to Q4 provided insight on cartographic interaction/data production and potential error. Q3.6 generated open-ended feedback on the sidebar/instructions. Results from Q3.1 - Q3.5 are shown in Table 3.5, while open-ended feedback from Q3.6 is detailed in the following paragraph.

Table 3.5 - Results from the Sidebar / Instructions Feedback portion (Section 3) of the exit survey.

\begin{tabular}{|c|c|c|c|c|}
\hline Q\# & Question & Options & $\mathrm{N}$ & $\begin{array}{l}\text { Frequency } \\
(\%)\end{array}$ \\
\hline \multirow[t]{6}{*}{3.1} & \multirow{6}{*}{$\begin{array}{l}\text { How easy or difficult was it to } \\
\text { understand the directions? }\end{array}$} & & & \\
\hline & & Very easy & 21 & 37.5 \\
\hline & & Easy & 22 & 39.3 \\
\hline & & Neither easy nor difficult & 10 & 17.9 \\
\hline & & Difficult & 3 & 5.4 \\
\hline & & Very difficult & 0 & 0 \\
\hline
\end{tabular}




\begin{tabular}{|c|c|c|c|c|}
\hline \multirow[t]{5}{*}{3.2} & \multirow[t]{5}{*}{$\begin{array}{l}\text { How easy or difficult was it to } \\
\text { figure out how to place your } \\
\text { first point on the map? }\end{array}$} & Very easy & 17 & 29.8 \\
\hline & & Easy & 27 & 47.4 \\
\hline & & Neither easy nor difficult & 6 & 10.5 \\
\hline & & Difficult & 6 & 10.5 \\
\hline & & Very difficult & 1 & 1.8 \\
\hline \multirow[t]{6}{*}{3.3} & \multirow{6}{*}{$\begin{array}{l}\text { How easy or difficult was it to } \\
\text { place subsequent points on the } \\
\text { map? }\end{array}$} & & & \\
\hline & & Very easy & 19 & 33.3 \\
\hline & & Easy & 28 & 49.1 \\
\hline & & Neither easy nor difficult & 4 & 7.0 \\
\hline & & Difficult & 5 & 8.8 \\
\hline & & Very difficult & 1 & 1.8 \\
\hline \multirow[t]{3}{*}{3.4} & \multirow{3}{*}{$\begin{array}{l}\text { Were there any points that you } \\
\text { wanted to delete but were not } \\
\text { able to? }\end{array}$} & & & \\
\hline & & No & 40 & 70.2 \\
\hline & & Yes & 17 & 29.8 \\
\hline \multirow[t]{6}{*}{3.5} & \multirow{6}{*}{$\begin{array}{l}\text { How easy or difficult was it to } \\
\text { figure out how to view and } \\
\text { record your AIN (anonymous } \\
\text { identification number)? }\end{array}$} & & & \\
\hline & & Very easy & 29 & 50.9 \\
\hline & & Easy & 22 & 38.6 \\
\hline & & Neither easy nor difficult & 2 & 3.5 \\
\hline & & Difficult & 3 & 5.3 \\
\hline & & Very difficult & 1 & 1.8 \\
\hline
\end{tabular}

Open-ended feedback related to Q3.6 generated fifteen responses. Of those, seven $(n=7)$ mentioned the inability to delete or change point after they had been added. One person ( $\mathrm{n}=1)$ noted that it took a moment for them to realize the "click on a colored dot" 
did not mean click and drag. Another $(n=1)$ mentioned the sidebar had "small font." The remaining answers were either positive or not specific to the sidebar/instructions.

\subsubsection{Popup Feedback}

Section four instructed users to "think about the popup survey" that appeared when they added a new point on the map. Six questions were asked, three of which were cartographic interaction / data production questions that elicited dichotomous responses related to users' desire to change answers (Q4.2), whether users ranked benefits (Q4.4), and if the popup blocked important map information (Q4.5). Q4.1 asked what the user thought about the number of questions, a matter related to satisfaction. Q4.6 was another general open-ended question about the users' impression of the popup. Results from Q4.1 - Q4.5 are detailed in Table 3.6, while open-ended responses to Q4.6 are discussed in the following paragraph.

Table 3.6 - Results from the Popups Feedback portion (Section 4) of the exit survey.

\begin{tabular}{|c|c|c|c|c|}
\hline Q\# & Question & Options & $\mathrm{N}$ & Frequency $(\%)$ \\
\hline \multirow[t]{4}{*}{4.1} & \multirow{4}{*}{$\begin{array}{l}\text { Thinking about the pop-up, } \\
\text { how did you feel about the } \\
\text { number of questions you } \\
\text { were asked? }\end{array}$} & & & \\
\hline & & Not enough questions & 2 & 3.5 \\
\hline & & The right number of questions & 38 & 66.7 \\
\hline & & Too many questions & 17 & 29.8 \\
\hline \multirow[t]{3}{*}{4.2} & \multirow{3}{*}{$\begin{array}{l}\text { Were there any answers that } \\
\text { you wanted to change but } \\
\text { were not able to? }\end{array}$} & & & \\
\hline & & No & 47 & 82.5 \\
\hline & & Yes & 10 & 17.5 \\
\hline 4.3 & $\begin{array}{l}\text { Did you prefer a particular } \\
\text { style of question? }\end{array}$ & & & \\
\hline
\end{tabular}




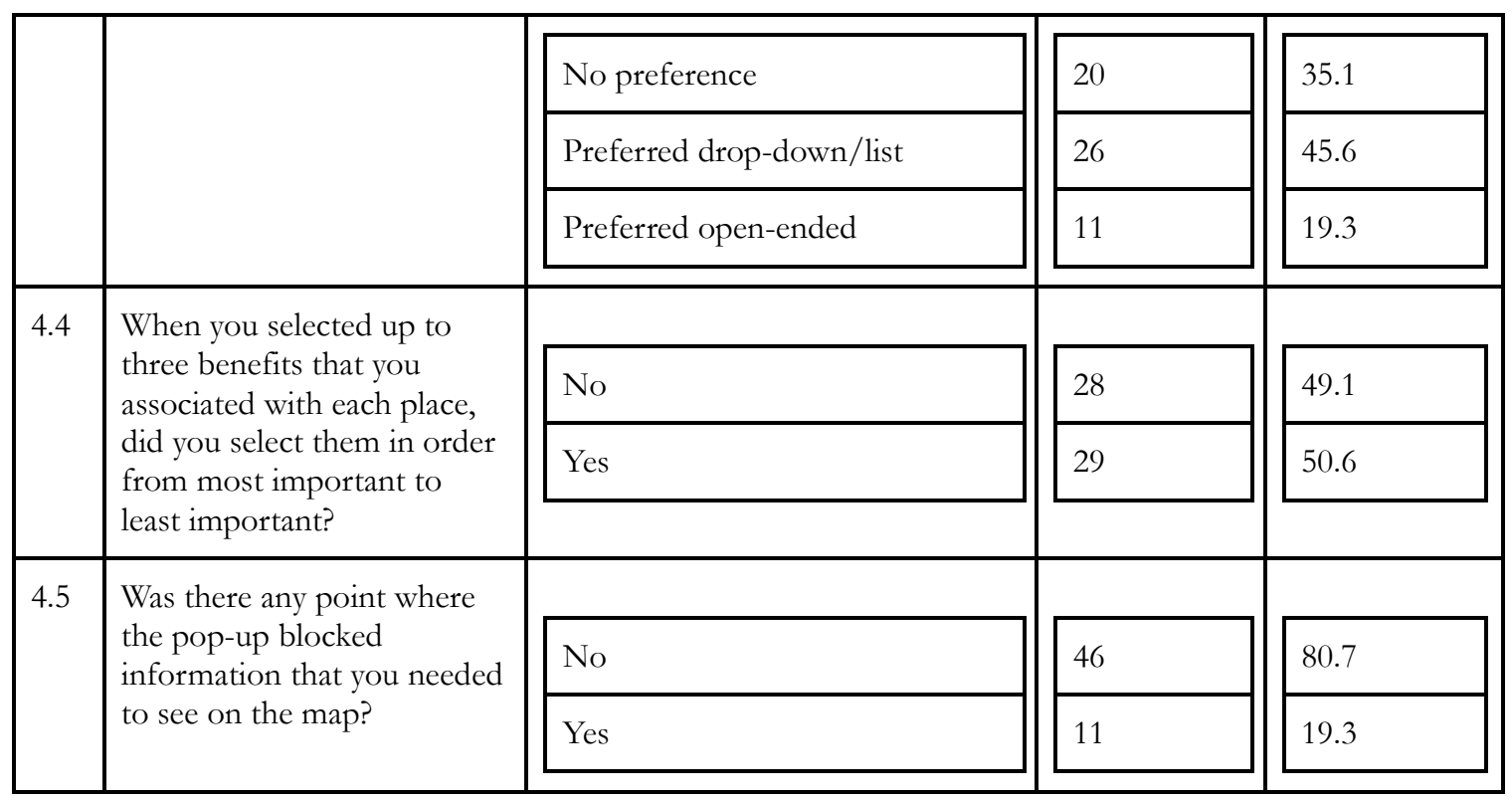

Fourteen $(n=14)$ participants responded to Q4.6. Seven of those responses

mentioned a desire to edit answers after the popup had been closed. Three others indicated a wanting to write-in an answer when selecting "other" from a drop-down box. Another two wished for more space to write open-ended answers. The remaining two expressed positive feedback.

\subsubsection{General Feedback}

Section 5 directed the users to "think about the mapping activity in general" and asked four questions, three of which were not SEQs but Likert scale/ordinal variables that also shed light on user satisfaction. Answers to these questions indicated whether the user thought the use session took more or less time than expected to complete (Q1), if they thought the information they provided was important to land management (Q2), and how motivated they were while using CFGCOS (Q3). The final open-ended question asked the 
user to discuss their overall experience and implicit satisfaction with using CFGCOS (Q4).

Table 3.7 details the results for Q5.1 - Q5.3. Open-ended results for Q5.4 are detailed in the following paragraph.

Table 3.7 - Results from the General Feedback portion (Section 5) of the exit survey.

\begin{tabular}{|c|c|c|c|c|}
\hline $\begin{array}{l}\mathrm{Q} \\
\#\end{array}$ & Question & Options & $\mathrm{N}$ & $\begin{array}{l}\text { Frequency } \\
(\%)\end{array}$ \\
\hline \multirow[t]{5}{*}{5.1} & \multirow{5}{*}{$\begin{array}{l}\text { Did the mapping activity } \\
\text { take more or less time } \\
\text { than you expected? }\end{array}$} & & & \\
\hline & & $\begin{array}{l}\text { I didn't have an expectation/ } \\
\text { didn't know what to expect }\end{array}$ & 10 & 17.5 \\
\hline & & Just what I expected & 26 & 45.6 \\
\hline & & Longer than I expected & 15 & 26.3 \\
\hline & & Shorter than I expected & 6 & 10.5 \\
\hline \multirow[t]{6}{*}{5.2} & \multirow{6}{*}{$\begin{array}{l}\text { How important or } \\
\text { unimportant do you feel } \\
\text { the information you } \\
\text { provided during the } \\
\text { mapping activity is for } \\
\text { land management and } \\
\text { planning? }\end{array}$} & & & \\
\hline & & Very important & 8 & 14.0 \\
\hline & & Important & 33 & 57.9 \\
\hline & & Neither important nor unimportant & 14 & 24.6 \\
\hline & & Unimportant & 2 & 3.5 \\
\hline & & Very unimportant & 0 & 0 \\
\hline \multirow[t]{6}{*}{5.3} & \multirow{6}{*}{$\begin{array}{l}\text { How motivated or } \\
\text { unmotivated were you to } \\
\text { complete the mapping } \\
\text { activity? }\end{array}$} & & & \\
\hline & & Very motivated & 5 & 8.8 \\
\hline & & Motivated & 38 & 66.7 \\
\hline & & Neither motivated nor unmotivated & 10 & 17.5 \\
\hline & & Unmotivated & 4 & 7.0 \\
\hline & & Very unmotivated & 0 & 0 \\
\hline 5.4 & $\begin{array}{l}\text { Overall, how would you } \\
\text { rate your experience } \\
\text { using this application? }\end{array}$ & open-ended & $\mathrm{NA}$ & NA \\
\hline
\end{tabular}


The open-ended responses to Q5.6 were wide-ranging. A total of twenty-one $(n=21)$ participants contributed their feedback. On the end of greatest positivity, responses included, "very easy and hopefully useful!" and, "I put a lot of thought into this and thoroughly enjoyed it." More neutral responses constituted responses such as, "pretty good" and, "not bad," while negative responses consisted of, "unsatisfactory" and, "It was difficult and I am a millennial who knows how to use technology." The remaining responses existed somewhere in between the range of experience.

\subsubsection{Backeground}

Section 6 asked the user "general questions about your background" and were mostly focused on gathering ordinal rankings of the users' mapping and computer literacy in order to provide context for how users produce data. Q1, Q2 and Q3 asked how often participants use maps on a computer, how comfortable they were using maps, and how often they used a computer, respectively.

Table 3.8 - Results from the Background portion (Section 6) of the exit survey.

\begin{tabular}{|c|c|c|c|c|}
\hline Q\# & Question & Options & $\mathrm{N}$ & $\begin{array}{l}\text { Frequency } \\
(\%)\end{array}$ \\
\hline \multirow[t]{6}{*}{6.1} & \multirow{6}{*}{$\begin{array}{l}\text { How often } \\
\text { do you use } \\
\text { maps on a } \\
\text { computer or } \\
\text { other } \\
\text { device? }\end{array}$} & & & \\
\hline & & Every day & 15 & 30.0 \\
\hline & & 2-3 week & 15 & 30.0 \\
\hline & & Once a week & 17 & 34.0 \\
\hline & & A few times a year & 3 & 6.0 \\
\hline & & Never & 0 & 0 \\
\hline
\end{tabular}




\begin{tabular}{|c|c|c|c|c|}
\hline \multirow[t]{5}{*}{6.2} & \multirow{5}{*}{$\begin{array}{l}\text { In general, } \\
\text { how } \\
\text { comfortable } \\
\text { do you feel } \\
\text { using a map? }\end{array}$} & Very comfortable & 36 & 63.2 \\
\hline & & Comfortable & 20 & 35.1 \\
\hline & & Neither comfortable nor uncomfortable & 1 & 1.8 \\
\hline & & Uncomfortable & 0 & 0 \\
\hline & & Very uncomfortable & 0 & 0 \\
\hline \multirow[t]{6}{*}{6.3} & \multirow{6}{*}{$\begin{array}{l}\text { How often } \\
\text { do you use a } \\
\text { computer? }\end{array}$} & & & \\
\hline & & Every day & 53 & 94.6 \\
\hline & & 2-3 week & 2 & 35.7 \\
\hline & & Once a week & 1 & 1.8 \\
\hline & & A few times a year & 0 & 0 \\
\hline & & Never & 0 & 0 \\
\hline
\end{tabular}

\section{$\underline{\text { 3.6 Data Capture Conclusion }}$}

This chapter highlighted the methods used to capture data regarding CFGCOS user interactions, usability metrics and subjective feedback as well as basic descriptive results. The data capture process also fulfilled the first major research goal outlined in Section 1.4. Automated data capture (interaction logging) produced a multitude of event timestamps helpful for defining learnability, efficiency, and error, as well as general quantitative variables related to data production. Non-automated data capture (exit survey) provided variables useful for defining satisfaction and general feedback regarding how CFGCOS users produced data. All data captured from interaction logging and Likert scale and open-ended text variables captured in the exit survey are analyzed in detail in the following chapter. The 
remaining dichotomous and nominal variables captured in the exit survey are used to contextualize the critical discussion in Chapter 5. The next chapter details the analysis stage of the UE and explains the methods and results used to identify problems in the CFGCOS interface and cartographic operators. 


\section{Chapter 4: Analysis Methods \& Results}

\subsection{Overview of Analysis Methods}

The second stage of the UE of CFGCOS incorporated analysis activities described by Ivory and Hearst (See Section 2.6) intended to identify problems in the CFGCOS interface that affected the production of spatial data. This process was executed through three stages of interrelated analyses with results from one informing the next. The first analysis quantified user performance (learnability, efficiency, and error) through metrics derived from timestamps and event counts collected during interactive logging (See Section 3.2). The second analysis quantified user preference (satisfaction) through metrics derived mostly from SEQs and open-ended questions captured during the exit survey (See Section 3.4). The final analysis utilized results from the previous two analyses to hone in on particular characteristics of data production and of the resulting data produced by CFGCOS users that may have been impacted by problems with the CFGCOS interface and its operators. This process of using one analysis method to inform the next helped to give a clearer picture of the entire data production system. Cumulative results of all three analyses informed the critiques of CFGCOS central to the discussion on data quality detailed in Chapter 5. The following sections explain the methods employed during each stage to analyze CFGCOS operators, task completion times, and sequential interaction patterns as well as the results of those analyses. 


\subsection{Performance Evaluation}

The performance evaluation sought to analyze and answer questions related to the users' learnability (how quickly a new user can learn to finish intended tasks), efficiency (how quickly a user performed tasks after the interface was learned), and error (how frequently the user made an error, severity of the error) when interacting with cartographic and noncartographic operators, which, along with the map, comprise the CFGCOS interface. The performance evaluation was critical to understanding how successful users' interactions were with CFGCOS. The following subsections detail the specific methods used in the performance evaluation.

\subsubsection{Learnability Evaluation Method}

The learnability evaluation incorporated a descriptive statistical and visual analysis that explored task completion times for first time executions of a task. When a user began a CFGCOS use session, they were instructed to follow five steps, each directing them to interact with a particular operator to complete a specific task (See Section 3.2). Every time a user engaged with a particular operator, an event timestamp was logged. Using these timestamps, task completion times were calculated, one for every iteration of the task. This analysis examined the first iteration of each task to provide insight for how long it took a user to learn how to use an operator to complete a task. Initial task completion times for clicking the AIN button, panning, zooming, and adding a point were calculated by 
subtracting start session (on-load) timestamp from the event timestamp logged when a user interacted with the respective operator. Popup task completion times were calculated by subtracting the first open popup event from the first close popup event. Popup task completion times were separated from the other tasks because the popup component of CFGCOS was associated with textual annotation. The other tasks were associated with point annotation (click AIN is associated with both), two related but different aspects of the CFGCOS data production system.

\subsubsection{Learnability Evaluation Results}

Table 4.1 provides insight on the users' learnability through descriptive statistics that highlight the minimum, maximum, mean, and standard deviations of initial task completion times occurring during the fifty-five $(n=55)$ use sessions. These numerical benchmarks provide a cumulative overview of how CFGCOS users first engaged with the interface. The count column represents the number of use sessions that had a recordable task completion. Count values below the total represent use sessions where particular tasks did not occur a first time (or at all) during a use session. Frequency values represent the percentage of use sessions where a particular task occurred and was recorded. Inspection of the table reveals that start panning had the minimum task completion time (1.60s) and standard deviation (90.49s), while annotate first point had the maximum task completion time (992.35s) and standard deviation (194.89s). 
Table 4.1 - Descriptive statistic results of the learnability evaluation incorporating task completion times for first time executions of a task during a use session. The associated operator, task, step and event are included for reference. Min, max, mean, and standard deviation (sd) values are provided in seconds. The last record was the only task completion that was not calculated using the on-load event.

\begin{tabular}{|c|c|c|c|c|c|c|c|c|c|}
\hline Operator & Task & Step & Events & $\begin{array}{l}\text { Min } \\
(\mathrm{s})\end{array}$ & $\operatorname{Max}(\mathrm{s})$ & $\begin{array}{l}\text { Mean } \\
(\mathrm{s})\end{array}$ & $\begin{array}{r}\mathrm{SD} \\
(\mathrm{s})\end{array}$ & Count & $\begin{array}{l}\text { Frequency } \\
(\%)\end{array}$ \\
\hline button & $\begin{array}{l}\text { first AIN } \\
\text { button } \\
\text { click }\end{array}$ & 1 & $\begin{array}{l}\text { on-load \& } \\
\text { on-click }\end{array}$ & 2.65 & 386.31 & 53.81 & 90.54 & 55 & 100.00 \\
\hline pan & $\begin{array}{l}\text { start } \\
\text { panning }\end{array}$ & 2 & $\begin{array}{l}\text { on-load \& } \\
\text { pan }\end{array}$ & 1.60 & 564.45 & 62.61 & 90.49 & 51 & 92.73 \\
\hline zoom & $\begin{array}{l}\text { start } \\
\text { zooming }\end{array}$ & 2 & $\begin{array}{l}\text { on-load \& } \\
\text { extent- } \\
\text { change }\end{array}$ & 3.66 & 794.63 & 147.74 & $\begin{array}{l}180.5 \\
3\end{array}$ & 44 & 80.00 \\
\hline annotate & $\begin{array}{l}\text { click on } \\
\text { first } \\
\text { colored } \\
\text { dot }\end{array}$ & $3 a$ & $\begin{array}{l}\text { on-load \& } \\
\text { on-click }\end{array}$ & 8.14 & 426.87 & 195.04 & $\begin{array}{l}125.8 \\
0\end{array}$ & 55 & 100.00 \\
\hline annotate & $\begin{array}{l}\text { annotate } \\
\text { first point }\end{array}$ & $3 b$ & $\begin{array}{l}\text { on-load \& } \\
\text { graphic-add }\end{array}$ & 43.92 & 992.35 & 259.17 & $\begin{array}{l}194.8 \\
9\end{array}$ & 55 & 100.00 \\
\hline annotate & $\begin{array}{l}\text { annotate } \\
\text { first } \\
\text { popup }\end{array}$ & $3 c$ & $\begin{array}{l}\text { graphic-add } \\
\text { \& on-click }\end{array}$ & 30.92 & 373.94 & 116.31 & 63.77 & 55 & 100.00 \\
\hline
\end{tabular}

Figures 4.1, 4.2 and 4.3 provide a visual representation of first time task completions using boxplots grouped according to each task. Boxplots (also referred to as box and whisker plots) are useful in showing the range of completion times for each task. The whiskers at each end of the box mark the highest and lowest (non-outlier) observations while the box itself shows the interquartile range of observations. The central line in the 
box represents the median observation. The dots outside the box and whiskers represent outlier observations.

Figure 4.1 shows task completion times calculated using the start session event (onload) detailed in the first five records of Table 4.1. Outliers in Figure 4.1 exists in all of the tasks except for the click on a colored dot task. For reference, the plot also includes a vertical line indicator of the mean time it took users to annotate their first point (259.17s). Figure 4.1 shows that the general trend of completion times for each task were ordered in the same step sequence that the designers intended when developing the application: Step 1 (click AIN $) \rightarrow$ Step $2($ pan $/$ zoom $) \rightarrow$ Step 3 a (click on colored dot $) \rightarrow$ Step $3 b$ (annotate first point $) \rightarrow$ Step 3c (annotate popup). More specifically, in regards to step 2, CFGCOS users generally completed pan tasks before zoom tasks. 


\section{Time for First Task Completion}

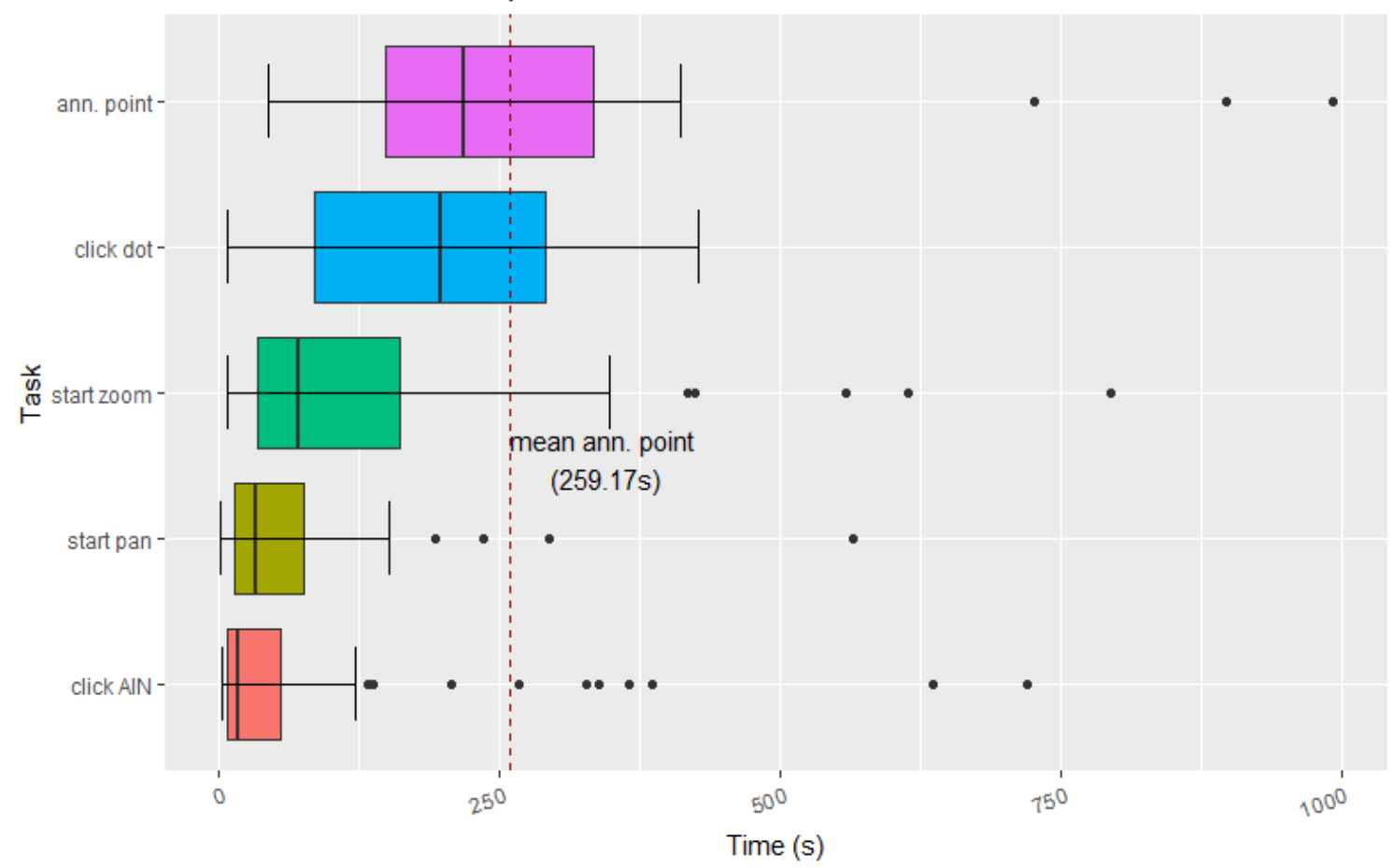

Figure 4.1 - Boxplots for first time task completions of CFGCOS users grouped by task. The dotted line shows the mean completion time for annotating the first point. Only tasks that were calculated using the start session timestamp event are shown here.

Figure 4.2 provides a visual representation of how CFGCOS users first interacted with the popup while completing an annotate popup task detailed in the last record in Table 4.1. The data sample size used to visualize popup learnability was fifty-five $(n=55)$. Task times were calculated using the popup open event timestamp triggered by the graphic-add event occurring when a user annotated a new point. The figure shows how CFGCOS users moved through annotating each form box in the first location popup from the moment it opened. The first twelve boxplots in the figure show task completion times for each of the twelve corresponding form boxes, while the thirteenth boxplot shows the task completion time range for filling out the entire first popup. Notice the range in each boxplot shows a 
general increasing trend until the threats form box. Potential reasons for this are discussed in Chapter 5. In order to better visualize the data, a y-axis limit of 250 seconds was used.

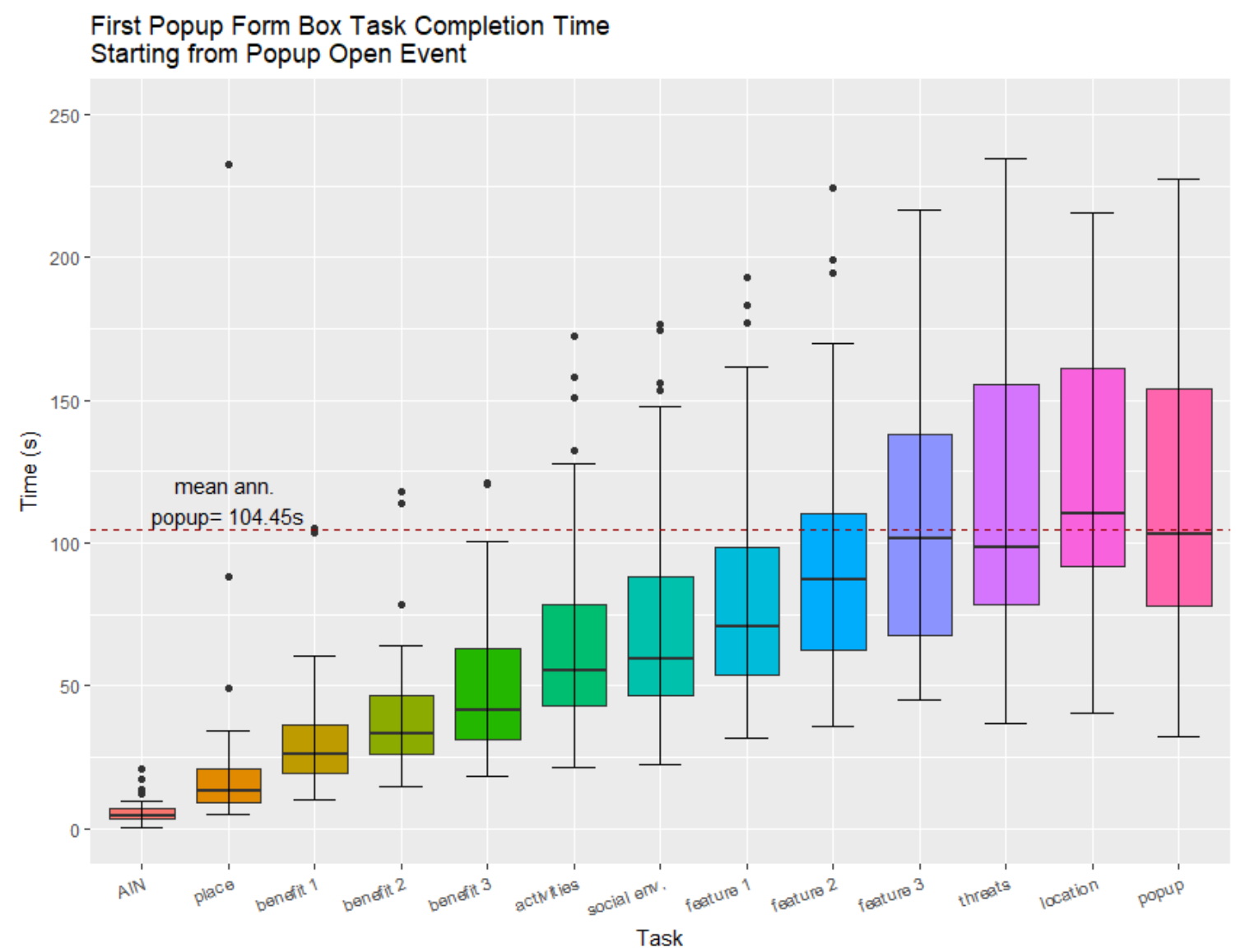

Figure 4.2 - Boxplots of the range of form box annotation task completion times starting with the graphicadd (open popup) event timestamp. The first twelve boxplots relate to specific form box annotation tasks while the thirteenth boxplot shows the annotation task completion times for the entire popup annotation task.

Figure 4.3 incorporates task completion times calculated using the on-focus and onblur event timestamps for each form box resulting in values that represent the amount of time it took CFGCOS users to annotate that individual form box. The visualization shows the range of time CFGCOS users spent in each form box. When analyzing Figure 4.3, it is important to consider the different types of each of the form boxes (See Appendix A). The 
AIN, place, activities, and threats form boxes are open-ended text boxes. Each of the benefit, feature, social environment form boxes are drop-downs with limited options from which the user selects. The location form box is also a drop-down, however the value in the text area is already populated with the location number of the point that triggered the open popup box event (graphic-add).

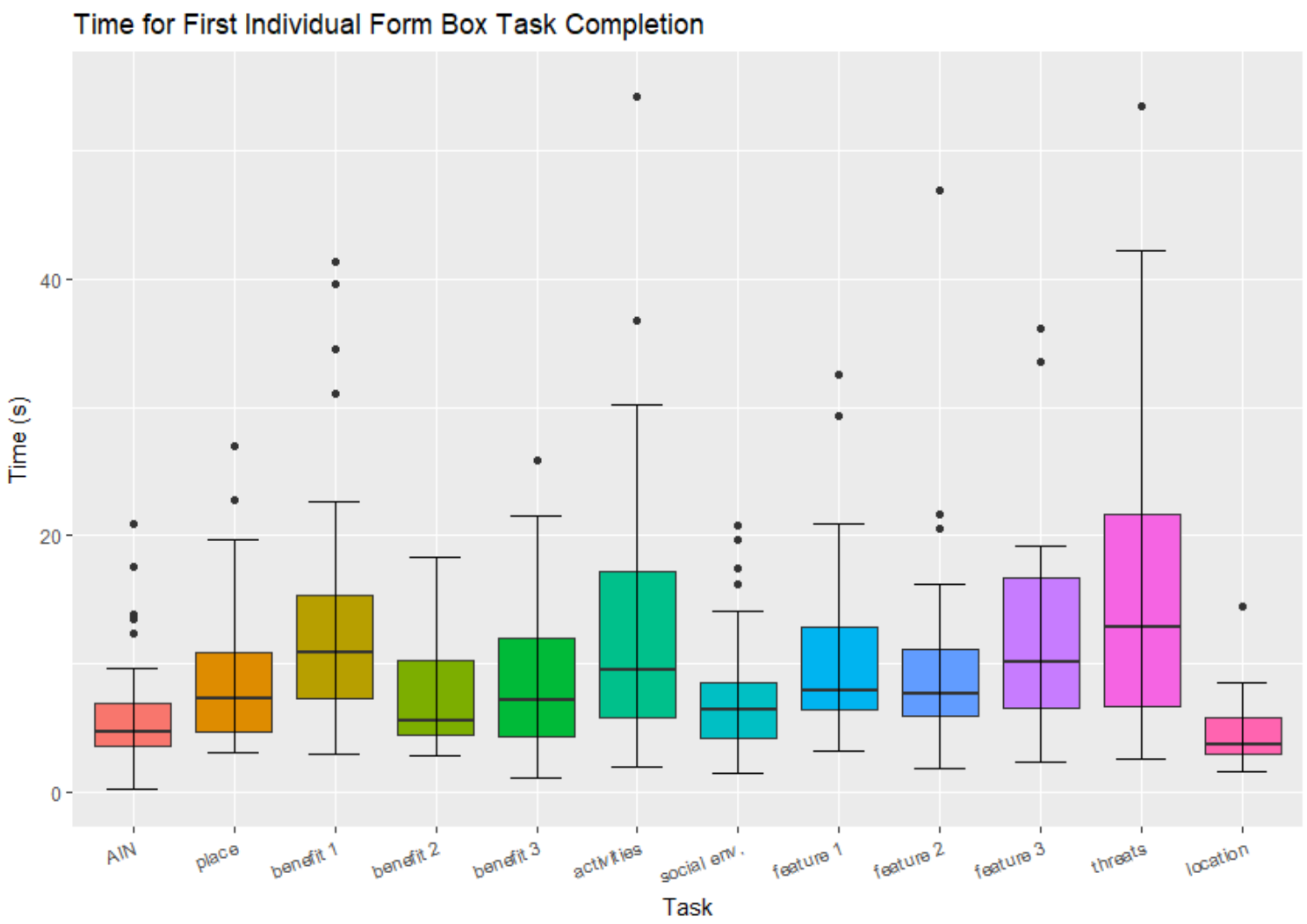

Figure 4.3 - This figure visualizes the range of individual form box annotation task completion times. The AIN, place, activities and threats form boxes are open-ended text boxes, and all the benefit, feature, and social environment form boxes are drop-down boxes. The location form box is a prepopulated drop-down form box.

Table 4.2 provides more detailed descriptive statistics regarding observations visualized in Figures 4.2 and 4.3. The columns display both individual and from start 
annotation task completion time ranges. The minimum, maximum, and mean observation values for each form box annotation task, as well as the total count of interactions that occurred for a form box in every popup in the sample, are detailed. Inspection of the table shows the increasing trend of from start annotation tasks. It also indicates that the minimum individual annotation task completion occurred during interaction with a benefit 3 form box (1.10s). The maximum individual annotation task completion time occurred for a place form box (211.89s). The $N$ column shows the count of form box interaction. A total on fiftyfive $(n=55)$ popups from fifty-five use sessions were included in this analysis. By default, each form box has a total of fifty-five possible interactions that can occur (assuming that task completion times/interactions are aggregated and only counted one per popup as was done in this analysis). $N$ values less than fifty-five the represent form boxes for which no interaction occurred. One form box had very little interaction (location), while four form boxes (AIN, place, benefit 1, social env.) received maximum interaction.

Table 4.2 - Descriptive statistics showing the range of values visualized in Figures 4.2 and 4.3. From start columns show an upward trend and individual columns highlight task completion times for individual form box interaction. The $N$ column details the count of times for which interaction occurred with the form box during all recorded popup interaction. Cells in light grey indicate values discussed in this section.

\begin{tabular}{|c|c|c|c|c|c|c|c|}
\hline $\begin{array}{l}\text { Annotation } \\
\text { Task }\end{array}$ & $\begin{array}{l}\text { Min } \\
\text { Individual } \\
\text { (s) }\end{array}$ & $\begin{array}{l}\text { Min } \\
\text { from } \\
\text { Start (s) }\end{array}$ & $\begin{array}{l}\text { Max } \\
\text { Individual } \\
\text { (s) }\end{array}$ & $\begin{array}{l}\text { Max from } \\
\text { Start } \\
\text { (s) }\end{array}$ & $\begin{array}{l}\text { Mean for } \\
\text { Individual } \\
\text { (s) }\end{array}$ & $\begin{array}{l}\text { Mean from } \\
\text { Start } \\
\text { (s) }\end{array}$ & $\mathrm{N}$ \\
\hline AIN & 1.27 & 2.15 & 20.86 & 23.63 & 5.71 & 6.93 & 55 \\
\hline place & 3.08 & 5.01 & 211.89 & 232.75 & 12.74 & 20.79 & 55 \\
\hline benefit 1 & 2.92 & 10.27 & 41.36 & 105.19 & 13.30 & 30.96 & 55 \\
\hline benefit 2 & 2.84 & 14.56 & 18.38 & 117.79 & 7.30 & 38.74 & 51 \\
\hline
\end{tabular}




\begin{tabular}{|l|l|l|l|l|l|l|l|} 
benefit 3 & 1.10 & 18.16 & 25.84 & 121.30 & 8.59 & 49.05 & 44 \\
\cline { 2 - 8 } activities & 1.98 & 21.25 & 150.93 & 172.17 & 17.79 & 65.76 & 54 \\
\cline { 2 - 8 } social env. & 1.43 & 22.48 & 59.27 & 176.53 & 8.43 & 72.41 & 55 \\
\cline { 2 - 8 } feature 1 & 3.21 & 31.47 & 32.57 & 192.72 & 10.27 & 82.82 & 52 \\
\cline { 2 - 8 } feature 2 & 1.87 & 35.65 & 46.90 & 224.04 & 9.73 & 94.85 & 39 \\
\cline { 2 - 8 } feature 3 & 2.29 & 45.22 & 33.57 & 216.74 & 11.21 & 109.03 & 30 \\
\hline \multirow{2}{*}{$\begin{array}{l}\text { threats } \\
\text { location }\end{array}$} & 2.57 & 37.01 & 150.55 & 374.59 & 27.26 & 126.12 & 44 \\
\hline
\end{tabular}

\subsubsection{Efficiency Evaluation Method}

While analysis of learnability was concerned with users' first time task completions using the CFGCOS interface, efficiency evaluation was focused on every subsequent task completion in comparison to the first. In order to make meaningful comparisons, use sessions were segmented according to each location being added to the map (up to five). Specifically, tasks were classified according to the location number for which the user was producing data. This categorization process allowed for comparisons of task completion times and between iterations of each location-related task. If a user annotated multiple points or popups per location, task completion times were aggregated. This resulted in a total of two-hundred-twenty-two $(n=222)$ popup and point annotation tasks used in the analysis. Incorporating a combination of descriptive and elementary statistics as well as 
boxplot and barplot visualizations, the efficiency evaluation provided answers to how quickly a user performed annotation tasks after the interface was learned.

To determine efficiency, the analysis explored three categories of annotation task completion times over the course of a use session - point annotation, popup annotation (cumulatively), and form box annotation (individually). First, point annotation task completion times were calculated for each iteration of an annotated point by using the start session (on-load) and annotate point (graphic-add) timestamps for location \#1, and the popup close (on-click) and annotate point (graphic-add) timestamp for the subsequent points (locations \#2 - \#5). Second, the analysis investigated task completion times for popup annotations. Like in the assessment of point annotation efficiency, popup annotations were categorized according to their associated location. Each popup annotation task completion time (the entire time spent in a popup) was calculated using the popup open (graphic-add) and popup close (on-click) timestamps. Finally, popup form box annotation task completion times were individually explored using the enter (on-focus) and exit (onblur) timestamps. The following section details the results of the efficiency evaluation.

\subsubsection{Efficiency Evaluation Results}

Using boxplots, Figure 4.4 visually details the task completion times calculated for each point annotation per location. Inspection of the figure shows a slight downward trend in the task completion times over the course of each point. To further investigate if there was a linear relationship between task completion times and each subsequent location, a Spearman's correlation coefficient was calculated. Spearman's correlation coefficients are helpful 
for assessing correlations between continuous (task completion time) and ordinal (location number) variables. The resulting coefficient $($ rho $=-0.26)$ indicates a very small negative correlation between point annotation task completion times and location number.

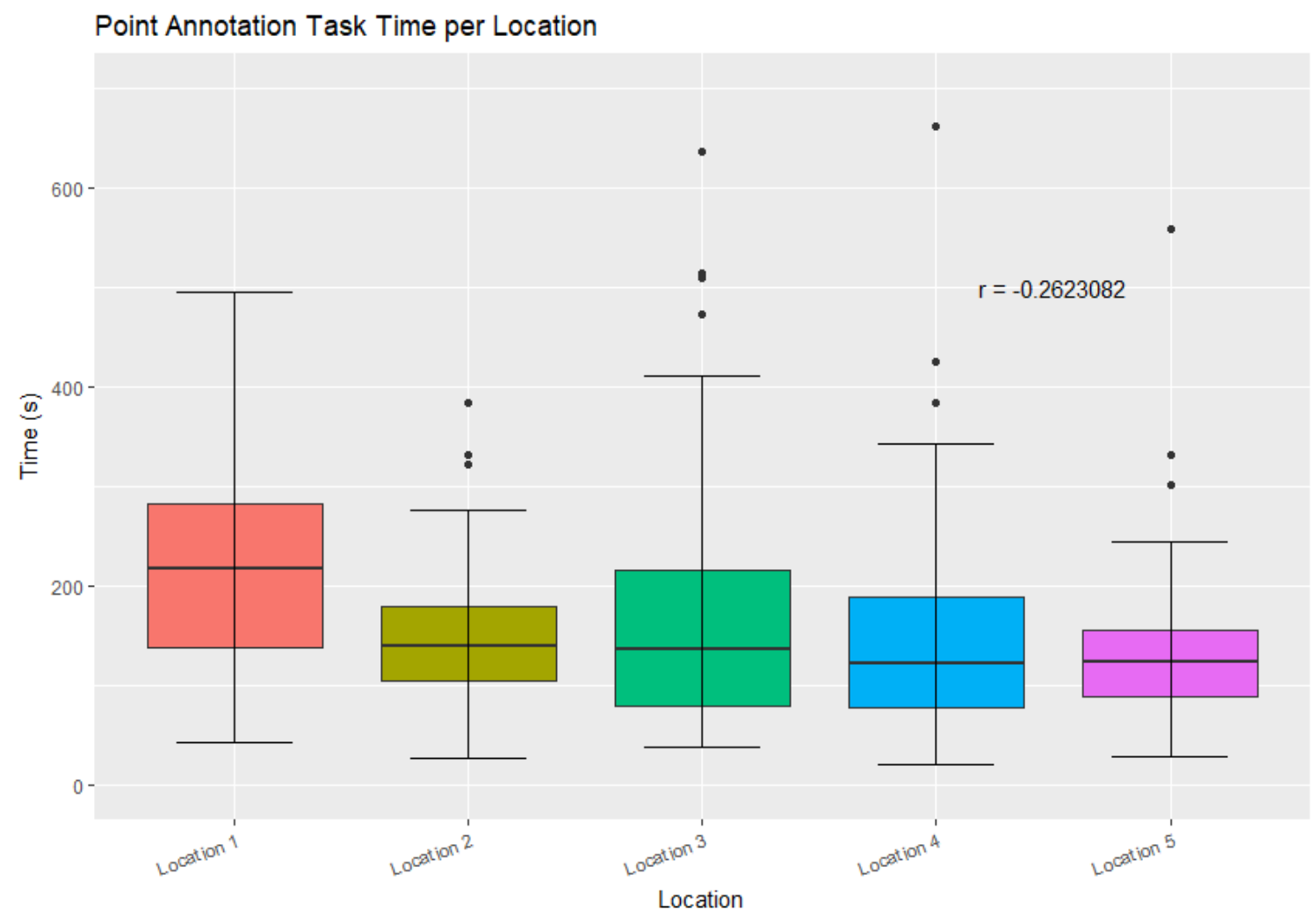

Figure 4.4 - Task completion times for point annotations related to a specific location. The small negative Spearman's correlation coefficient indicates a slight decline in task completion times over the course of each additional point.

Figure 4.5 visualizes the task completion times of each popup, grouped according to location. Inspection of the plot shows a small downward trend in task completion times as the location increases. Again, further investigation prompted calculating a Spearman's correlation coefficient to determine any linear relationship between popup annotation task 
completion times and location number. The resulting coefficient $($ rho $=-0.29)$ indicates a slight decrease in task completion time for each subsequent location related popup.

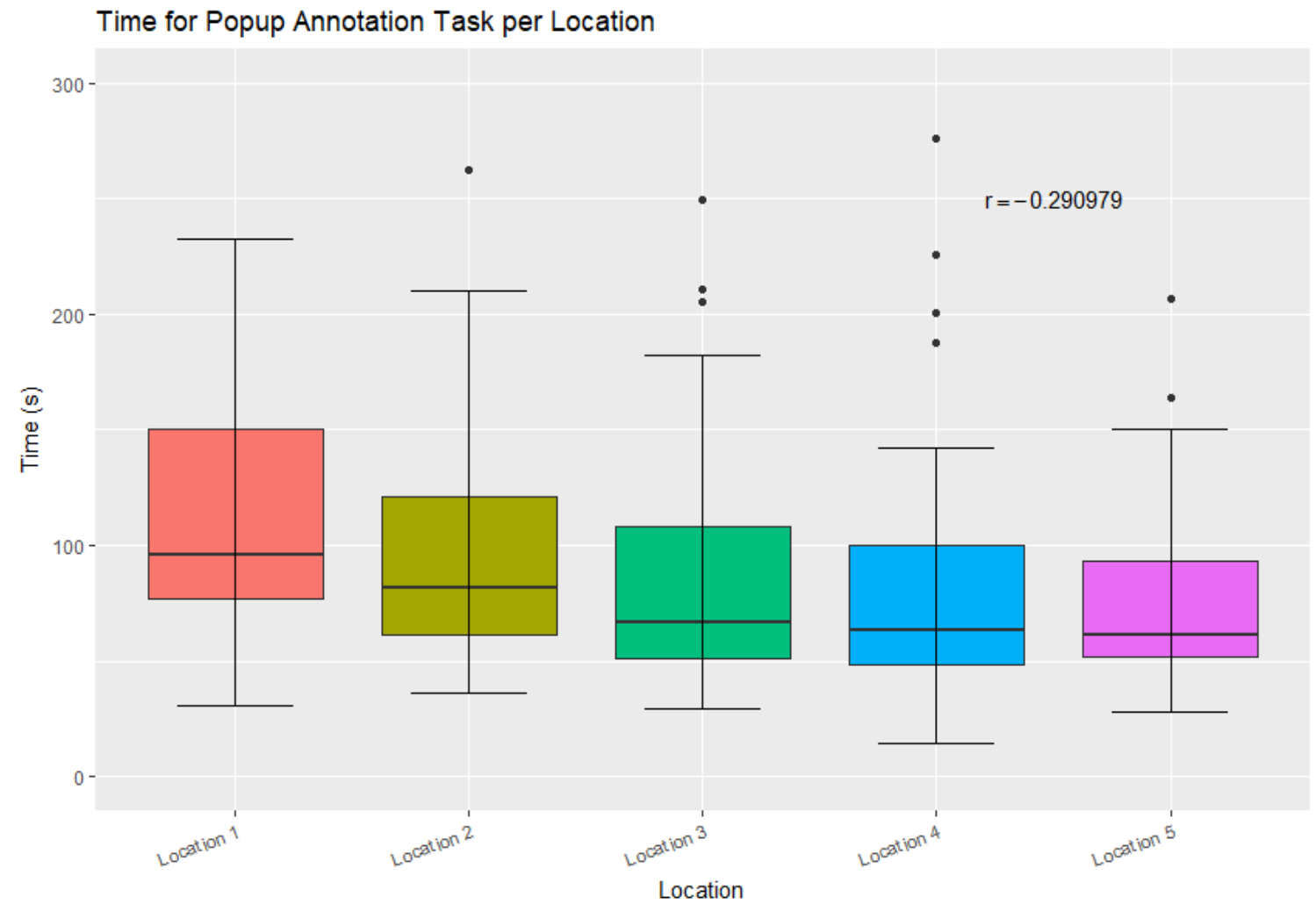

Figure 4.5 - Popup annotation task completion times for each associated location. The small negative Spearman's correlation coefficient indicates a slight decline in task completion times over the course of each additional popup.

Table 4.3 further details the results in Figures 4.3 and 4.4 through descriptive statistics. The table shows the mean point and popup annotation task completions times as well as the difference in the amount of time between each subsequent annotation. In all cases except one (location \#2 - \#3 point annotation), annotation tasks took less (mean) time than during the previous annotation. This result supports the negative correlation results 
previously mentioned. Also included in this table is an $N$ column which indicates the number of task completion times that were included for each location in the analysis decreased as the location number increased. This suggests that fewer points (and popups) were annotated for each consecutive location.

Table 4.3 - This table shows mean annotation task completion times and the difference between each of those times for points and popups. The $N$ column also shows the number of annotation tasks included in the analysis.

\begin{tabular}{|l|l|l|l|l|l|}
\hline $\begin{array}{l}\text { Location } \\
\#\end{array}$ & $\begin{array}{l}\text { Mean Point } \\
\text { Annotation } \\
\text { Task Time }(\mathrm{s})\end{array}$ & $\begin{array}{l}\text { Difference in } \\
\text { Point Annotation } \\
\text { Task Time } \\
(\mathrm{s})\end{array}$ & $\begin{array}{l}\text { Mean Popup } \\
\text { Annotation Task } \\
\text { Time (s) }\end{array}$ & $\begin{array}{l}\text { Difference in Popup } \\
\text { Annotation Task } \\
\text { Time } \\
(\mathrm{s})\end{array}$ & N \\
\hline 1 & 255.26 & NA & 125.61 & NA & 54 \\
\hline 2 & 194.54 & -60.72 & 95.92 & -29.69 & 52 \\
\hline 3 & 204.16 & +9.62 & 90.26 & -5.66 & 47 \\
\hline 4 & 172.97 & -31.19 & 81.83 & -8.43 & 40 \\
\hline 5 & 157.24 & -15.73 & 77.84 & -3.99 & 29 \\
\hline
\end{tabular}

Figure 4.6 visualizes the mean form box annotation task completion times segmented into two categories, mean times for location \#1 and mean times for locations \#2 through \#5 combined. The resulting barplot shows that the average time taken by a user to annotate a form box for location \#1 was greater in every instance than for locations \#2 through \#5 combined. The greatest mean differences occurred in the benefit 1 (drop down), activities (open-ended), and threats (open-ended) form boxes. 


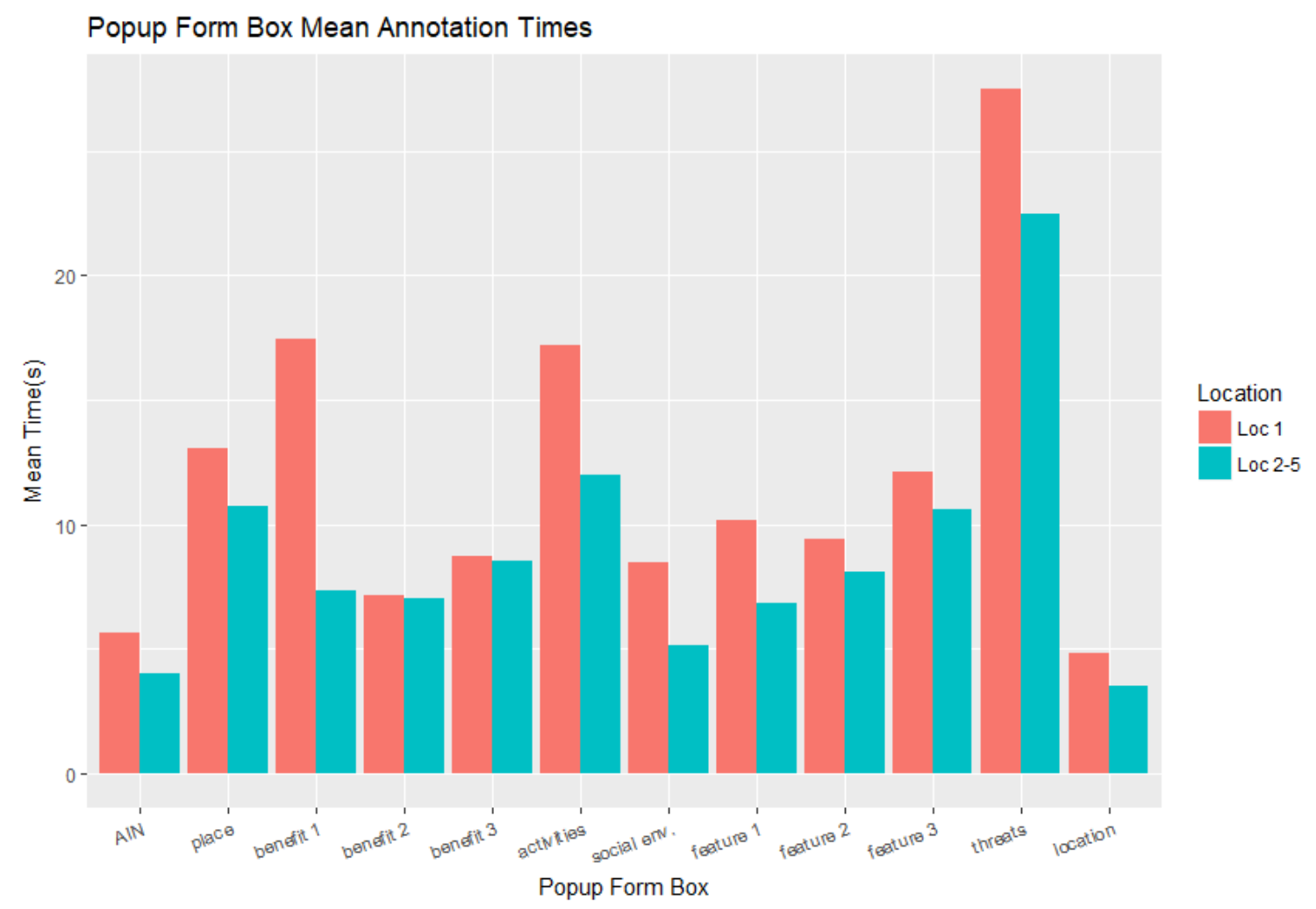

Figure 4.6 - Mean popup form box annotation task times for grouped into location 1 and locations 2-5.

\subsubsection{Error Evaluation Method}

The final component of the performance evaluation focused on error and severity of error. Error was determined by quality of solution - how far a user deviated from the intended instructional step sequence the designers of CFGCOS intended the user to take (See Section 3.1). Using timestamps collected from each event captured during interaction logging, a new categorical sequence (flow) dataset was created for every use session included 
in this part of the analysis $(n=55)$. Each categorical sequence data was then segmented into five location groups, one for each iteration of the instructions followed to annotate a point and popup. Each sequence was then compared to the intended sequence using the Trajectory Miner R (TraMineR) package developed by Gabadinho et al. TraMineR computes pairwise dissimilarity from a reference sequence, in this case being the intended instruction sequence. Specifically, sequence distance is calculated using an optimal matching algorithm (Needleman and Wunsch) that traverses over a categorical state sequence and assigns a cost of one for every insertion or deletion required to match the reference sequence. For example, if a state sequence $\mathrm{X} \rightarrow \mathrm{A} \rightarrow \mathrm{C}$ was compared to a reference sequence $\mathrm{A} \rightarrow \mathrm{B} \rightarrow \mathrm{C}$, a sequence distance of two would result. Deletion of $\mathrm{X}$ costs one and insertion of B costs one for a total cost of two. In other words, the state sequence of $\mathrm{X} \rightarrow \mathrm{A} \rightarrow \mathrm{C}$ has sequence distance of two from the reference sequence $\mathrm{A} \rightarrow \mathrm{B} \rightarrow \mathrm{C}$.

A total of two-hundred-twenty-two $(n=222)$ state sequences were included in the analysis. Each state sequence represented an actual iteration of events triggered to annotate a point and popup for each location by a CFGCOS user. The reference sequences used to determine sequence distance from state sequences within a location group were the same, except for location \#1, which included the start (on-load), and click AIN (step 1) events appended to the beginning of the sequence. Every state sequence also had the stop event (step 5) removed, as there was no defined time that user might finish annotating points. Step four was not included at all since it only instructed users to repeat previous steps. Pan and zoom events (step 2) and popup open and close events (step 3c) were aggregated into single events. After sequence distances were calculated, they were grouped by location into three 
categories - expected or exact match (zero distance), distance of one to three, and distance more than three. Grouping sequence distances provided general insight into how dissimilar (error prone) user engagement was with CFGCOS from what was intended by the designers. Higher sequence distances suggested greater error.

State sequences for the first location group were also visualized using Sankey flow diagrams built with the networkD3 R package (Gandrud), a wrapper for the D3 (DataDriven Documents) JavaScript library (Bostock et al.). A Sankey diagram shows the volume of energy or product flows between nodes of metabolism (Schmidt 84). In a diagram, nodes, shown as colored boxes, represent events logged a given sequence position, with each node scaled vertically according to the frequency of that event. Nodes are aligned along vertical axes, with each axis representing a position in the overall event sequence. The connections between nodes, or links, are scaled in thickness according to the frequency of the sequence of events that the link connects. The node bordering the left side of a link is referred to that link's source event, and the node on the right side is the target event (Sack 48-49).

Severity of error was determined by calculating the insertion and deletion costs of single and chained error event sequences. Single state sequence events that occurred out of order had a cost of two (one for deletion and one for insertion). Single events that did not occur had an insertion cost of one. Single events that occurred more frequently than the expected reference sequence had a deletion cost of one. Chained events had similar costs for insertion or deletion except that the costs were multiplied by the number of error events in the chain. Consequently, error event chains (vs single error events) had a greater impact 
on the total sequence distance. Chained error events were thus more severe than single error events.

The last part of the analysis concentrated on benchmarking expected event counts (from reference sequences) and comparing them to actual event counts (from state sequences) for all use sessions without regard to their sequential order. This process sought to clarify how far users collectively deviated from what was intended by the designers. This process resulted in a quantitative difference between expected and observed event counts and helped to establish which types of events occurred more or less frequently than expected during all use sessions.

\subsubsection{Error Evaluation Results}

The results of the optimal matching sequence distance calculations grouped by location for each use session are shown in Table 4.4. The results indicate that the vast majority of state sequences were within a sequence distance of zero to three. However, fewer sequences matched exactly to the reference sequence than those that did not.

Examination of the final row of the table shows that for all state sequences analyzed, thirtyseven percent $(37 \%)$ were exact matches, fifty-five percent $(55 \%)$ had a distance of one to three, and eight percent $(8 \%)$ had a distance of more than three.

Table 4.4 - Sequence distances from optimal matching grouped according to location and distance. Each distance category contains an $\mathrm{N}$ and frequency value representing the count and percentage of state sequences deviating from the reference sequence.

\begin{tabular}{|l|l|l|l|l|l|}
$\begin{array}{l}\text { Location } \\
\text { Group }\end{array}$ & Reference Sequence & $\begin{array}{l}\text { Exact Match (0) / } \\
\text { Frequency }(\%)\end{array}$ & $\begin{array}{l}1 \text { to } 3 \\
/ \text { Frequency }(\%)\end{array}$ & $\begin{array}{l}\text { More than } 3 \\
/ \text { Frequency }(\%)\end{array}$ & N \\
\hline
\end{tabular}




\begin{tabular}{|l|l|l|l|l|l|}
\hline 1 & $\begin{array}{l}\text { start } \rightarrow 1 \rightarrow 2 \rightarrow 3 \mathrm{a} \rightarrow \\
\mathrm{b} \rightarrow 3 \mathrm{c}\end{array}$ & $23 / 43$ & $26 / 48$ & $4 / 7$ & 54 \\
\hline 2 & $2 \rightarrow 3 \mathrm{a} \rightarrow 3 \mathrm{~b} \rightarrow 3 \mathrm{c}$ & $18 / 35$ & $29 / 56$ & $5 / 9$ & 52 \\
\hline 3 & $2 \rightarrow 3 \mathrm{a} \rightarrow 3 \mathrm{~b} \rightarrow 3 \mathrm{c}$ & $14 / 30$ & $30 / 64$ & $3 / 6$ & 47 \\
\hline 4 & $2 \rightarrow 3 \mathrm{a} \rightarrow 3 \mathrm{~b} \rightarrow 3 \mathrm{c}$ & $12 / 30$ & $22 / 55$ & $6 / 15$ & 40 \\
\hline 5 & $2 \rightarrow 3 \mathrm{a} \rightarrow 3 \mathrm{~b} \rightarrow 3 \mathrm{c}$ & $15 / 51$ & $14 / 49$ & $0 / 0$ & 29 \\
\hline Total & NA & $82 / 37$ & $121 / 55$ & $18 / 8$ & 222 \\
\hline
\end{tabular}

Figure 4.7 displays a Sankey diagram to visualize all of the state sequences by event name (as opposed to step number) included in location group \#1. Each vertical node represents one of the events within a state sequence. The events include start in purple, click AIN in dark green, pan/zoom in red, get point in light green, add point in light orange, and open/close рорир in pink. Unlike in the reference sequence, the stop event (step 5) was also included as a node. The connections between the nodes signify the sequence distance group for which the state sequence was categorized. Light blue represents exact match state sequences, dark blue represents sequences with a distance of one to three, and orange represents sequences with a distance more than three. The diagram shows that most sequences ended after six events which was the length of the reference sequence for location one group detailed in Table 4.4 . 


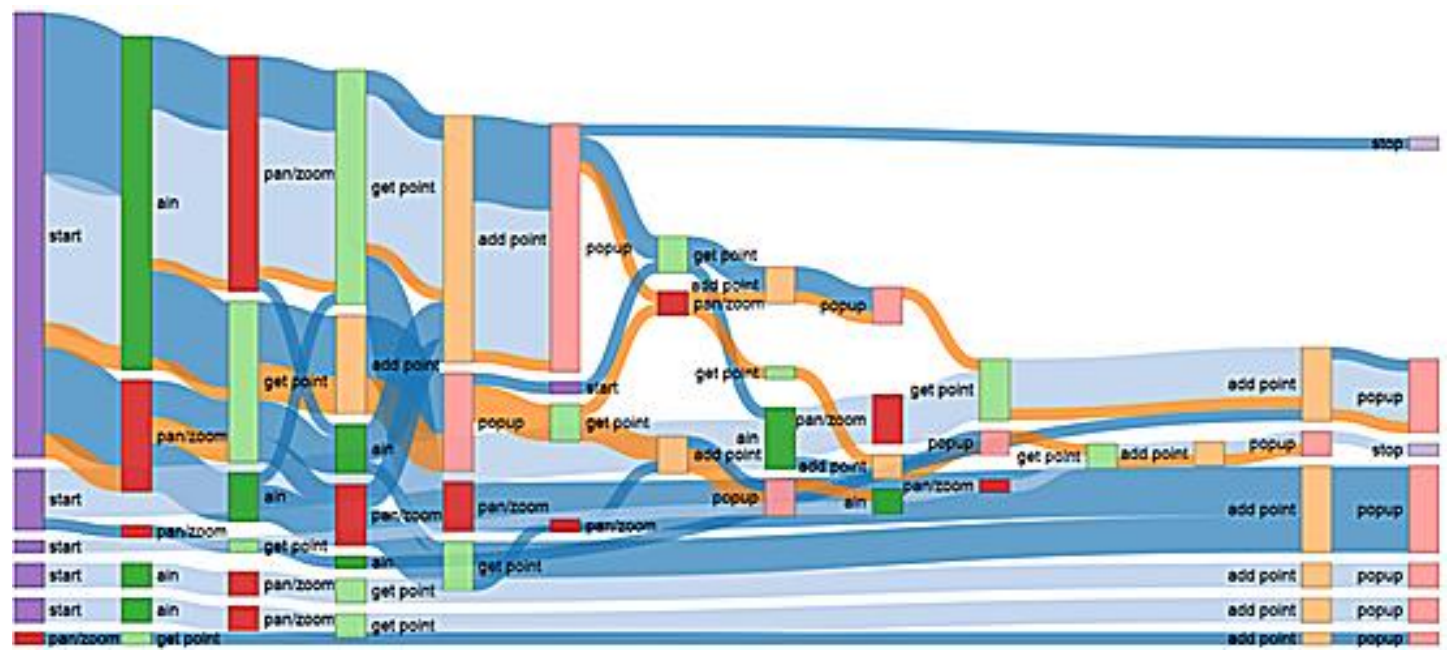

Figure 4.7 - Sankey diagram for state sequences in location group one. Vertical nodes represent events and connections represent the sequence distance groups.

The top three most common non-exact matching state sequences (sequence distance $>0$ ), and state sequences with the greatest sequence distance for location one and locations \#2 through \#5 respectively are detailed in Tables 4.5. Examination of specific state sequences with sequence distances greater than zero highlight common errors CFGCOS users committed. For location group \#1, the three most common deviations from what was expected included not panning/zooming at all (10\%), panning/zooming after getting a point ready to annotate $(8 \%)$ and clicking the AIN button after getting a point ready to annotate (8\%). The most severe error sequence for the location group \#1 involved annotating two additional points and additional out-of-order panning/zooming (sequence distance $=7$ ). For location groups \#2 through \#5, the three most common errors included not panning/zooming at all (40\%), additional panning/zooming after getting a point ready for 
annotation (5\%), and clicking the AIN button after getting a point ready for annotation $(4 \%)$. The most severe error sequence for location groups two through five involved an additional get point click, no panning/zooming and two additional points (sequence distance $=7$ ). Collectively, the information provided in both tables show similar types of errors were committed regardless of the location group.

Table 4.5 - Three most common state sequences with a sequence distance greater than zero grouped by location in the top six rows. State sequences with the highest sequence distance in the bottom two rows.

\begin{tabular}{|c|c|c|c|c|}
\hline $\begin{array}{l}\text { Location } \\
\text { Group }\end{array}$ & State Sequence & Error Description & $\begin{array}{l}\text { Sequence } \\
\text { Distance }\end{array}$ & $\begin{array}{l}\mathrm{N} / \\
\text { Frequency } \\
(\%)\end{array}$ \\
\hline 1 & start $\rightarrow 1 \rightarrow 3 \mathrm{a} \rightarrow 3 \mathrm{~b} \rightarrow 3 \mathrm{c}$ & no pan/zoom (step 2) & 1 & $5 / 10$ \\
\hline 1 & $\begin{array}{l}\text { start } \rightarrow 1 \rightarrow 2 \rightarrow 3 a \rightarrow 2 \rightarrow 3 b \rightarrow \\
3 c\end{array}$ & $\begin{array}{l}\text { additional pan/zoom (step 2) } \\
\text { after getting point (step 3a) }\end{array}$ & 1 & $4 / 8$ \\
\hline 1 & start $\rightarrow 2 \rightarrow 3 \mathrm{a} \rightarrow 1 \rightarrow 3 \mathrm{~b} \rightarrow 3 \mathrm{c}$ & $\begin{array}{l}\text { AIN click (step 1) after } \\
\text { getting point (step 3a) }\end{array}$ & 2 & $4 / 8$ \\
\hline $2-5$ & $3 \mathrm{a} \rightarrow 3 \mathrm{~b} \rightarrow 3 \mathrm{c}$ & no pan/zoom (step 2) & 1 & $70 / 40$ \\
\hline $2-5$ & $3 \mathrm{a} \rightarrow 2 \rightarrow 3 \mathrm{~b} \rightarrow 3 \mathrm{c}$ & $\begin{array}{l}\text { pan/zoom (step 2) after } \\
\text { getting point (step 3a) }\end{array}$ & 2 & $8 / 5$ \\
\hline $2-5$ & $3 a \rightarrow 3 b \rightarrow 3 c \rightarrow 3 a \rightarrow 3 b \rightarrow 3 c$ & $\begin{array}{l}\text { no pan/zoom (step 2) and } \\
\text { additional point (steps } 3 \mathrm{a}- \\
\text { 3c) }\end{array}$ & 4 & $7 / 4$ \\
\hline 1 & $\begin{array}{l}\text { start } \rightarrow 1 \rightarrow 2 \rightarrow 3 \mathrm{a} \rightarrow 3 \mathrm{~b} \rightarrow 3 \mathrm{c} \\
\rightarrow 2 \rightarrow 3 \mathrm{a} \rightarrow 3 \mathrm{~b} \rightarrow 3 \mathrm{c} \rightarrow 3 \mathrm{a} \rightarrow 3 \mathrm{~b} \\
\rightarrow 3 \mathrm{c}\end{array}$ & $\begin{array}{l}\text { two additional points added } \\
\text { (steps } 3 \mathrm{a}-3 \mathrm{c} \text { ) and additional } \\
\text { pan/zoom (step } 2)\end{array}$ & 7 & $1 / 2$ \\
\hline $2-5$ & $\begin{array}{l}3 \mathrm{a} \rightarrow 3 \mathrm{a} \rightarrow 3 \mathrm{~b} \rightarrow 3 \mathrm{c} \rightarrow 3 \mathrm{a} \rightarrow 3 \mathrm{~b} \\
\rightarrow 3 \mathrm{c} \rightarrow 3 \mathrm{a} \rightarrow 3 \mathrm{~b} \rightarrow 3 \mathrm{c}\end{array}$ & $\begin{array}{l}\text { additional get point click, no } \\
\text { pan/zoom (step 2) and } 2 \\
\text { additional points (steps } 3 \mathrm{a} \text { - } \\
\text { 3c) }\end{array}$ & 8 & $1 / 1$ \\
\hline
\end{tabular}


Table 4.6 shows all the single error event and chained error event sequences along with their description, combined insertion and deletion cost (severity), count of occurrences, total cost (calculated by multiplying the combined insertion/deletion cost by the count of occurrences), and the percent of total costs for all matched sequences that were identified in the analysis. The most costly (severe) error was a chained sequence caused by the three events required to annotate an additional point/popup (deletion cost $=3$ ). This error chain accounted for the second largest percent of the costs (30\%). The most common error $(n=90)$ occurred when there was no pan/zoom single event (insertion cost $=1)$ which accounted for the greatest percentage of the total costs $(39 \%)$. The remaining four error sequences were all single events that accounted for the remaining percentage of total costs (38\%).

Table 4.6 - All six of the identified error sequences in the analysis with a description of the error, insertion and deletion costs (severity), total occurrences, and total cost.

\begin{tabular}{|c|c|c|c|c|}
\hline Error sequence & Description & $\begin{array}{l}\text { Insertion/ } \\
\text { Deletion } \\
\text { Cost } \\
\text { (Severity) }\end{array}$ & $\mathrm{N}$ & $\begin{array}{l}\text { Total } \\
\text { Cost / } \\
\%\end{array}$ \\
\hline$\ldots 2 \ldots$ & no pan/zoom & $1 / 0$ & 90 & $90 / 39$ \\
\hline$\ldots 2 \ldots$ & $\mathrm{pan} /$ zoom out of expected sequence & $1 / 1$ & 17 & $34 / 15$ \\
\hline$\ldots 1 \ldots$ & additional AIN click & $0 / 1$ & 12 & $12 / 5$ \\
\hline$\ldots 1 \ldots$ & AIN click out of expected sequence & $1 / 1$ & 19 & $38 / 16$ \\
\hline$\ldots 3 \mathrm{~b} \ldots$ & additional get point click & $0 / 1$ & 6 & $6 / 3$ \\
\hline$\ldots 3 \mathrm{a} \rightarrow 3 \mathrm{~b} \rightarrow 3 \mathrm{c} \ldots$ & additional point/popup & $0 / 3$ & 23 & $69 / 30$ \\
\hline
\end{tabular}


Table 4.7 shows the results of the benchmarking analysis of the collective use of CFGCOS. Fifty-five (n=55) AIN clicks were expected, one for each use session in the analysis, but twelve more $(\mathrm{n}=+12)$ actually occurred. The remaining events had an expected count of two-hundred-twenty-two $(n=222)$, one for each of the reference sequences (iterations of the instructions). The aggregated pan/zoom event associated with step 2 occurred sixty-eight fewer times than expected $(n=-68)$. The get point or click on a colored dot event (step 3a) occurred twenty-six additional times $(n=+26)$ while both the add point and open/close popup aggregated events (steps 3b and 3c) occurred an additional twentythree times $(\mathrm{n}=+23)$.

Table 4.7 - Benchmarking analysis results categorized according to expected and actual event counts and the difference between them.

\begin{tabular}{|l|l|l|l|l|}
\hline Step & Event & Expected & Observed & Difference \\
\hline 1 & AIN click & 55 & 67 & +12 \\
\hline 2 & pan/zoom & 222 & 154 & -68 \\
\hline $3 a$ & get point & 222 & 248 & +26 \\
\hline $3 b$ & add point & 222 & 245 & +23 \\
\hline $3 c$ & open/close popup & 222 & 245 & +23 \\
\hline
\end{tabular}

\subsection{Preference Evaluation}

The next stage in the usability evaluation of CFGCOS included a preference analysis that was concerned with getting at the heart of users' impressions of the CFGCOS interface. Preference was assessed by determining satisfaction, a subjective metric that 
answers if the users liked the interface. The following subsection details the method and results of the satisfaction evaluation method used to determine preference.

\subsubsection{Satisfaction Evaluation Method}

CFGCOS users' satisfaction was first measured by calculating descriptive statistics (frequency) and visualizing the results of single ease questions (SEQ) and user attitude questions captured during the exit survey (See Section 3.2). A total of fifty-seven ( $n=57$ ) participants answered the survey. Five SEQs sought to answer questions related to task level satisfaction, the perceived difficulty in completing specific tasks when using the CFGCOS interface. SEQs asked users to rate the difficulty in placing their first point (Q3.2), placing subsequent points (Q3.3), view and record their $\mathrm{AIN}$ (Q3.5), find places on the map (Q1.1), and understand the directions (Q3.1). While Q1.1 (understand the directions) was not related to a specific task, it was considered related to all the other tasks and therefore kept in the task level analysis. Attitude rating questions answered questions about test level satisfaction, the users' overall impression of and experience with CFGCOS. Five user attitude questions focused on how complicated users found the map (Q1.3), user motivation when completing the survey (Q5.3), perceived importance in contributing data to the CFGCOS project (Q5.2), feeling about the number of popup questions (Q4.1), and length of the use session (mapping activity) itself (Q5.1).

Visualization of task and test level questions is accomplished using barplots. Stacked barplots are perfect for displaying task level Likert scale data because they show side-by-side frequency of ranked data. One stacked barplot was used to show the results of all the task 
level SEQs since the answer options were all the same. Regular barplots were used for the various user attitude questions since the answer options were not the same.

The last part of the satisfaction evaluation qualitatively assessed the results of the open-ended long text questions related to perceived difficulty and satisfaction briefly detailed in Section 3.2. This was done to provide a subjective context to not only the general satisfaction analysis, but also the previously discussed quantitative analyses in this chapter. Open-ended questions asked users to discuss what was helpful or difficult about the map (Q1.4), sidebar (Q3.6), and popup (4.6), and to give an overall rating of their experience with CFGCOS (Q5.4). Responses that captured general themes (mentioned more than once) were segmented into positive, neutral, and negative categories according to the attitude towards CFGCOS conveyed in the response. Negative classification occurred if the response conveyed frustration or a problem with the interface. Positive classification occurred it the response conveyed excitement or ease when using CFGCOS. Neutral classifications occurred if neither positive nor negative attitude could be qualitatively assessed. The following section details the results of the satisfaction evaluation.

\subsubsection{Satisfaction Evaluation Results}

Descriptive statistic results of the task level satisfaction SEQs are displayed in the stacked barplot in Figure 4.8. The vast majority of responses were positive and suggest the users were comfortable using the CFGCOS interface and did not find it difficult to use. The highest positive ratings (very easy or easy) were reported for viewing and recording the AIN (89\%) while the lowest positive ratings were reported for placing the first point and 
understanding the directions (77\%). Positive ratings for adding subsequent points $(82 \%)$ and finding places on the map (86\%) fell right in between. All positive ratings were within a range of twelve percent $(12 \%)$. The lowest ratings (difficult or very difficult) were reported for adding the first point $(12 \%)$ with adding subsequent points very closely trailing $(11 \%)$. Neutral ratings (neither easy nor difficult) ranged from a low of four (4\%) to a high of eighteen percent (18\%) for viewing and recording the AIN and understanding the directions respectively.

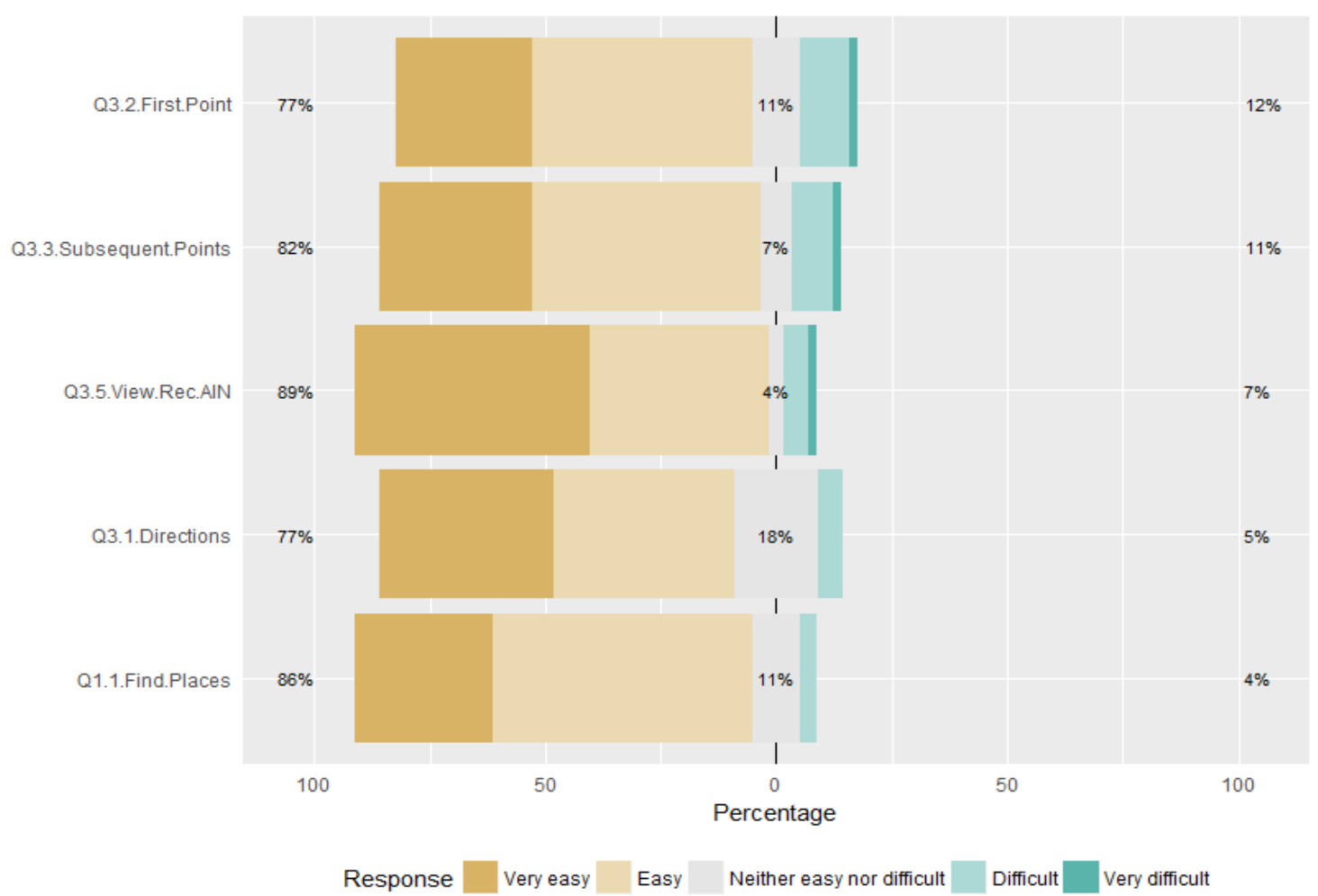

Figure 4.8 - Results from the task level satisfaction analysis.

Descriptive statistic results for the five test level user attitude questions are detailed in Figure 4.9. Again, the responses were generally positive. When asked about how simple or complicated the map was, most users gave a high positive rating. Ninety percent $(90 \%)$ 
responded the map was simple or very simple. In regards to the mapping activity, most answers were neutral. Sixty-four percent (64\%) responded that the mapping activity took just as long as expected or that they had no expectation. It is important to note however, that more people $(26 \%)$ thought the mapping activity took longer than expected than expected than those who thought it took shorter than expected (10.5\%). Responses about motivation completing the mapping activity had high positive ratings. Seventy percent $(70 \%)$ of responses were very motivated or motivated. In regards to the amount of popup questions, responses primarily neutral as sixty-seven percent $(67 \%)$ responded that they thought there was the right number of questions. Notably, more people responded that there were too many questions $(30 \%)$ than those that who though there were too few (3.5). Finally, responses to whether users though the information they contributed was important to land management and planning, the majority indicated that their contributions were very important or important $(71 \%)$. Twenty-five percent $(25 \%)$ of the responses were neutral. 

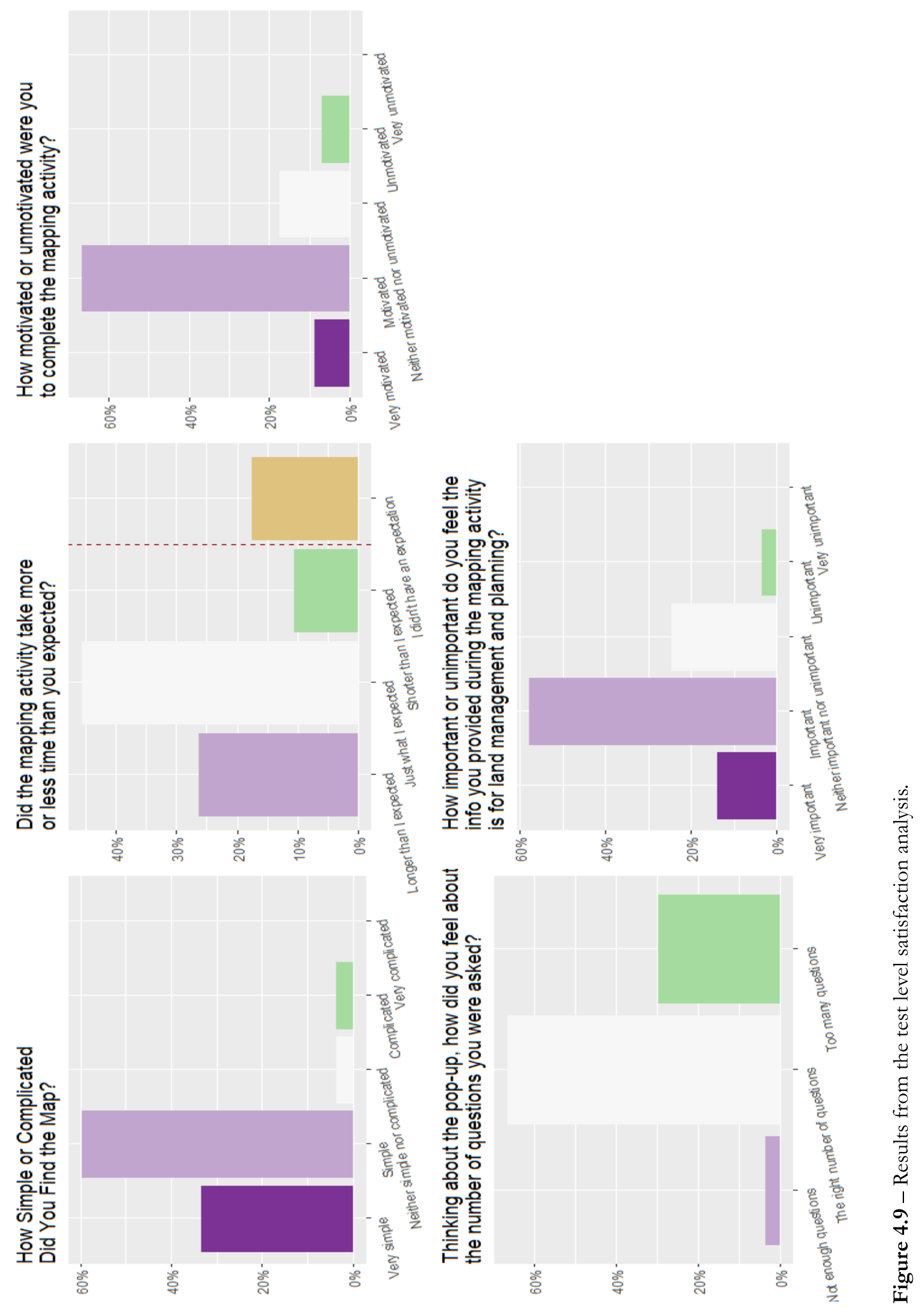
Qualitatively assessed responses to the four open-ended questions in the satisfaction evaluation are detailed in Table 4.8. Selected quotes from general themes were used to populate the table. The subjective feedback conveyed positive and negative attitudes toward CFGCOS in an evenly distributed manner for all questions except the one regarding the popup (Q4.6). Responses about the map suggested it was easy to navigate, but more detail would have been helpful. Sidebar responses ranged from ease in understanding the instructions to critique about the location template, the process of remembering which points to add next, and the inability to annotate shapes other than points. Popup responses were all negative and focused on the inability to edit answers after the popup was closed, lack of attribute options, and that there were too many questions. Lastly, responses to rating the experience using CFGCOS were wide ranging, from "great" and "easy" to "unsatisfactory" and "frustrating."

Table 4.8 - Qualitatively assessed responses from the exit survey indicating varying degrees of user attitude towards CFGCOS.

\begin{tabular}{|c|c|c|c|c|}
\hline $\mathrm{Q} \#$ & Question & Positive response & Neutral response & Negative response \\
\hline 4 & $\begin{array}{l}\text { Was there anything else } \\
\text { about the map that was } \\
\text { particularly helpful? } \\
\text { Difficult? Any other } \\
\text { feedback? }\end{array}$ & $\begin{array}{l}\text { "easy to find what part } \\
\text { I was looking at" } \\
\text { "found everything" } \\
\text { "very intuitive" } \\
\text { "easy to understand" }\end{array}$ & "Very basic map..." & $\begin{array}{l}\text { "Not a lot of } \\
\text { geographical features" } \\
\text { "trying to locate more } \\
\text { small streams and } \\
\text { tributaries" } \\
\text { "map would not load" }\end{array}$ \\
\hline 3.6 & $\begin{array}{l}\text { Was there anything else } \\
\text { about the sidebar that } \\
\text { was particularly } \\
\text { helpful? Difficult? Any } \\
\text { other feedback? }\end{array}$ & $\begin{array}{l}\text { "It worked very well!" } \\
\text { "instructions were } \\
\text { helpful” }\end{array}$ & $\begin{array}{l}\text { "Would be nice if } \\
\text { the Location \# } \\
\text { changed to the } \\
\text { name of the place" } \\
\text { "I would prefer to } \\
\text { use shapes" }\end{array}$ & $\begin{array}{l}\text { "hard time } \\
\text { remembering which } \\
\text { points I had already } \\
\text { mapped" } \\
\text { "Font was too small" } \\
\text { "wanted to delete } \\
\text { point" }\end{array}$ \\
\hline
\end{tabular}




\begin{tabular}{|c|c|c|c|c|}
\hline 4.6 & $\begin{array}{l}\text { Was there anything else } \\
\text { about the pop-up that } \\
\text { was particularly } \\
\text { helpful? Difficult? Any } \\
\text { other feedback? }\end{array}$ & NA & NA & $\begin{array}{l}\text { "accidentally closed } \\
\text { the popup before I } \\
\text { was done" } \\
\text { "couldn't edit it after it } \\
\text { closed" } \\
\text { "Lots of questions" } \\
\text { "Missing some items } \\
\text { of importance." }\end{array}$ \\
\hline 5.4 & $\begin{array}{l}\text { Overall, how would } \\
\text { you rate your } \\
\text { experience using this } \\
\text { application? }\end{array}$ & $\begin{array}{l}\text { It was a great } \\
\text { experience" } \\
\text { "Very easy to navigate" } \\
\text { "easy to use" } \\
\text { "Very simple and } \\
\text { straight forward." }\end{array}$ & $\begin{array}{l}\text { "OK" } \\
\text { "Fairly easy to use" } \\
\text { "Not too bad" }\end{array}$ & $\begin{array}{l}\text { "interface was not the } \\
\text { most user friendly" } \\
\text { "It reminded me of } \\
\text { Windows 3.1" } \\
\text { "Unsatisfactory" } \\
\text { "Kind of frustrating" }\end{array}$ \\
\hline
\end{tabular}

\subsection{Data Production Evaluation}

The final analysis component of the UE explored various cartographic interaction aspects of the CFGCOS data production system to provide greater context to the preference and performance evaluations already detailed in this chapter as well as offer more perspective on the discussion on data quality in chapter 5. The core purpose for this research was to assess the relationship between PPGIS usability and the production of spatial data. To execute the research goal properly, it was important to analyze all related characteristics of how users interacted with CFGCOS operators to produce spatial data not already explored in the previous analyses. The ultimate goal for a PPGIS practitioner is to not only make an interface that is usable, but also one that is capable of producing highquality, reliable data that can be incorporated into a decision-making environment where 
prospective users are already skeptical of PPGIS data. The following section details the analysis methods and results of the data production evaluation.

\subsubsection{Data Production Evaluation Method}

To evaluate related general use aspects of how CFGCOS users produced data, several analyses were employed. The first analysis incorporated descriptive statistics to examine the extent to which users utilized the pan and zoom operators before every iteration of a point annotation. Results from the learnability and error evaluations indicated that many users failed to pan and/or zoom before adding points to the map. To explore how much panning and zooming actually occurred, events occurring in a subset of fifty-five $(n=55)$ uses sessions were summarized by location group. Location group \#1 contained all the pan and zoom events occurring before the first location annotation event (graphic-add). Location groups \#2 through \#5 contained all the pan and zoom events occurring in between each subsequent point annotation event. Two-hundred-forty-five $(n=245)$ point annotations were included in the analysis. The summarized events included map click and drag (delta) pan events and scale-change (zoom related extent-change) events.

The next part of the data production evaluation explored the spatial extent (xmin, xmax, ymin, ymax) characteristics of sequential groups of annotated points per use session for which no panning events occurred vs those where panning events did occur. Seventy-one observations $(\mathrm{n}=71)$ were included. This analysis sought to provide context to the discussion on data completeness (See section 2.1.4) detailed in chapter 5. A two sample t-test was 
implemented to test the hypothesis that the mean extent of groups of points for which no panning occurred before annotation was less than those for which panning did occur.

The last portion of the data production evaluation analyzed specific characteristics of the resultant data produced by CFGCOS users. First descriptive statistics were calculated and visualized to determine the zoom level for which subset points were annotated. A Pearson's correlation coefficient was also calculated to determine if an association existed between the number of zoom events for which a user engaged before annotating a point and the zoom level for which the point was annotated. Results from this analysis were intended to contextualize another segment of the data quality discussion- positional accuracy. Second, degrees of textual annotation for popup form boxes over the course of a use session were examined. When CFGCOS was in development, researchers wondered if fatigue over the number of questions asked would result in a decrease of textual annotation. This question was answered by calculating descriptive statistics and visualizing the number form boxes that were annotated vs those that were not. Supplemental to this analysis was a closer visual examination of which form boxes were the least annotated.

\subsubsection{Data Production Evaluation Results}

Results from the pan event per location group analysis are summarized in Table 4.9. Counts show the number of subset points in the location group. Results indicate the number of points decreased per location group. Delta counts and mean delta counts per location refer to the total and mean count of click and drag events tallied for the location group. On average, location group \#2 had the lowest delta events (8.6) and location group \#3 had the 
highest (10.7) delta event counts occurring before a point annotation. The no pan event and no pan event frequency columns show the count and frequency of times no pan events occurred before a point annotation. Results indicate the lowest frequency occurred for location group \#1 (9.1\%) and the highest occurred for location \#3 (18.4\%). Overall, approximately fourteen percent $(13.9 \%)$ of points were annotated with no prior panning. These findings support those in those detailed in the learnability and error evaluations, and also the responses to Q2.2 and Q2.3 from the exit survey where users indicated they were reminded of many of their points when they started panning around the map.

Table 4.9 - Results from the pan event per location analysis.

\begin{tabular}{|l|l|l|l|l|l|}
\hline $\begin{array}{l}\text { Location } \\
\#\end{array}$ & Count & $\begin{array}{l}\text { Delta } \\
\text { Count }\end{array}$ & $\begin{array}{l}\text { Mean Delta } \\
\text { per Location }\end{array}$ & $\begin{array}{l}\text { No Pan } \\
\text { Event }\end{array}$ & $\begin{array}{l}\text { No Pan Event } \\
\text { Frequency (\%) }\end{array}$ \\
\hline 1 & 55 & 525 & 9.5 & 5 & 9.1 \\
\hline 2 & 52 & 448 & 8.6 & 9 & 17.3 \\
\hline 3 & 49 & 523 & 10.7 & 9 & 18.4 \\
\hline 4 & 47 & 451 & 9.6 & 6 & 12.8 \\
\hline 5 & 42 & 404 & 9.3 & 5 & 11.9 \\
\hline total & 245 & 2351 & 9.6 & 34 & 13.9 \\
\hline
\end{tabular}

Results from the zoom event per location group analysis are summarized in Table 4.10. Like in the previous table, the count and zoom event count columns show the total number of points and zoom events per location group. Mean zoom events show the average 
number zoom events occurring per annotated point, which range from between 2.0 and 2.2 events. The no zoom event count and frequency columns signify the count and percentage of points that were annotated with no prior zooming. Results indicate that location group \#1 had the most points added without a previous zoom event, (41.8\%) while the least was for location group \#5 (30.9\%). In total, approximately thirty-seven $(36.7 \%)$ percent of points were annotated with no previous zoom event.

Table 4.10 - Results from the zoom event per location analysis.

\begin{tabular}{|l|l|l|l|l|l|}
\hline $\begin{array}{l}\text { Location } \\
\#\end{array}$ & Count & Zoom Events & $\begin{array}{l}\text { Zoom Events } \\
\text { per Location }\end{array}$ & No Zoom Event & $\begin{array}{l}\text { No Zoom Event } \\
\text { Frequency (\%) }\end{array}$ \\
\hline 1 & 55 & 120 & 2.2 & 23 & 41.8 \\
\hline 2 & 52 & 114 & 2.2 & 19 & 36.5 \\
\hline 3 & 49 & 106 & 2.2 & 19 & 38.7 \\
\hline 4 & 47 & 95 & 2.0 & 16 & 34.0 \\
\hline 5 & 42 & 102 & 2.4 & 13 & 30.9 \\
\hline total & 245 & 547 & 2.2 & 90 & 36.7 \\
\hline
\end{tabular}

Table 4.11 exhibits the results of the t-test used to determine whether the mean spatial extent of point groups for which no prior panning occurred before annotation was less than those where panning did occur before hand. The hypotheses for this test were as follows: 
$H O$ : The is no difference in the spatial extent means between point groups with prior panning and those without.

$H_{A}$ : The true difference in means between point groups without prior panning and those with is $<0$

Results show that that with a $99 \%$ confidence level, the spatial extent of point groups for which no previous panning occurred is less than for cases where panning did occur. Implications of this finding are further discussed in chapter 5.

Table 4.11 - Two sample t-test results the spatial extent of points where prior panning did and did not occur.

\begin{tabular}{|c|c|l|}
\hline Test Statistic & DF & P-val \\
\hline-4.33 & 65 & $0.00002661 * * *$ \\
\hline
\end{tabular}

The results of the descriptive statistical analysis of zoom level recorded during point annotation are shown in Table 4.12 and visualized in Figure 4.10. The table shows that the while the annotation zoom levels are generally even, the most points $(n=93)$ were annotated at level zero, the smallest scale of the three. A Pearson's correlation coefficient was also calculated to determine associations between zoom events and zoom level during annotation. The result $(\mathrm{r}=0.567375)$ signifies a moderate positive association between number of zoom events and annotation zoom level.

Table 4.12 -Descriptive statistics of zoom level when point was annotated.

\begin{tabular}{|l|l|l|}
\hline Zoom Level & Count & Frequency (\%) \\
\hline 0 & 93 & 38.0 \\
\hline 1 & 75 & 30.6 \\
\hline 2 & 77 & 31.4 \\
\hline
\end{tabular}




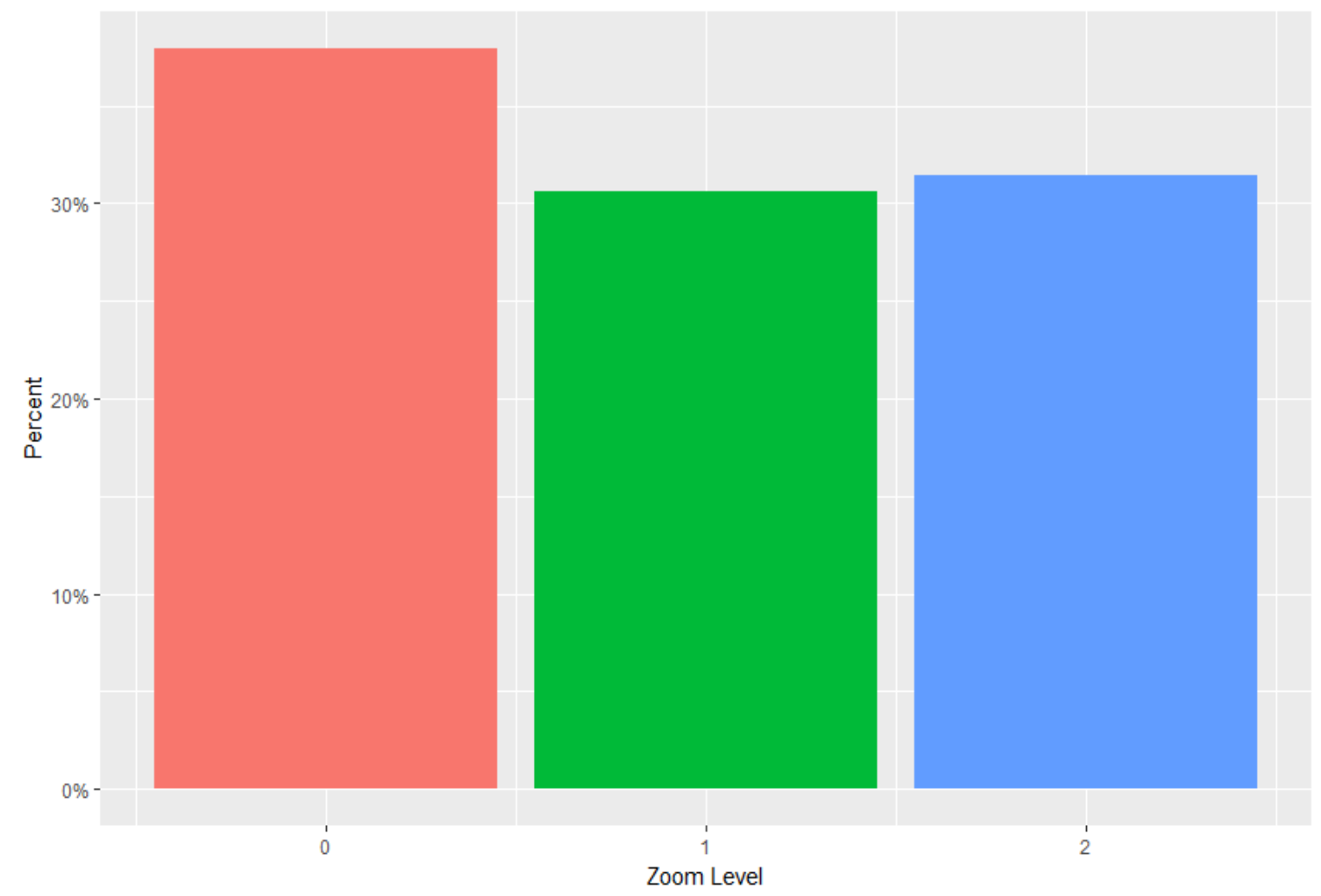

Figure 4.10 - Barplot showing the percentage of points annotated at each zoom level. Zoom 0 is the most zoomed out (smallest scale) and zoom level 2 is the most zoomed in (largest scale).

The final results from the textual annotation analysis of popup form boxes are visualized in Figures 4.11 and 4.12. The first of the figures shows that the percentage of form boxes that were annotated with data $(\sim 87.5 \%)$ vs those that were not $(\sim 12.5)$ were nearly identical for every location. All five location popups contained about eighty-eight percent $(88 \%)$ of the form boxes annotated with data vs those that did not $(12 \%)$. The second figure delves a bit deeper into which form boxes were annotated more or less than others. Results indicate that the least annotated drop-down form box was feature 3 (55\%), 
and threats was the least annotated open-ended form box. Results also indicate that the AIN, benefit 1, benefit 2 from boxes were annotated in every instance. They do not appear in Figure 4.12 at all.

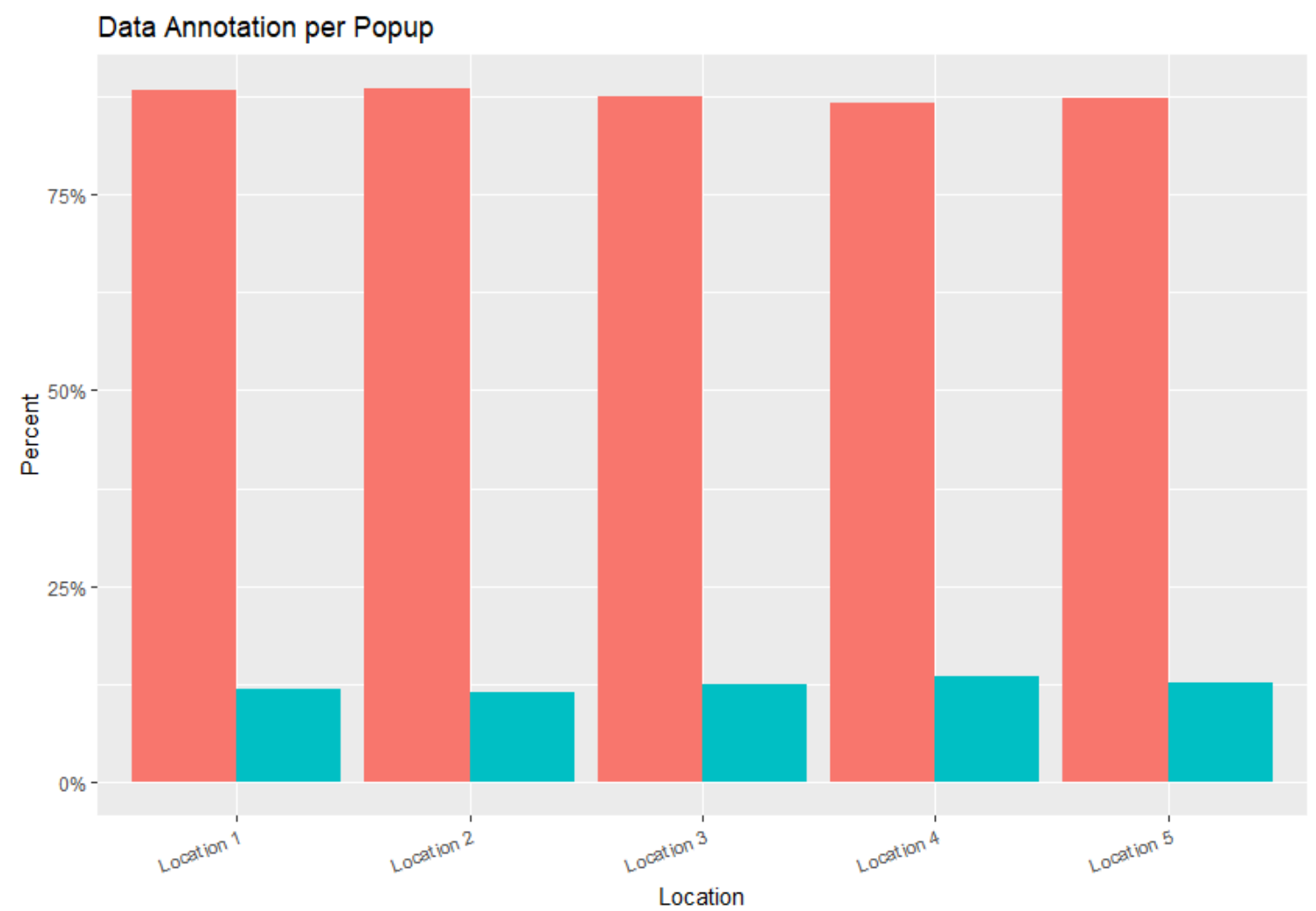

Figure 4.11 - Barplot showing the percentage of all form boxes annotated with (orange) and without data (blue) per location. 


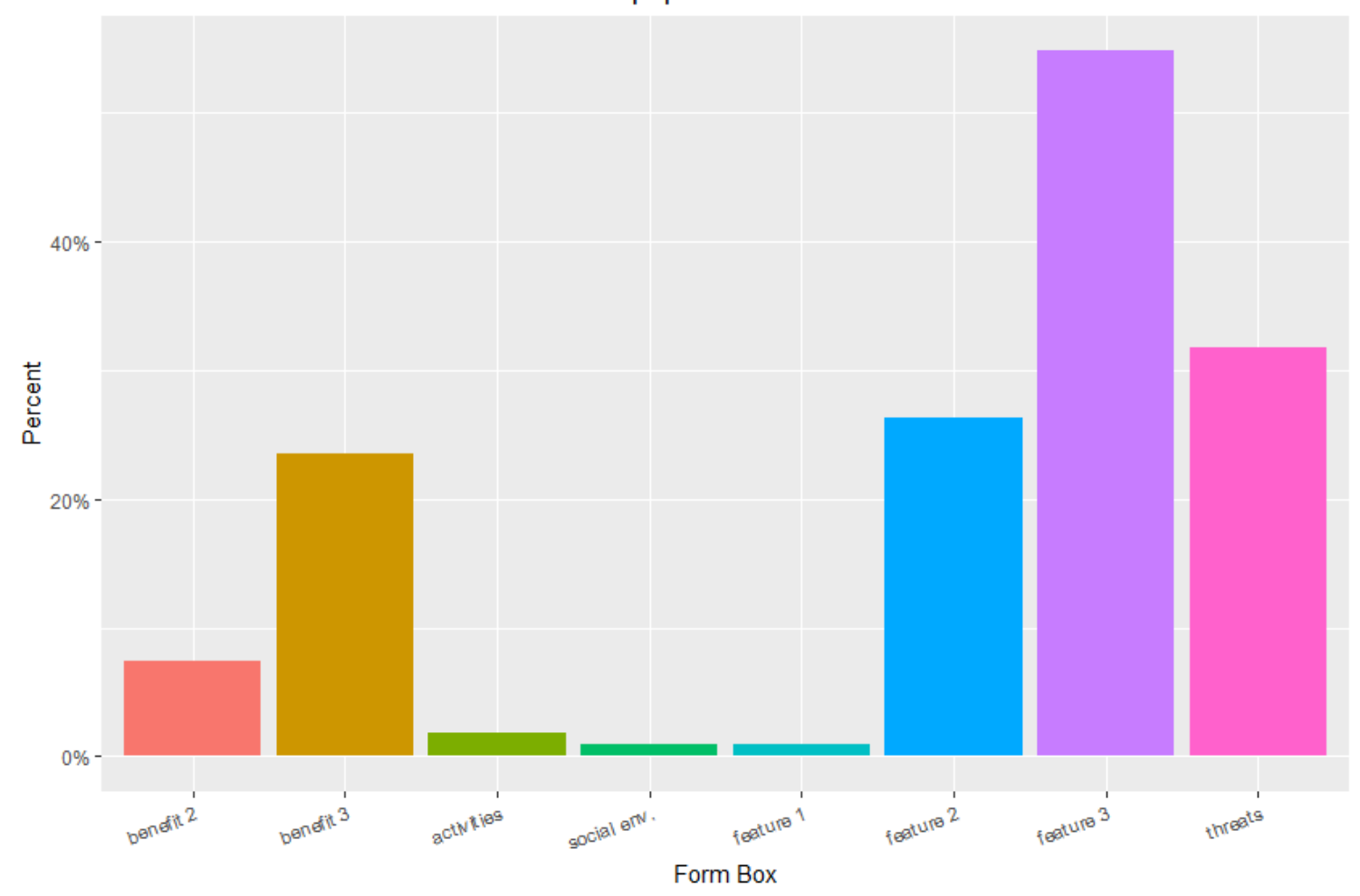

Figure 4.12 - Barplot showing the percentage of all form boxes that were not annotated by form box.

\section{$\underline{4.5 \text { Analysis Conclusion }}$}

This chapter highlighted the methods and results of the analysis stage of the UE aimed at identifying problems in the CFGCOS interface. It also honed in on cartographic interaction aspects of the CFGCOS data production system indirectly related but inextricably linked to the same operators explored in the general usability evaluation. Visual, descriptive, and elementary statistical methods were incorporated throughout the process to fulfill the second major research goal in this thesis. Results of each analyses are synthesized in the next chapter which first offers a solution-oriented critique of the interface, then 
discusses potential implications of the CFGCOS data production system on data quality, and concludes with a discussion of how lessons learned from this research can inform the development of future PPGIS applications. 


\section{Chapter 5: Critique of CFGCOS}

\subsection{CFGCOS Critique Overview}

The final stage of the UE of CFGCOS synthesizes the results of the previous two stages (data capture and analysis) to critique the usability of the CFGCOS operators and interface, contextualize a critical discussion of CFGCOS data quality, and conduct an informed discussion on the development of future PPGIS applications. These critique activities (See Section 2.2.2) fulfill the final research goal of this thesis (See Section 1.4). The chapter begins with both a detailed and digested account of how each operator and the interface as a whole performed within both a usability and data production frame. In the process, critical solutions are offered as ways to mitigate future problems with similar applications. The chapter then draws on data quality theory (Section 2.1.4) to inform a discussion of usability implications on both CFGCOS and more general PPGIS data quality. The chapter then ends with concluding remarks about the importance of UE for the design and development of future PPGIS applications and research.

\subsection{CFGCOS Operator and Interface Usability Critique}

CFGCOS usability critique is a qualitative, subjective process informed by the quantitative results of the performance and data production evaluation and the qualitative results of the preference evaluation and exit survey data not incorporated in the analysis activities. The combined insights provide a comprehensive view of application interface 
problems for which a researcher can interpret and offer critical solutions. This usability critique finds that many of the same problems were identified by the various analyses, but from different perspectives. The following sections detail the critiques of each of the operators first, then of the interface in summary.

\subsubsection{AIN Button}

The AIN button was a non-cartographic operator which the designers intended the user to interact with once after they read the initial instructions and before any other interaction with the interface occurred. CFGCOS designers expected the user to click the step 1 button to trigger a popup displaying a randomly generated identification number for which they were to write down (See Appendix A). When the user reached the textual annotation component of the popup, they were expected to annotate the AIN from box with the number they wrote down. Results indicate that users did click the AIN button during every use session (See Table 4.1), record their number in the AIN form box (Figure 4.11), and find the process of recording their AIN easy (See Figure 4.7). However, in five instances the AIN was misrecorded. This was discovered after the error evaluation upon visual inspection of the spatial dataset produced by CFGCOS. Also, on average, users interacted with the AIN button before any of the other operators; however there was at least one instance where a user panned first. The error evaluation also showed that users clicked the AIN button more frequently than expected (See Table 4.7) or after they retrieved a point from the location template to annotate (See Table 4.5). This suggests that users forgot their number or did not write it down before moving on to point annotation (step 3), however it 
is not possible to know the true reason without a method like Verbal Protocol Analysis (VPA).

Potential future solutions to mitigate AIN button problems include automating the AIN process so that the AIN form box is automatically annotated with the AIN itself either known or unknown to the user. A potential benefit to the AIN being known to the user is that they could come back to the survey at a later time (provided that functionality was incorporated in the development of the application). This would completely eliminate a step, reduce potential from error both from writing down or annotating the wrong number in the form box, and save time overall.

\subsubsection{Pan \& Zoom}

Both pan and zoom were cartographic operators associated with step 2, an important map navigation precursor to point annotation (Step 3a and 3b). The designers expected the user to pan and/or zoom to the location for which they wanted to mark on the map, ideally before the addition of every point. Results showed users chose to pan before zoom and pan a great deal more than zoom (See Tables 4.1, 4.9, and 4.10). Many panned/zoomed out of the expected sequence (See Table 4.6), did not pan or zoom before adding a new point (See Table 4.7), or even at all during the use session (See Tables 4.1). A moderately positive association was also found between the number of zoom events before annotation and annotation scale (See Section 4.4.2). Surprisingly however, although a vast majority of users found it easy or very easy to find a place they were looking for (See Figure 4.7), about a quarter of the users also indicated they wanted more zoom levels and a greater 
cartographic extent. This could be related to the fact that nearly as many wanted more geographic features on the map (See Section 3.5.1, Table 4.8). More research would need to be done in this area to be able to know the reasons for sure. Still, the most surprising results was the under-utilization (learnability) of the pan and zoom operators and the moderately positive association between zoom level and annotation scale. Potential implications of low engagement with the pan/zoom operators on data quality are discussed in Section 5.3.

Mitigating solutions to the lack of user engagement with the pan and zoom operators might include inclusion of more explicit instructions, perhaps with an interactive tutorial or video showing the users exactly how to pan and zoom. The idea behind such a solution would be for the user to learn exactly how to use the operators before beginning the process of finding a location to annotate.

\subsubsection{Point Annotation}

Point annotation involved two cartographic operators, the location template click (step 3a) and the annotation itself (step 3b). The designers expected that the user would pan and zoom to their desired location (step 2) then click on the location template to retrieve a point and finally click on the map to add the point. Results showed that users generally found this process easy (See Figure 4.7) and became more and more efficient with it (See Figure 4.3). However, many were unsatisfied with the process and considered it difficult, even over the course of adding subsequent points (See Figure 4.7 and Tables 4.8). This research assumed frustration was due to a CFGCOS design decision that removed the ability 
to delete or move a point after they added it to the map (See Table 4.8). In fact, approximately $1 / 3$ of users responded that they wanted to change/delete their point (See Table 3.5). This assumption was also supported by the error results that indicated that many extra points were added per location, a high severity error (See Tables 4.5, 4.6, and 4.7). Some users also clicked on the location template more than expected (See Tables 4.6 and 4.7), likely because users could not remember which location they were annotating (See Table 4.8).

Solutions to address the identified problems with point annotation would start with incorporating the ability for user to delete or move points after annotation (step 3b). This change alone could significantly improve the usability of CFGCOS, especially in terms of error and satisfaction. Secondly, the location template from which points were collected in preparation for annotation would need a complete redesign. Perhaps after location annotation was completed, the location template could be updated to hide points that were already added. An alternative approach would be to show only one point in the template that was updated after every annotation step.

\subsubsection{Pорир Annotation}

Popup annotation operators (step 3c) involved a series of textual annotation within varying types of form boxes (See Appendix A). After point annotation (step 3b), the designers expected the user to scroll down the popup and fill in each of the form boxes (except for benefit/feature 1 and 2 which had an option to be left blank), and then click on the " $\mathrm{X}$ " at the top of the box when they were finished. Results indicate that users learned to 
properly complete this task and became more efficient with it over the course of a use session (See Figure 4.4). Specifically users became more efficient with each form box annotation location iteration (See Figure 4.5), and annotated the form boxes evenly over the course of the use session (See Figure 4.10). Users also spent more time in the open-ended form boxes than the drop-downs (See Table 4.2 and Figure 4.3). About a third of the users said they preferred the drop-downs to the open-ended boxes (See Table 3.6) and a quarter of the users indicated there were too many questions (See Figure 4.8). This likely contributed to the threats form box, which was at the very end of the popup, being the least annotated of all the form boxes not having the option to be left blank (See Figure 4.11).

Other significant problems identified were that a fifth of users wanted to change answers after they closed the popup either on purpose or by mistake and a fifth of users indicated the popup blocked information they needed to see on the map (See Tables 3.6 and 4.8). As with already annotated points, the decision for users to not have the ability to edit points was made during the design process. Coupled with the inability to delete/change points, these factors likely contributed to additional unnecessary points. This is another instance where VPA could help with verification of the suspected cause of the problem.

Solutions to mitigate the problems identified with popup annotation start with allowing edits after the popup box is closed and not allowing the popup to close from an accidental click outside of it. This might require an entire redesign of the popup box, perhaps by adding in another side panel where all the previous annotations could be accessed. This would also solve the issue of the popup blocking important map information. Reduction of the number of questions and/or changing the order of the 
open-ended form boxes might also encourage more users to annotate the form boxes that take more time to complete, but this could also be solved by reducing the number of questions asked altogether.

\subsubsection{CFGCOS Critique Summary}

For the most part, the CFGCOS interface allowed for successful cartographic interaction to produce spatial data. The UE analysis activities confirmed its usability. On average, users understood the directions, learned how to complete tasks with all the operators, and became more efficient with them over the course of a use session. Users were also satisfied with the interface as indicated by task and test level responses. Most found it easy to use, were motivated to contribute data, and conveyed a positive attitude towards it. However, despite the users' familiarity and background with computers and mapping (See Section 3.5.6), the design of the interface also allowed for a great deal of error, with chained annotation sequence errors being the most severe. In the context of data production, the interface encouraged an underutilization of the pan/zoom operators and forced repetition of annotation tasks (point and popup) though lack of editing functionality. The AIN button was also problematic and required users to take extra steps and remember their assigned number. The suggested engagement with the interface (completing the mapping activity) was also on the long side, as expressed by a fifth of the users (See Figure 4.8). In the context of data quality, these accumulated errors and factors that potentially impact the quality of the data created by the interface must be considered. The next section discusses PPGIS data quality, framed by this research. 


\subsection{Data Quality Critique}

\subsubsection{A New Conceptual Framework}

Before delving into a discussion on data quality, a conceptual and visual examination of PPGIS usability evaluation and spatial data production in CFGCOS is pertinent. Figure 5.1 shows the conceptual framework from which this research is oriented. On the top left is the public as defined in the Chapter 2 literature review (See Section 2.1.1). Within the public are individuals who start a use session with CFGCOS and begin interacting with the interface and form impressions of it. A user initiates the stages of interaction for every cartographic interaction. Cartographic interaction occurs in a semi-predictable sequence, but sometimes outside of what is expected. Unexpected events have the potential to affect data quality. Interaction is captured through interaction logging and exit surveys. Captured usability and data production metrics are then analyzed to identify problems in the interface and provide metadata context to the spatial data. Future data quality can be improved through critique. Critique is a type of fine tuning of the interface, fostered through a usability evaluation in the realm of controlled experimentation. At the end of a use session, spatial data is produced. Related data production metrics provide context (metadata) to the spatial data. Through this frame, a discussion of CFGCOS data quality is possible. 


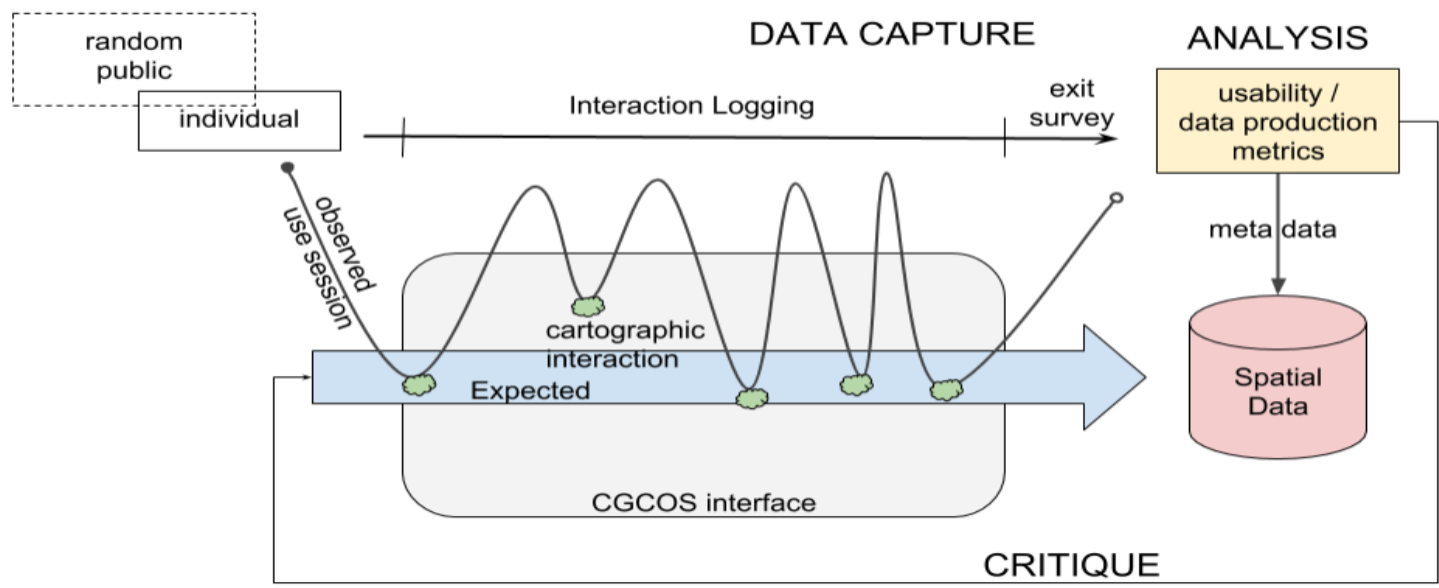

Figure 5.1 - Conceptual diagram of the usability evaluation and data production.

\subsubsection{Discussion on Internal Data Quality}

Internal data quality "corresponds to the level of similarity that exists between the data produced and the 'perfect' data that should have been produced - that is, data produced without error" (Guptill 37). According to the error evaluation metrics, fifty-five ( $\mathrm{n}=55)$ CFGCOS users produced two-hundred-forty-five points $(n=245)$, a mean of about five (mean=4.5) per person. Of those points, twenty-three $(n=23)$ were identified to be errors defined as deviations from what was expected. That is an error rate of approximately nine percent $(9 \%)$. The data production evaluation metrics indicated that about thirty-seven percent $(36.7 \%)$ were annotated without a prior zoom event, and thirty-eight percent $(38 \%)$ were annotated at the largest possible scale $(z o o m=0)$. These factors are all important in contextualizing the data's positional accuracy. Some CFGCOS users indicated difficulty in 
annotating their first and subsequent points, and many stated the desire to delete points. If any of these points were added to the wrong location or at a scale that did not offer enough cartographic detail $($ zoom $=2)$, the positional accuracy of the data would be compromised.

Data production metrics also indicated that users failed to pan before about fourteen percent $(13.9 \%)$ of the locations they added. A two sample t-test showed that the spatial extent of point groups for which no previous panning occurred was less than the where panning did occur. This finding is important in the context of data completeness. CFGCOS was designed to collect data related to three different public lands. If users panned to a location to annotate a point and then stayed there for several more location annotations, then many of their points will be clustered. Clustered features in one part of the study area means the absence of features in another part. One interpretation of this result is that the absence of features infers lack of completeness.

Completeness is also important to consider in terms of textual attribute annotation. Results of the data production evaluation showed that form boxes were annotated across locations evenly, despite concerns raised about the mapping activity length. This a good sign for attribute completeness. However, open-ended threat form box annotations were the least attributed, perhaps because they were the last question in the popup. This suggests that form box ordering is an important factor to consider if attribute completeness is important to a PPGIS project. 


\subsubsection{Discussion on Fitness for Use}

Fitness for use or external data quality "corresponds to the level of concordance that exists between a product and user needs, or expectations in a given context" (Guptill 39). One of the biggest issues with the inclusion of socio-spatial data in planning and land management decision frameworks, is that the users of the data - planners and managers accustomed to quantitative expert-derived data - are not properly trained or don't know how to interpret the data. Usability metrics (particularly error and efficiency) and data production metrics, as quantified in this research, can help to address this issue by providing the context for how the data was acquired. The metrics help to define lineage, the methods used to obtain the data that answers questions of "how" (Bédard and Vallière).

Lineage can be improved through strategic inclusion of the user for whom the data is being produced. They can help to formalize the acquisition objectives during the development phase by answering what is expected of the data. However, gathering information on acquisition objectives assumes that the end user knows what they actually need from the data. Specific questions regarding the appropriate resolution for annotation, what type of geometry should be allowed for annotations, what density of data is required in areas of the study area to make it complete (which may be different for specific zones in the study area). These are just a few of the specific questions that can help the designers set benchmarks for what is expected of the user contributing data. The application can be 
designed around those expectations and questions surrounding the data's external quality mentioned above will be more answerable.

\section{$\underline{5.3 \text { Future Implications for PPGIS }}$}

Mistrust of PPGIS data quality, suspicion of data collection methods, and the lack of integration into the planning and decision support process itself are some of the major obstacles facing modern PPGIS projects. This research shows usability evaluation coupled with data production evaluation can help to address some of these impedances. The research delves into aspects of the entire PPGIS data production system to make sense of the way the public use an interface to produce data. It also suggests solutions to improve the way the system acquires data. Much like the way quantitative data acquisition (LiDAR for example) tools need to be calibrated, PPGIS data acquisition systems need to be fine-tuned as well. Obviously human ecology, sense-of-place, socio-spatial data collected from a PPGIS is much different from the laser returns of a LiDAR system, but the idea is the same - calibrated data acquisition systems will produce higher quality data. Usability and data production evaluations provide methods for honing the PPGIS data production system. In practice, such evaluation could be included in a User Centered Design (UCD) process described by Roth (263-264).

It is in the opinion of this researcher that future PPGIS research efforts should focus on improving the data collection/production systems within PPGIS applications. PPGIS literature rarely addresses the inner-workings of the interactive applications used in the research. Interactive map usability research rarely addresses PPGIS or the operators that 
produce data. More research like that of Gottwald et al., which addresses PPGIS usability among older adults is a step in the right direction (2321-2338). Still very little modern research exists that merges the two topics. This research illuminates what is possible, but only addresses a single case study application.

\section{$\underline{5.4 \text { Concluding Remarks }}$}

This research was conducted to address some of the critiques that are commonly made of PPGIS. It introduces new integrated approaches to assessing the relationship between interactive map usability and spatial data production. It shows coupled usability and spatial data production metrics captured for analysis in a usability evaluation can provide a holistic overview of how a PPGIS data production system performs. While this research only studied a single PPGIS application, similar methods could be applied to any application that engages the public to produce spatial data. It is in the opinion of this researcher that future PPGIS projects should seriously consider the importance of finely tuned PPGIS data acquisition systems. 


\section{References}

“About.” Discover Your Forest, http://discoveryourforest.org/about/. Accessed 1 July 2018.

Aalders, H. and Morrison, J., "Spatial Data Quality for GIS.” Geographic Information Research: Trans-Atlantic Perspectives. Edited by Craglia M. and Onsrud H. London/Bristol. Taylor \& Francis. 1998. p 463-75.

Anderson, Candace, et al. "Lessons for PPGIS from the Application of a Decision-Support Tool in the Nova Forest Alliance of Nova Scotia, Canada." Journal of Environmental Management, vol. 90, no. 6, May 2009, pp. 2081-89.

Bedard Y. and Valliere D., Qualité des données à référence spatiale dans un contexte gouvernemental, technical report, 1995, Quebec City, Laval University.

Beverly, Jennifer L., et al. "Assessing Spatial Attributes of Forest Landscape Values: An Internet-Based Participatory Mapping Approach." Canadian Journal of Forest Research, vol. 38, no. 2, Feb. 2008, pp. 289-303.

Bostock, M., Ogievetsky, V., Heer, J., "D3: Data-Driven Documents. IEEE Transactions in Visualization and Computer Graphics.” 2011.

Brown, G., Reed, P.. "Validation of a Forest Values Typology for Use in National Forest Planning." Forest Science, vol. 46, 2000, 240-247.

Brown, Gregory. "Mapping Spatial Attributes in Survey Research for Natural Resource Management: Methods and Applications.” Society \& Natural Resources, vol. 18, no. 1, Dec. 2004, pp. 17-39.

Brown, Gregory G., and Pat Reed. "Public Participation GIS: A New Method for Use in National Forest Planning." Forest Science, vol. 55, no. 2, 2009, pp. 166-182.

Brown, Greg. "An Empirical Evaluation of the Spatial Accuracy of Public Participation GIS (PPGIS) Data.” Applied Geography, vol. 34, May 2012, pp. 289-94. 
Brown, Gregory, et al. "Which 'Public'? Sampling Effects in Public Participation GIS (PPGIS) and Volunteered Geographic Information (VGI) Systems for Public Lands Management." Journal of Environmental Planning and Management, vol. 57, no. 2, 2014, pp. $190-214$.

Brown, Gregory. "Public Participation GIS (PPGIS) for Regional and Environmental Planning: Reflections on a Decade of Empirical Research.” URISA J., vol. 25, Jan. 2012, pp. 5-16.

Brown, Greg, and Pat Reed. "Values Compatibility Analysis: Using Public Participation Geographic Information Systems (PPGIS) for Decision Support in National Forest Management." Applied Spatial Analysis and Policy, vol. 5, no. 4, Dec. 2012, pp. 317-32.

Brown, Greg, and Marketta Kyttä. "Key Issues and Research Priorities for Public Participation GIS (PPGIS): A Synthesis Based on Empirical Research.” Applied Geography, vol. 46, Jan. 2014, pp. 122-36.

Brown, Gregory, and Delene Weber. "Using Public Participation GIS (PPGIS) on the Geoweb to Monitor Tourism Development Preferences." Journal of Sustainable Tourism, vol. 21, no. 2, Mar. 2013, pp. 192-211.

Brown, Greg, and Shannon Donovan. "Measuring Change in Place Values for Environmental and Natural Resource Planning Using Public Participation GIS (PPGIS): Results and Challenges for Longitudinal Research.” Society \& Natural Resources, vol. 27, no. 1, Jan. 2014, pp. 36-54.

Brown, Greg, et al. "Is PPGIS Good Enough? An Empirical Evaluation of the Quality of PPGIS Crowd-Sourced Spatial Data for Conservation Planning.” Land Use Policy, vol. 43, Feb. 2015, pp. 228-38.

Brown, Greg. "A Review of Sampling Effects and Response Bias in Internet Participatory Mapping (PPGIS/PGIS/VGI): Sampling Effects and Response Bias in Internet Participatory Mapping." Transactions in GIS, vol. 21, no. 1, Feb. 2017, pp. 39-56. 
C Gandrud, JJ Allaire, K Russell, BW Lewis, K Kuo, C Sese, P Ellis, J Owen, J Rogers. “networkD3: D3 JavaScript network graphs from R.” R package version 0.2, vol. 8, 2016

Castree, Noel. "Is geography a science?” Questioning geography: fundamental debates. Edited by Noel Castree, Alisdair Rogers, and Douglas Sherman. Blackwell. 2005

Federal Register. Forest Service, USDA. 36 CFR Part 219, vol. 77, no. 68, 9 Apr. 2012

Frøkjær, Erik, et al. Measuring Usability: Are Effectiveness, Efficiency, and Satisfaction Really Correlated? ACM Press, 2000, pp. 345-52.

Gabadinho, Alexis, et al. "Analyzing and Visualizing State Sequences in R with TraMineR." Journal of Statistical Software, vol. 40, no. 4, 2011.

Goodchild, Michael F. CITIZENS AS SENSORS: THE WORLD OF VOLUNTEERED GEOGRAPHY. p. 15.

Gottwald, Sarah, et al. "Exploring the Usability of PPGIS among Older Adults: Challenges and Opportunities.” International Journal of Geographical Information Science, vol. 30, no. 12, Dec. 2016, pp. 2321-2338.

Guptill, Stephen C. "Fundamentals of Spatial Data Quality - Edited by RODOLPHE DEVILLERS AND ROBERT JEANSOULIN." Transactions in GIS, vol. 12, no. 1, 2008, pp. 161-162.

Haklay, Mordechai, and Carolina Tobón. "Usability Evaluation and PPGIS: Towards a UserCentred Design Approach.” International Journal of Geographical Information Science, vol. 17, no. 6, Sept. 2003, pp. 577-92.

Haklay, Mordechai. "How Good Is Volunteered Geographical Information? A Comparative Study of OpenStreetMap and Ordnance Survey Datasets." Environment and Planning B: Planning and Design, vol. 37, no. 4, Aug. 2010, pp. 682-703. 
Ivory, Melody Y., and Marti A. Hearst. "The State of the Art in Automating Usability Evaluation of User Interfaces.” ACM Computing Surveys, vol. 33, no. 4, Dec. 2001, pp. $470-516$.

ISO/TC 211, 19113 Geographic Information - Quality Principles, International Organization for Standardization (ISO), 2002.

McLain, Rebecca, et al. "Making Sense of Human Ecology Mapping: An Overview of Approaches to Integrating Socio-Spatial Data into Environmental Planning." Human Ecology, vol. 41, no. 5, Oct. 2013, pp. 651-65.

McLain, Rebecca J., et al. "Multiple Methods of Public Engagement: Disaggregating SocioSpatial Data for Environmental Planning in Western Washington, USA.” Journal of Environmental Management, vol. 204, Dec. 2017, pp. 61-74.

Needleman, and Wunsch. "A General Method Applicable to the Search for Similarities in the Amino Acid Sequence of Two Proteins.” Journal of Molecular Biology, vol. 48, no. 3, 1970, pp. 443-453.

Norman, D. A. The design of everyday things. Basic Books, New York, NY, 1988.

Plaisant, Catherine. The Challenge of Information Visualization Evaluation. ACM Press, 2004, p. 109.

Pyla, Pardha S., et al. Vizability: A Tool for Usability Engineering Process Improvement through the Visualization of Usability Problem Data. ACM Press, 2006, p. 620.

Rolston, H, and J Coufal. "A FOREST ETHIC AND MULTIVALUE FOREST MANAGEMENT - THE INTEGRITY OF FORESTS AND OF FORESTERS ARE BOUND TOGETHER.” Journal Of Forestry, vol. 89, no. 4, 1991, pp. 35-40.

Roth, Robert E., and Mark Harrower. "Addressing Map Interface Usability: Learning from the Lakeshore Nature Preserve Interactive Map.” Cartographic Perspectives, no. 60, June 2008, pp. 46-66. 
Roth, Robert Emmett. Interacting with Maps: The Science and Practice of Cartographic Interaction.

The Pennsylvania State University, 2011. ProQuest,

http://search.proquest.com/docview/926948433/abstract/5637942A0BC44E37PQ/1.

Roth, Robert E. 'Interactive Maps: What We Know and What We Need to Know." Journal of Spatial Information Science, no. 6, June 2013.

Roth, Robert, et al. "User-Centered Design for Interactive Maps: A Case Study in Crime Analysis." ISPRS International Journal of Geo-Information, vol. 4, no. 1, Feb. 2015, pp. 262-301.

Sack, Carl M. (2013). Mapmaking for Change: Online Participatory Mapping Tools for Revealing Landscape Values in the Bad River Watershed. Retrieved from http://www.northlandia.com/pubs/Sack_MS_Thesis.pdf

Schlossberg, Marc, and Elliot Shuford. Delineating "Public" and "Participation" in PPGIS. Vol. 16, no. 2, 2005, p. 12.

Schmidt, Mario. “The Sankey Diagram in Energy and Material Flow Management.” Journal of Industrial Ecology, vol. 12, no. 1, 2008, pp. 82-94.

Sieber, Renee. "Public Participation Geographic Information Systems: A Literature Review and Framework." Annals of the Association of American Geographers, vol. 96, no. 3, 2006, pp. 491-507.

Sieber, Renée E., et al. "Doing Public Participation on the Geospatial Web." Annals of the American Association of Geographers, vol. 106, no. 5, Sept. 2016, pp. 1030-46.

Tulloch, David L. "Is VGI Participation? From Vernal Pools to Video Games." GeoJournal, vol. 72, no. 3-4, Aug. 2008, pp. 161-71.

Usability Evaluation Basics. 8 Oct. 2013, /what-and-why/usability-evaluation.html.

Wright, Dawn J., et al. "Social Power and GIS Technology: A Review and Assessment of Approaches for Natural Resource Management." Annals of the Association of American Geographers, vol. 99, no. 2, Apr. 2009, pp. 254-72. 
Wolf, Isabelle D., et al. "The Use of Public Participation GIS (PPGIS) for Park Visitor Management: A Case Study of Mountain Biking.” Tourism Management, vol. 51, Dec. 2015, pp. 112-30. 


\section{Appendix A}

The CFGCOS side panel containing the instructions.

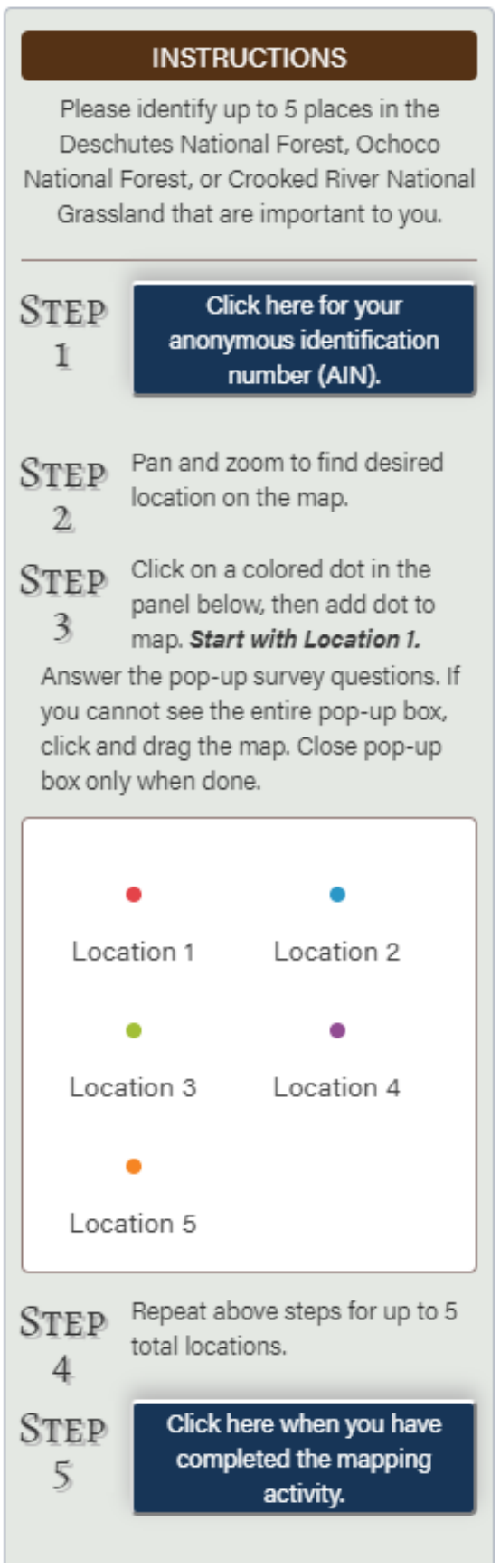


Part 1 and 2 of the CFGCOS popup. Some form boxes are open-ended, others are drop-down.

\section{Close box ONLY when done. $\square \times$}

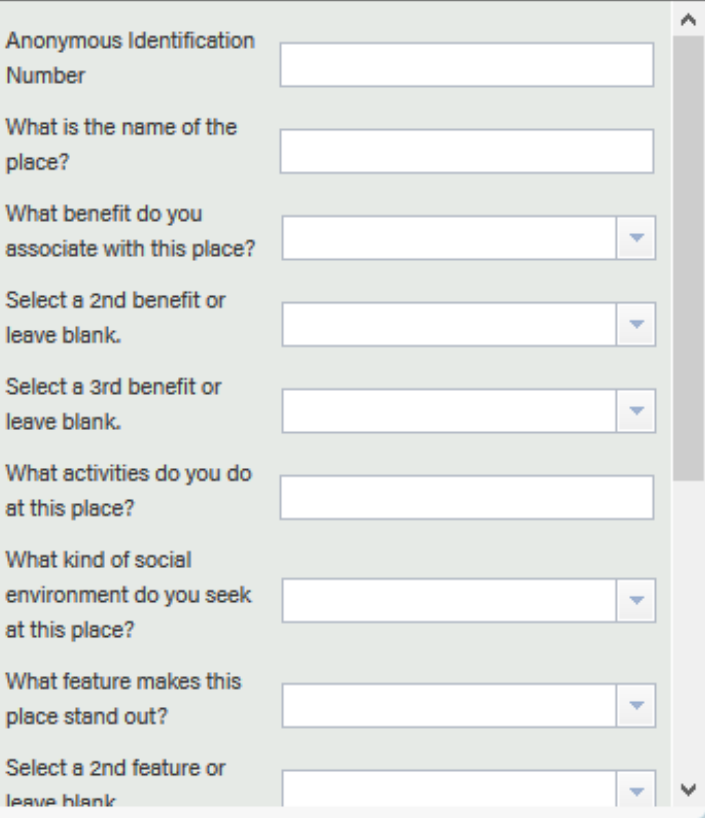

\section{Close box ONLY when done.}

What activities do you do

at this place?

What kind of social

environment do you seek

at this place?

What feature makes this

place stand out?

Select a 2nd feature or leave blank.

Select a 3rd feature or leave blank.

What, if anything, threatens or detracts from

your experience at this

place? Are there changes you would like to see that

would improve your

experience here?

Location

Location 1 
Largest Scale of the CFGCOS Map (zoom 0).

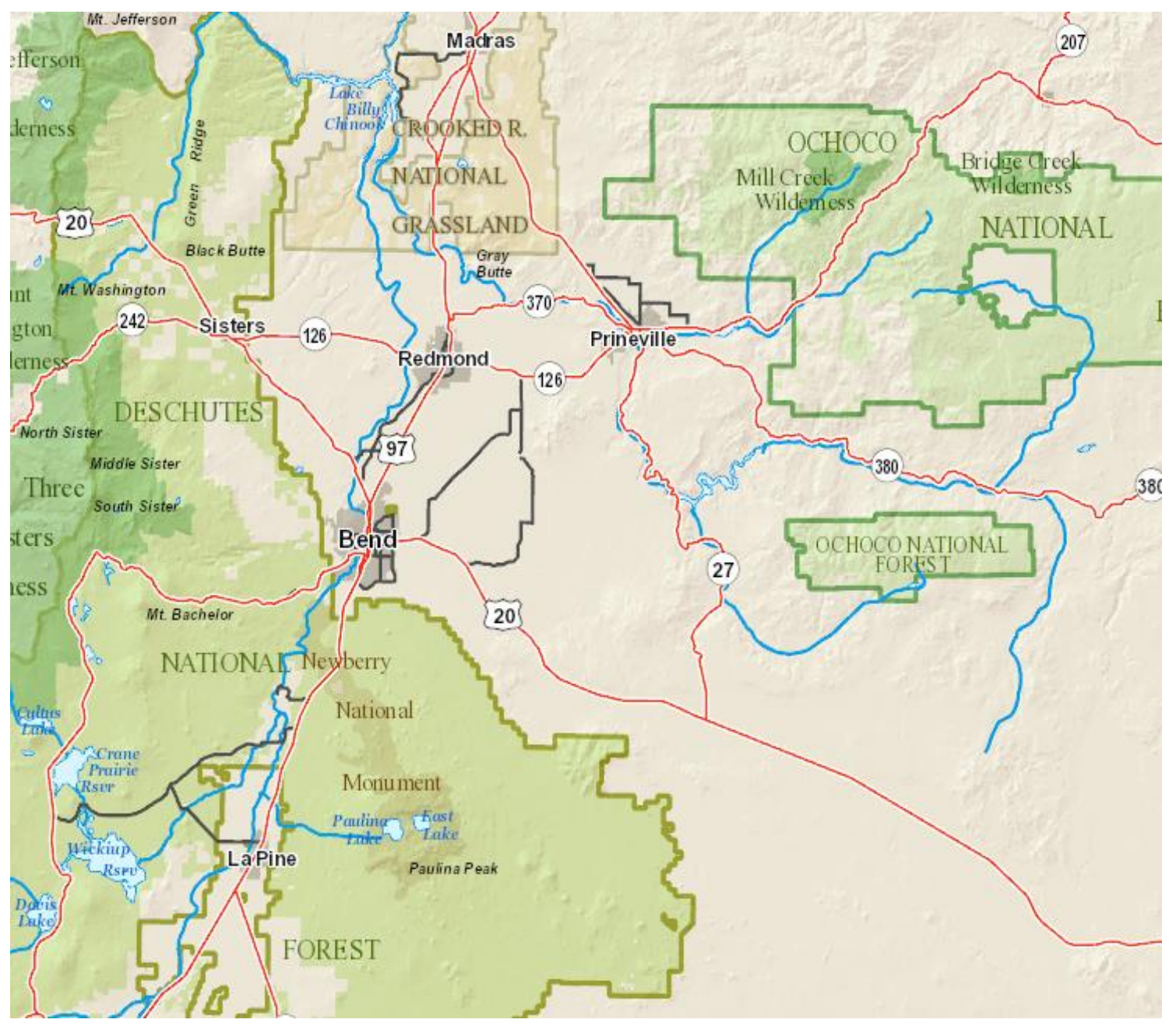


Mid-Scale of the CFGCOS Map (zoom 1).

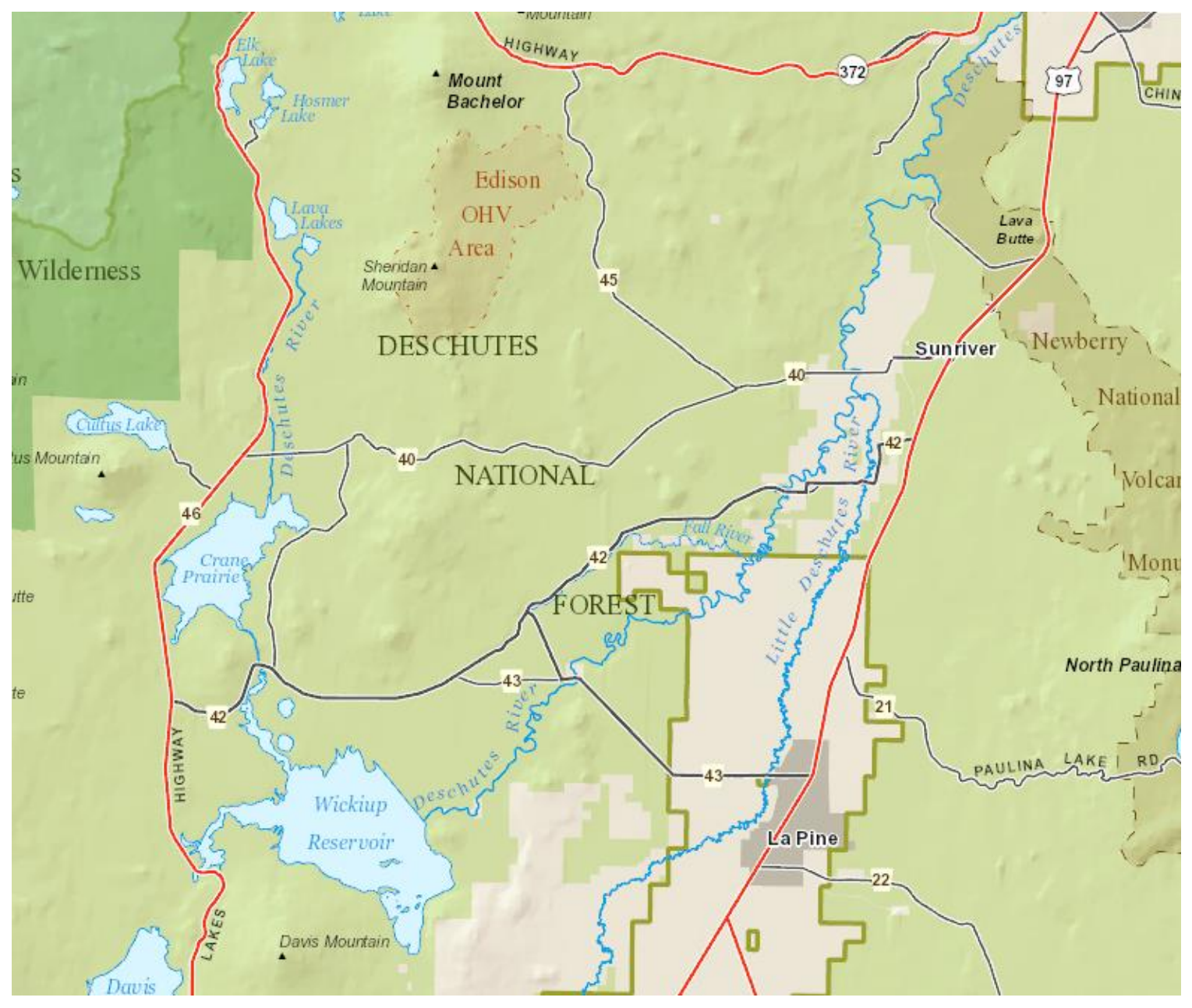


Smallest Scale of the CFGCOS Map (zoom 2).

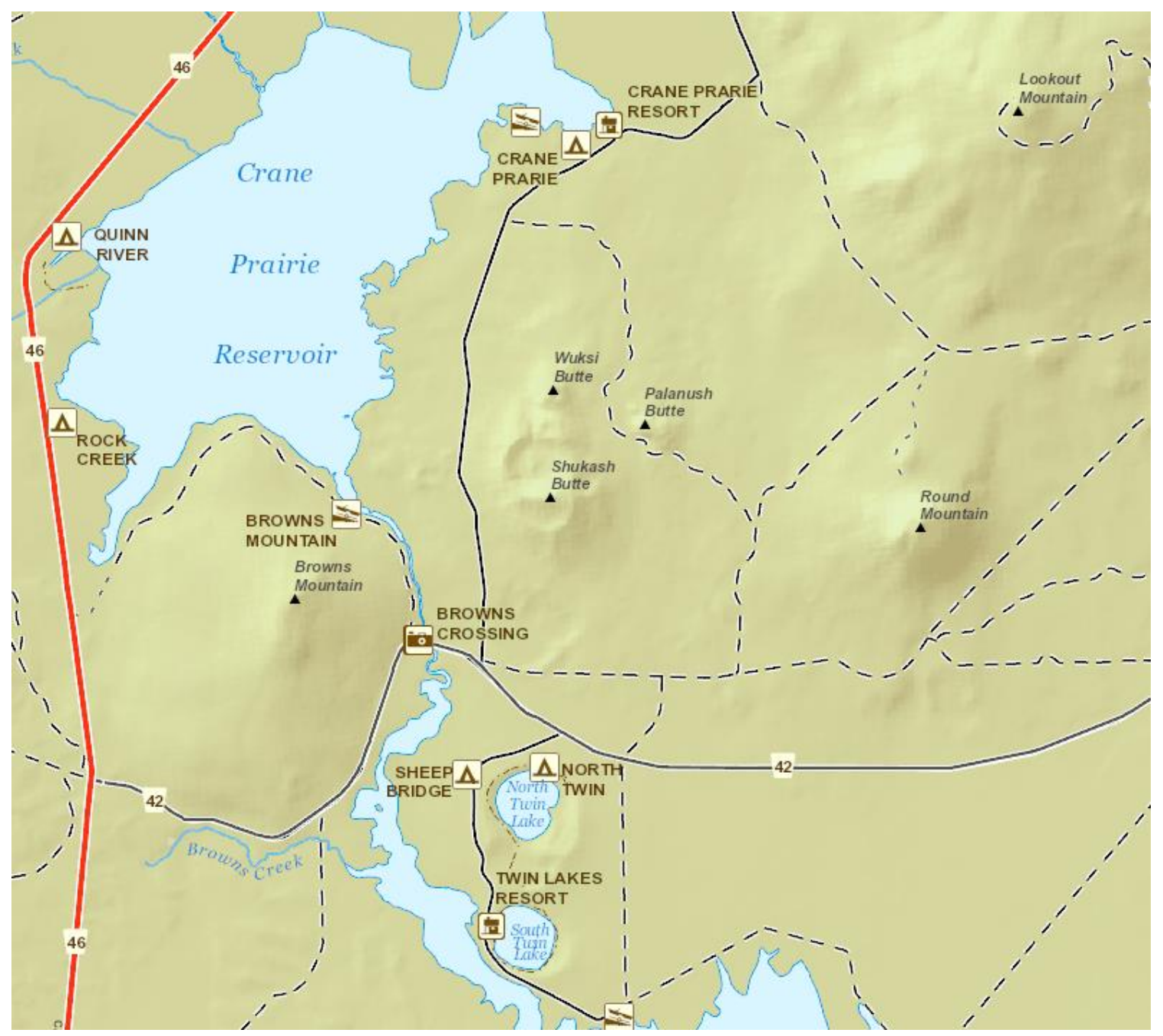

